\title{
Systems consolidation, transformation and reorganization: Multiple Trace Theory, Trace Transformation Theory and their Competitors
}

\author{
Morris Moscovitch, PhD \\ University Professor \\ Departmet of Psychology, University of Toronto, Toronto, Ontario, Canada \\ Rotman Research Institute, Baycrest, Toronto, Ontario, Canada \\ momos@psych.utoronto.ca
}

\begin{abstract}
Asaf Gilboa, PhD
Associate Professor

Department of Psychology, University of Toronto, Toronto, Ontario, Canada

Rotman Research Institute, Baycrest, Toronto, Ontario, Canada

agilboa@research.baycrest.org
\end{abstract}

To appear in: The Oxford Handbook of Human Memory, Volume 1: Foundations. M.J. Kahana \& A.D. Wagner, eds. (Oxford University Press) 


\begin{abstract}
We review the literature on systems consolidation by providing a brief history of the field to place the current research in proper perspective. We cover the literature on both humans and non-humans, which are highly related despite the differences in techniques and tasks that are used. We argue that understanding the interactions between hippocampus and neocortex (and other structures) that underlie systems consolidation, depend on appreciating the close correspondence between psychological and neural representations of memory, as postulated by Multiple Trace Theory and Trace Transformation Theory. We end by evaluating different theories of systems consolidation in light of the evidence we reviewed and suggest that the concept of systems consolidation, with its central concern with the time-limited role the hippocampus plays in memory, may have outlived its usefulness. We suggest replacing it with a program of research on the psychological processes and neural mechanisms that underlie changes in memory across the lifetime - a natural history of memory change.
\end{abstract}

Keywords systems consolidation, multiple trace theory, trace transformation theory, memory, hippocampus, neocortex, interactive systems reorganization, neural-psychological representational correspondence (NPRC)

\title{
Introduction
}

What is the relation between consolidation and cognition? Surprisingly, many theories of consolidation, particularly those concerned primarily with non-human behaviour, but not 
confined to them, view systems consolidation as a physiological process, with little or no consideration of its potential cognitive correlates. By this view, systems consolidation is mediated by the hippocampus, through hippocampal-neocortical interactions, and comes into play automatically only after all the heavy cognitive work is completed (see Craik, 2020; Tonegawa et al, 2015). As early as 1904, Burnham argued against this view of consolidation, noting that consolidation "is not merely a process of making a permanent impression upon the nerve cells, but also a process of association, of organization of the new impressions with the old ones." He does not indicate, however, how psychological and physiological processes are related to one another.

In this review we take up the challenge of relating psychological and neural processes to one another, beyond retention and loss, to explain the nature of the memory dynamics that have been dubbed 'systems consolidation'. We argue that neural changes cannot be understood without reference to psychological properties, and that classical notions of systems consolidation, and its contemporary varaints, may be hindering research efforts for understanding memory dynamics. In doing so we consider various models or theories of memory consolidation which we classify into three types: 1. Standard (Classical) Consolidation Theory which views systems consolidation as a uni-directional process in which declarative memories, initially mediated by the hippocampus, become independent of it as memories are consolidated in neocortex but without a change in their psychological representation. 2. Hybrid Theories that acknowledge the continuing involvement of the hippocampus in representing detailed, episodic memories in perpetuity but also posit that the hippocampus is always necessary for consolidating information in neocortical (extra-hippocampal) structures, with those memories ultimately existing independently of the hippocampus. Here, neocortical consolidation is still a uni-directional 
process, and the nature of the psychological representations that distinguish hippocampal from extra-hippocampal memories are left unspecified. Included in these theories, as well as those listed in 3 , is the idea that some system consolidation processes are evident in the hippocampus, with changes in neural representation along the anterior-posterior axis, and among the hippocampal subfields. 3. Dynamic systems re-organization theories that posit that interactions within the hippocampus, and between the hippocampus and neocortex (extra-hippocampal structures) are bi- (multi) directional from the moment of acquisition and throughout a memory's lifetime, with the correspondence between psychological and neural representations being an essential aspect of these theories. As the term systems consolidation implies a uni-directional process of memory stabilization, we, as proponents of this third view, recommend that it be replaced by the term interactive systems re-organization to reflect the dynamic, interactive and multi-directional nature of memory processes and mechanisms.

\section{History and nomenclature}

The term consolidation was fist coined by Müller and Pilzecker (1900) to describe the process by which memories become stabilized and resistant to interference or disruption (Lechner et al. 1999). These ideas on memory consolidation were soon linked to effects of lesions on memory in humans (Burnham, 1904; Korsakoff, 1889; Ribot, 1882) such that memory loss following brain damage was observed to follow a temporal gradient, with memories for recent events being more affected than memory for remote events. It took time to consolidate memories, but once consolidated, they were resistant to disruption by neurological insult (see Lechner et al., 1999; Russell, 1948; McGaugh, 2000). Though related, the time scales of evidence from the psychological laboratory and neurological clinic were orders of magnitude apart, suggesting that different mechanisms mediated them. 
In 1949, Hebb proposed his synaptic strength theory of memory formation, providing a plausible neurobiological mechanism for memory consolidation. He hypothesized that memories were represented/mediated by neuronal cell assemblies. These cell assemblies were formed by increasing synaptic strength through reverberation (repeated, sequential firing) of interconnected neurons which were activated by co-occurring aspects of an experience. Reactivating the cell assembly by stimulating only some of its neurons gives rise to a memory of the event that initially led to the assembly's formation. Disrupting the reverberation before the synapses were sufficiently strengthened prevented the formation of a cell assembly and the memory it supported.

Synaptic strengthening among local neuronal networks over short intervals is at the heart of most current theories of cellular consolidation (but see Gallistel, 2020; Gallistel \& Matzel, 2013, for another view). Rather than reverberation, however, it is now believed that an experience-initiated cascade of intracellular, and extracellular, molecular mechanism leads to strengthening of a Hebb synapse and memory formation (Kandel et al., 2014). Cellular or synaptic consolidation is a relatively rapid process, lasting on the order of minutes to hours. Disrupting the process of synaptic consolidation leads to memory loss; however, contrary to older notions, even apparently 'stable' memories can become labile again and susceptible to disruption - consolidation may never end (Dudai, 2012)..

Cell assemblies that represent memory are now construed as memory engrams, a term coined by Semon (Semon, 1904/1921; Schacter et al., 1978) to refer to the lasting physical changes that accompany an event or experience. He distinguished it from ecphory, the process by which retrieval cues interact with engrams to yield memories (Josselyn et al., 2017; Josselyn \& Tonegawa, 2020;). The engram provides the initial, dormant substrate that makes memory 
possible, but a memory does not exist until ecphory has occurred (Moscovitch, 2012). Like Bartlett (1932; see below), Semon thought that memories were dynamic, being modified in the process of retrieval, and becoming engrams themselves which can strengthen or add to previously related engrams (precursor to dynamic systems re-organization). According to Semon, engrams did not reside in a single cell or location, but rather were distributed among the neural elements that mediated that particular experience or event. The processes underlying cellular consolidation are believed to be common to all engrams, but the type of memory that engrams represent vary depending on the neurons forming the engram and their projections. These disturbed engrams, and their precursors, constitute the beginning of memory systems and ultimately would also lead to ideas about systems consolidation.

Beginning in the 1920s, Lashley, Hebb's mentor, embarked on a neurological search for engrams by ablating different parts of the cortex in rats and studying their effects on memory for mazes (Lashley, 1950). Because lesion size, rather than lesion location, determined the extent of memory loss, Lashley concluded, in accord with Semon, that memories were distributed throughout the cortex.

It was Hebb's student, Brenda Milner, working in collaboration with Penfield and Scoville, who discovered the crucial role that the medial temporal lobes, and the hippocampus in particular, played in memory formation and consolidation. They found that damage to the medial temporal lobes, particularly the hippocampus, caused a severe and lasting anterograde amnesia and a temporally graded retrograde amnesia (about three years in one of their patients, HM) with more remote memories being preserved (Milner \& Penfield, 1955; Penfield \& Milner, 1958; Scoville \& Milner, 1957). Memory loss, however, primarily involved declarative memory which includes 
both episodic memory and semantic memory, leaving other forms of memory, such as procedural memory and priming, relatively preserved.

Milner's findings, and subsequent research with other amnesic patients (Moscovitch, 1982, 1995, 2012; Squire, 2009), laid the groundwork for our knowledge of systems consolidation which is typically far more prolonged than cellular consolidation, beginning within hours, but lasting years or even decades, and is concerned with the organization of engrams, and their distributed representations, across neorcortical and other networks. Systems consolidation is the term adopted for the process by which memory engrams extend to new neural locations and, in some cases, cease to depend on structures, such as the hippocampus, that subserved their acquisition.

\section{Standard Consolidation Theory (SCT)}

Based on these findings, and adapting the theoretical frameworks we noted, investigators proposed what has come to be known as the Standard (Systems) Consolidation Theory (SCT). According to SCT, the hippocampus binds into a hippocampal-neocortical ensemble (memory trace or engram) the neuronal pattern that underlies the content and experience of an event. The sparsely-coded hippocampal neurons in this ensemble serve as pointers to the distributed neocortical representations of the engram (Teyler \& Rudy, 2007; Teyler \& DiScenna, 1986; Mosovitch, 1995). At retrieval, an internally generated or externally driven cue interacts with the hippocampal index which, in turn, reactivates the ensemble to yield an episodic memory of the event. Over time, and guided/reinforced by the hippocampus, possibly through replay of the hippocampal-neocotical ensemble (Wilson \& McNauhton, 1994; Buzsaki, 2019), the links among the neocortical elements of the ensemble are strengthened to the point that they can be reactivated without hippocampal input. This marks the end of the consolidation process, at which point memories are retrieved directly from neocortex and independently of the hippocampus 
(Moscovitch, 1995; Moscovitch \& Winocur, 1992; Squire \& Alvarez, 1995; Frankland and Bontempi, 2005)

\section{Early Challenges to SCT}

Since its inception following Milner's reports, SCT in its various iterations guided research on systems memory consolidation in rodents and humans, and provided the framework for interpreting the results. Despite its success and the advances in knowledge it fostered (Squire et al., 2015), troubling findings emerged which challenged some of these premises. Studying rodents, Misanin et al. (1968) noted that retrieving already consolidated memories made them vulnerable to disruption for a short time after retrieval, suggesting that consolidated memories are not as stable at SCT assumes (Hardt et al., 2009; Miller \& Matzel, 2006; Nader \& Hardt, 2009; Sara, 2000a, 2000b; Squire, 2006; see Nadel \& Sederberg in press).

Sanders and Warrington (1971) reported memory deficits following hippocampal lesions in humans that extended for decades, some covering a lifetime, suggesting that the role of the hippocampus is not time-limited. Even when not so prolonged, the extent of retrograde amnesia often lasted years suggesting, as Craik (2020), Burnham (1904) and Squire et al., (1984) surmised, that more than mere neurobiological strengthening of neocortical connections was involved. Following Tulving's (1972) proposal of a distinction between episodic and semantic memory, Kinsbourne and Wood, (1975) noted that amnesia primarily affected episodic memories, while relatively sparing semantic memory, suggesting that consolidation does not treat all declarative memories equivalently. Likewise, cognitive map theory (O'Keefe \& Nadel, 1978), one of the most influential theories of hippocampal function, does not assume an expiry date for the dependence of allocentric spatial representations on the hippocampus. If, however, cognitive maps do change with time, what is the nature of that change, and what is its neural 
substrate? Finally, some rodent models argued that some longer (days) retrograde gradients in fact reflect cellular consolidation (Rudy \& Sutherland, 2008); moreover, several tasks that are used to demonstrate hippocampal dependence through retrograde gradient experiments, can be performed normally when trained with hippocampal damage (anterograde memory) which is inconsistent with SCT (Sutherland et al., 2010).

\section{More Recent Challenges to SCT}

SCT continued to dominate the field despite these challenges both with respect to episodic and semantic memory (Squire, 1992; Squire \& Alvarez, 1995) and to spatial memory (Rosenbaum et al., 2000; Teng \& Squire, 1999, Rosenbaum et al., 2004a, 2004b, 2005b; see review in Rosenbaum et al., 2001) until the late 1990s and early 2000s. By then, new evidence on the functional neuroanatomy and interaction of the medial temporal lobes and prefrontal cortex, and on neurobiological basis of consolidation in rodents, revived these same critiques, which now took their toll on SCT. Equally important were the development of alternative theoretical frameworks that not only could accommodate the new data, but stimulate and guide research in new directions that expanded our understanding of hippocampal function and its interaction with neocortex. As much of this ground has been covered extensively (Kandel et al., 2014; Moscovitch et al., 2016; Sekeres et al., 2018a; Squire et al., 2015), we will only review it briefly here, and focus on the most recent empirical and theoretical developments.

\section{Multiple Trace Theory}

Although SCT could account for the temporally-graded retrograde amnesia for semantic memory following MTL damage, it had more difficulty in dealing with observations of severe and temporally extensive retrograde amnesia, sometimes encompassing a lifetime, for episodic 
memories of autobiographical events. In humans, episodic memory refers to recollection of a particular event and the experiences that accompany it, so that one effectively travels mentally back in time and relives the event by reinstating the context in which it occurred (Suddendorf \& Corballis, 1997, 2007; Tulving, 1985, 2001, 2002; See chapter 5.5 by Yonelinas, Ramey \& Riddell, 2022 and chapter 2.1 by Ranganath, 2022). A hallmark of episodic memory is that it is rich in perceptual, temporal, sequential and other contextual details that enable one to reexperience an event, By comparison, semantic memory is concerned only with general knowledge devoid of the contextual details that accompanied its acquisition (Moscovitch et al., 2016). Likewise, in non-human species, contextual specificity is considered to be the hallmark of episodic-like memory, whereas semantic-like memories were considered to be context general (Sekeres et al., 2018a; Winocur \& Moscovitch, 2011; Winocur et al., 2010).

To account for the extensive retrograde amnesia for episodic memory (context-specific in rodents), and relatively preserved semantic (context-general) memory, Nadel and Moscovitch (1997) proposed that the MTL, and hippocampus in particular, is needed for the retention and retrieval of episodic memories in perpetuity. Because there was suggestive evidence that the extent and severity of retrograde amnesia for episodic memories is related to the size of the MTL lesion (Fujii et al., 2000), Nadel and Moscovitch proposed that each time a memory is retrieved, it is re-encoded as a separate, sparsely-distributed trace in the hippocampus along with the new context in which retrieval occurs (Nadel et al., 2000). These multiple traces are more numerous, and more widely distributed for older memories that have had more opportunities for retrieval than did newer memories. As a result, older memories are more resistant than newer memories to the effects of hippocampal damage, leading to a temporal gradient of retrograde amnesia; extensive damage would affect even the oldest memories. The re-encoding of retrieved 
memories was based on the idea that the hippocampus obligatorily encodes all information in conscious awareness, whether externally presented or internally generated (Moscovitch, 1992, 1995, 2008).

Semantic memory representations, on the other hand, do not rely for retention and retrieval on the specific circumstances/context that accompanied their acquisition. They are presumed to be derived from extraction of statistical regularities across neocortical representations related to their content, or by assimilation to representations of prior knowledge, a process that may be prolonged (McClelland et al., 1995). Once formed, however, semantic memories are resistant to hippocampal damage, consistent with both MTT and SCT.

The differential effects of hippocampal lesions on remote episodic and semantic memory suggest that it is not the memory's age, but the nature of the memory, that distinguishes memories whose retention and retrieval are dependent on the hippocampus from those that are not. The hippocampus's role with respect to episodic memory is not time-limited, but continues over the life of the memory. In agreement with SCT, MTT acknowledges that semantic memories, unlike episodic memories, do become independent of the hippocampus with time, suggesting that systems consolidation is not equivalent for all declarative memory as assumed by SCT.

Having a plausible, alternative theoretical framework to SCT led to a burgeoning of studies and theories on systems consolidation. Investigators began to examine recent and remote memories in patients with memory disorders from a new perspective, placing as much weight on psychological changes as on neural ones. This approach also informed functional neuroimaging studies in neurologically intact people (see Sekeres et al., 2018a). Comparable studies were conducted in non-human species, usually rodents. At first, most of these studies used classical lesion methods (Sutherland et al., 2010; Winocur et al., 2010) but later came to rely increasingly 
on newly developed neurobiological techniques that allowed for more precise tracking of the engrams that supported recent and remote memories, and provided greater control over them (Jasnow et al., 2017; Josselyn \& Tonegawa, 2020; Sekeres et al., 2018a).

New evidence emerged that was consistent, for the most part, with MTT, greatly enabled by the development of more sensitive measures which targeted those aspects of memory which were at the heart of the debate between SCT and MTT: episodic vs. semantic contributions to remote memories for autobiographical and public events (Kopelman et al., 1989; Kopelman \& Marsh, 2018; Levine et al., 2002; Piolino et al., 2003, 2009; Renoult et al, 2020), and schematic vs. fine detail to spatial memories (Herdman et al., 2015; Hirshhorn et al., 2012a, 2012b; Rosenbaum et al., 2000, 2001, 2005b). Compromised hippocampal function led to a reduction in episodic aspects of recent and remote memories, whether for events or for environments, across the lifespan, with relative sparing of semantic or schematic aspects. This pattern of impoverished contextual details specific to an episode or location, with retention of general, non-specific information was observed in patients with extensive hippocampal damage whether caused by excisions or trauma (Sekeres et al., 2018a; Winocur \& Moscovitch, 2011), by infection by herpes simplex (Fujii et al., 2019) or by autoimmune disorders (Argyropoulos \& Butler, 2020; Argyropoulos et al., 2019; Lad et al., 2019; Miller et al., 2020), by dementia (Gilboa et al., 2005; Piolino et al., 2009), by amnestic mild cognitive impairment (Murphy et al., 2008) or atrophy and dysfunction in normal aging (Levine et al., 2002; Viard et al., 2007), by accelerated long term forgetting and epilepsy (Butler \& Zeman, 2008), by electroconvulsive therapy (ECT; Lomas et al., 2021) and by psychiatric disorders such as depression (Söderlund et al., 2014; Williams, et al., 2007) and schizophrenia (McLeod et al., 2006; Herold et al., 2015) 
The same pattern is also observed with damage restricted to the CA1 (Bartsch et al., 2011; Bartsch \& Butler, 2013) and CA3 (Miller et al., 2020) subfields of the hippocampus and presubiculum, to its output pathways, such as the fornix (Poreh et al., 2006; Gilboa et al., 2006b) or to structures, such as retrosplenial cortex (Summerfield et al., 2009; Vann et al., 2009; Foster et al., 2013) and diencephalon (Kopelman, 1989; 1999), that receive projections from the hippocampus to form part of the extended hippocampal system.

A similar picture emerged from studies on animal models. Typically, hippocampal damage or disruption, whether caused by surgical lesions, pharmacological intervention, or optogenetic and transgenic techniques, led to retrograde memory loss without a temporal gradient, as long as context-specificity determined performance (Sekeres et al., 2018a; Sutherland \& Lehmann, 2011; Sutherland et al., 2010). This pattern was observed in a variety of paradigms, such as contextual fear conditioning (Jasnow et al., 2017; Sekeres et al., 2018a; Wiltgen \& Silva, 2007; Winocur et al., 2007), socially-acquired preference tasks (Winocur et al., 2007), water maze and cross maze tasks (Winocur et al., 2013), regardless of whether they were based on positive or negative reinforcement (Winocur et al., 2007). There also were studies in which a temporal gradient was observed (Kim \& Fanselow, 1992; Winocur, 1990), but this occurred not because the initial memories became consolidated in neocortex but because their context-specificity declined (Winocur et al., 2013), turning them into context-general memories, or their representation was altered (Jasnow et al., 2017; Wiltgen et al., 2010; Wiltgen \& Tanaka, 2013; Winocur et al., 2010), making them more compatible with neocortical than hippocampal function.

Although the consensus favoured MTT, proponents of SCT countered that temporally extensive loss of episodic memory only occurred when damage extended beyond the hippocampus (Squire 
\& Bayley 2007; Squire et al., 2015; Lah \& Miller, 2008). Although this claim has been disputed (Rosenbaum et al., 2008, 2009), the critique does not apply to studies of patients with damage restricted to hippocampal subfields or output pathways (see above, this section), or to work on animal models where location of lesions or disruption is controlled.

Another objection is that patients' impaired anterograde memory made them lose track of their own narratives causing them to go on tangents when recounting their memories, making performance suffer (Dede et al., 2016) unless they are provided with appropriate guidance. Here, too, the objection does not hold water, as temporally extensive deficits in episodic memory are observed even in studies using recognition (Gilboa et al., 2006a) or the Autobiographical Interview (Levine et al., 2002), a test that consists of a structured interview that probes the participants' memories should their narrative be curtailed or derailed (Rosenbaum et al., 2008, 2009; Sheldon \& Levine, 2016, 2018; Sheldon et al., 2019; see chapter 5.12 by levine, Fan, Simpson \& Sokolowki, 2021).

Neither of these objections to MTT from proponents of SCT, however, apply to functional neuroimaging studies that assess the differential involvement of the hippocampus in retrieving recent and remote episodic memories in neurologically intact humans (Cabeza \& St. Jacques, 2007; Maguire et al., 1999; Svoboda et al., 2006). As predicted by MTT, functional neuroimaging studies of autobiographical memory overwhelmingly show that the hippocampus is activated by recollection of vivid, detailed context-specific memories from across the lifespan, the extent of activation being modulated by episodic richness rather than memory age (Moscovitch et al., 2005, 2016; Sekeres et al., 2018a). When episodic detail and richness are not taken into account, there is the expected reduction in hippocampal activation with memory as it ages (Boccia et al., 2020; Gilboa et al., 2004; see chapter 5.12 by Levine et al, 2022). 
To date, almost all the neuroimaging studies on autobiographical memory had participants either answer true- false questions or mentally relive the events while being scanned, followed by extensive off-line narratives which were scored for details. The same pattern of results was observed even when participants narrate memories in the scanner. Gilmore et al. (2021) found that a decline in posterior hippocampal activation with time from memories acquired the same day to ten years earlier, was associated with a comparable decline in functional connectivity between the hippocampus and neocortical regions implicated in memory (see section of Hippocampal Neocortical Interacctions). Consistent with MTT, the decline in activation was accompanied by a decline in internal, episodic details from recent to remote memories.

From the earliest neuroimaging studies on remote memory (Addis et al., 2004; Gilboa et al., 2004; Maguire, 2001; Maguire et al., 1999, 2001; Ryan et al., 2001 see reviews in Cabeza \& St. Jacques, 2007; Svoboda et al., 2006) to the most recent (see reviews in Sekeres et al., 2018a; Sheldon \& Levine, 2016, 2018; Sheldon et al., 2019), it was clear that the hippocampus, however, does not act alone (Cabeza \& Moscovitch, 2013; Moscovitch et al, 2016) but is coactivated with a set of structures which include the precuneus, retrospelinal and parahippocampal cortex, and the ventromedial prefrontal cortex, along with the postero-lateral parietal cortex, which together form an autobiographical memory or recollection network (Ranganath \& Ritchey, 2012; Ritchey \& Cooper, 2020; Rugg \& Vilberg, 2013; see chapter 2.1 by Ranganath, 2022 ). Each node in this network is likely activated by different aspects of the episodic memory e.g., precuneus by imagery (Fletcher et al., 1996; Shallice et al., 1994), retrosplenial and parahippocampal cortex by spatial information (Epstein, 2008; Epstein \& Baker, 2019; Vann et al., 2009), vmPFC by schemas related to the content of the memory (Gilboa \& Marlatte, 2017), and the parietal cortex by attention (Ciaramelli et al., 2008; Cabeza et 
al., 2008, 2012; Cabeza \& Moscovitch, 2013), number of details (Vilberg \& Rugg, 2008, 2009, 2012), the subjective sense of re-experiencing (Richter et al., 2016; Simons \& Mayes, 2008), multimodal integration (Bonnici et al., 2016), or the processes needed to retrieve (Fletcher, 1998a, 1998b) and monitor episodic memories (e.g. vmPFC; Gilboa et al., 2006b, Moscovitch et al., 2016).

More investigations are needed to determine the precise contribution of the extra-hippocampal regions. Transcranial magnetic stimulation (TMS) has proven to be a useful tool in this regard. A recent study using TMS to interfere with the function of the precuneus led to a reduction in perceptual aspects of the autobiographical memory (Hebscher, et al., 2020). Conversely, stimulation of mPFC led to reduced false memories in the Deese-Roediger-McDermott (Deese, 1959, Roediger \& McDermott, 1995) paradigm (Berkers et al., 2017; see also Chadwick et al, 2016, for the role of the temporal pole) presumably reflecting reduced activation of prior knowledge that biases episodic (detailed) encoding in this paradigm. Likewise, depending on the type, stimulation of the parietal cortex can enhance memory formation and retrieval (Wang et al., 2014) or diminish the subjective sense of remembering (Yazar et al., 2014).

\section{Critique of MTT}

MTT focused on one salient issue, the continued involvement of the hippocampus in remote episodic, but not semantic, memory. In doing so, it neglected many other issues. Thus, while MTT differentiated between episodic and semantic memory, it did not consider the kind of qualitative changes that memories of even single episodes undergo. As well, by treating episodic and semantic memory dichotomously, MTT ignored the highly interactive, and interdependent nature of the two. With respect to transition from episodic to semantic memory, MTT did not consider mechanisms other than the extraction of statistical regularities among events, fueled 
perhaps by repeated retrieval of episodes either voluntarily or through off-line replay during sleep or rest (Wilson \& McNaughton, 1994) (Dinkelmann \& Born, 2010; Dudai et al., 2015; Kim et al., 2019). With its focus on the hippocampus, MTT did not consider the contribution of other structures that operate in concert with the hippocampus in encoding, retention and retrieval of episodic memory, and that operate independently of it in the case of "consolidated" memories. Even with respect to the hippocampus, the field at the time MTT was proposed tended to treat it as a unitary structure, rather than as highly differentiated one, a view that is now prevalent and figures prominently in current research on recent and remote memory (Maguire \& Mullally, 2013; Robin \& Moscovitch, 2017; Sekeres et al., 2018a; Zeidman \& Maguire, 2016). Most importantly, MTT paid little heed to the dynamic nature of memory (Bartlett, 1932; Squire et al., 1984) that continues to play increasingly larger roles in contemporary theories of memory (Schacter, 2011, 2012a, 2012b; Schacter et al., 2012).

These can all be construed as errors of omission that can be rectified without violating any of the basic tenets of MTT. One set of findings, however, is problematic: Contrary to MTT, the size of hippocampal lesions is not related to the extent of retrograde memory loss, in either humans

(Winocur et al., 2010; Winocur \& Moscovitch, 2011) or rodents (Sutherland et al., 2010, 2020). We take up this issue at the end of the next section titled, "Trace Transformation Theory (TTT): Details, gist, schema, and semantics".

\section{Trace Transformation Theory (TTT): Details, gist, schema, and semantics}

Trace Transformation Theory (TTT; Winocur et al., 2007, 2010; Winocur \& Moscovitch, 2011;

Sekeres et al., 2018a) builds on MTT's foundations but extends its scope to deal with some of MTT's limitations. In its most recent version (Robin \& Moscovitch, 2017; Sekeres et al., 2018a), TTT incorporated recent developments on the distinctions between gist, schema and semantics, 
and their neural correlates. Whereas full-blown episodic memories are rich in detail unique to the event (e.g. what everyone at the birthday party wore, how the cake looked and tasted), some episodic memories retain only the gist of the event, which effectively is a summary of its central elements, without the peripheral, incidental details (Reyna \& Brainerd, 1995). One way of thinking about detailed memories and gist is that they vary in granularity from fine to coarsegrained, and as such have been postulated to be represented preferentially by the posterior and anterior hippocampus, respectively (Brunec et al., 2018; Poppenk \& Moscovitch, 2011; Poppenk et al., 2013; Moser et al., 2008; Robin, 2018; Robin \& Moscovitch, 2017; Strange et al., 2014). While gist retains a measure of contextual specificity, schemas are more general still, referring to what is common across a series of similar events (what happens at a typical birthday party) and have been proposed to be mediated by the vmPFC (Ghosh et al., 2014; Gilboa \& Marlatte, 2017; Tse et al., 2007, 2011; Wang and Morris, 2010; see chapter 7.2 by Varga, Morton \& Preston, 2022). Semantics refers to the conceptual aspect of an event (what "birthday party" means - a celebration of one's date of birth) that does not include what typically transpires at the event, and implicates a different network of structures, with the anterior and lateral temporal, and inferior, lateral frontal, cortex playing central roles (Lambon Ralph, 2014; Lambon Ralph \& Patterson, 2008; Lambon Ralph et al., 2017; Martin, 2016; Martin et al., 2014).

\section{Three basic principles underlie TTT.}

1. The hippocampus retains its function in representing detailed, episodic memories (contextspecific memories in rodents) as long as they exist, whether they are memories of the past or of episodic simulations of future or imagined events (Addis et al. 2007b; Addis \& Schacter, 2012; Addis, 2020; Hassabis et al., 2007; Maguire \& Hassabis, 2011; Maguire \& Mullally, 2013; 
Moscovitch et al., 2016; Viard et al., 2012). The hippocampus does not relinquish this representational function to other structures over time.

2. Systems consolidation is not a unidirectional time-dependent process, but a dynamic multidirectional process in which different forms of memory can co-exist and interact with one another. (Sekeres et al., 2017, 2018a; Winocur \& Moscovitch, 2011). The passage of time, as well as task demands at encoding and retrieval dictate the strength or dominance of each of these representations and determine the form of the memory that is expressed.

3. Each of these psychological representations is supported by distinct neurobiological substrates and processes, and their interactions drive memory dynamics (Robin \& Moscovitch, 2017;

Sekeres et al., 2018a; Winocur \& Moscovitch, 2011). Our view is that these processes, and the distributed neural substrates that mediate them, are implicated in memory formation, organization and expression from even before an event occurs, and thus diverges from the idea that the hippocampus is the gateway to systems consolidation (Gilboa \& Moscovitch, 2021). As such, systems consolidation is not the mere relinquishing of hippocampal involvement to the neocortex over time, (in fact, for truly episodic memories that may never occur) but a dynamic process of hippocampal-neocortical interactions that determine the organization and expression of memory that begins even before acquisition, and continues throughout life. Consequently, we believe the term memory systems re-organization, rather than systems consolidation, best describes this process neural-psychological process.

The evidence we present accords with a more general principle termed neural-psychological representation correspondence (NPRC), namely that each type of representation is mediated by its corresponding structure and vice-versa (Gilboa \& Moscovtich, 2021). If episodic memory is mediated by the hippocampus, this relationship should hold regardless of whether the memory 
occurred recently or long ago. Conversely, if there is a change in the mediating structure, such as sometimes occurs as memories age, there should also be a corresponding change in the nature of the psychological representation.

Thus, according to TTT, these different representations related to an episode can be encoded into memory concurrently, can co-exist with one another in memory, and can interact dynamically with each other, supporting one another in some instances, competing in others, and, in still other instances, transforming from one into the other and back again (Gilboa \& Moscovitch, 2021; Sekeres et al., 2018a; Robin \& Moscovitch, 2017). The variants that are expressed are determined by a variety of factors, including the age of the memory and the demands of the task. The important point is that whichever variant is expressed, it is accompanied by co-activation of its corresponding neural structure, and vice-versa (Moscovitch et al., 2016; Sekeres et al., 2018a), according to NPRC (Gilboa \& Moscovitch, 2021).

While incorporating these new developments, TTT accepts MTT's basic premise that as long as episodic memories remain detailed and context-specific, they will continue to depend on the hippocampus for retention and retrieval. With age and experience, however, some episodic memories, likely the majority, will be transformed into variants of the original or will express some aspects of the original while de-emphasizing others. Some will retain or express the gist of the episode with few contextual details while others may retain the general schema without any episodic remnant; some may be forgotten entirely, while others may remain detailed, but the details themselves may be modified by prior knowledge and subsequent experiences (Robin \& Moscovtich, 2017; Sekeres et al., 2016, 2018a; Squire et al., 1984; Winocur \& Moscovitch, 2011). In accord with NPRC, TTT posits that the nature of the transformed memory determines how it will be represented neuraly; conversely, if neural representations change, so will the 
nature of the memory that is represented and/or the processes that operate on it (Gilboa \& Moscovitch, 2021) ${ }^{1}$.

\section{Systems consolidation in humans: recent evidence}

We begin by reviewing the most recent evidence of differences in how memories are represented by the hippocampus and neocortex, particularly the mPFC. We first consider evidence from univariate analyses of fMRI data, and then from multivariate analyses, particularly representational similarity analyses, to argue consistently with our NRPC hypothesis, that it is the nature of the memory, rather than its age, that determines its neural representation. We next show that different representations of the same event can co-exist in hippocampus and neocortex. Because the representation of a memory is not confined to a single structure, we turn to the literature on functional connectivity and neural oscillations to show that the full representation of a memory depends on interactions between the hippocampus and neocortex, that themselves change along with the nature of the memory. Last, we examine how damage to HPC and mPFC alters the nature of memory representations, and how interactions between the structures are implicated in the formation, and expression, of episodic memories and schemas.

\section{Time and experience dependent changes in memory representations mediated by the hippocampus and mPFC: Univarite, fMRI analyses}

\footnotetext{
${ }^{1}$ Consideration of the full implication of the NPRC principle, and the evidence that semantic and schematic memory traces are created at the time of encoding (Hebscher et al., 2019b), led Gilboa and Moscovitch (2021) to suggest that the concept of systems consolidation itself might be a misnomer. Instead, multiple memory traces may be formed concurrently, and expressed differentially depending on factors such as task demands at encoding and retrieval; time and subsequent experiences influence synaptic strengthening or pruning of each of these traces and determine the way they interact with each other. While a full discussion of this possibility is beyond the scope of the present chapter, much of the data on systems consolidations described below is consistent with this view.
} 
Using fMRI during encoding and retrieval of memories of the video clips from St-Laurent et al. (2009), Sekeres et al. (2018b) found that at encoding and immediate retrieval, when memory for both central (gist) and peripheral details was high, posterior and anterior regions of the hippocampus were activated as was the mPFC. At a week's delay, when memory for peripheral details was reduced disproportionately compared to central details, activation was diminished in posterior hippocampus, remained stable in anterior hippocampus, and increased in mPFC, as participants' memory came to rely more on gist and schemas. If, however, memory remained vivid and detailed, activation remained high in posterior hippocampus, but increased somewhat in $\mathrm{mPFC}$, suggesting that even detailed memories mediated by the hippocampus rely on schematic support from the mPFC once they age. Also, providing a reminder before test (a blurred small section of a screen shot of the clip which lacks significance on its own), increased the probability of successful recall. The reminder shortened the temporal onset of peak mPFC activation so that it preceded the peak anterior hippocampus activation which also was enhanced by the reminder (Sekeres et al., 2021).

To examine the role of schemas more closely in memory transformation, Bonasia et al. (2018), using Sekeres et al.'s (2018b) data, found that clips which conformed to typical scenarios (schema-congruent) engaged the mPFC more than schema incongruent clips, at encoding and at both delay conditions. The reverse held for the hippocampus at encoding and at a week's delay. Importantly, mPFC activation was related to the type of errors people made in 1-week delayed recall, such that schema congruent and incongruent errors were positively and negatively related, respectively, to mPFC activation, (Bonasia, thesis; see below in relation to SLIMM model in the section on Theories of Schema). 
Using much longer (27 min) narrative clips, Furman et al. (2012) showed that memory for them decreased between three hours to three months, but like Sekeres et al., they found stable anterior hippocampal activity on tests of recall, but markedly reduced hippocampal activation on recognition, presumably because the recollection component of recognition declines with time. Nonetheless, remote recognition memory that captured the "crux of the event" or its gist, was significantly correlated with residual hippocampal activation, suggesting that only a fraction of hippocampal cells are needed to code memory over extended delays (Ziv et al, 2013).

In a meta-analysis of studies on autobiographical memory in young and older adults, Viard et al. (2007) found that retrieval cues associated with the gist of the event activated the anterior hippocampus regardless of memory age. This effect, especially pronounced in older compared to younger adults, was consistent with older adults' greater reliance on gist as their detailed, episodic memories declined with age (Levine et al., 2002).

Thus, patterns similar to those observed for narrative video clips were evident in cross-sectional and longitudinal studies of autobiographical memories whose age extends from days to years. If memories are allowed to take their natural course and decline with time since acquisition, univariate analyses of the level of activation with time, yields increases in mPFC activity, relative stability in anterior hippocampus and declines in posterior hippocampus (see Boccia et al., 2019, but see Söderlund et al., 2012). For memories that remain detailed and context specific over time, both univariate and multivariate analyses (see sections on Multivariate fMRI analysis) show increases in $\mathrm{mPFC}$, with variable activity in anterior and posterior hippocampus. According to TTT, these findings suggest that schemas mediated by the mPFC become increasingly important over time in retention and retrieval of episodic memories, even those that 
remain detailed and context specific. Variations in anterior and posterior hippocampal involvement may depend on the extent to which gist and details contribute to retrieval.

Studies that target coarse or fine-grained detail at retrieval are consistent with this interpretation: retrieving coarse, large scale information about spatial location of remote memories (e.g. venue of wedding) is associated with anterior hippocampal activation, whereas retrieving fine-grained information (seating arrangement) is associated with posterior hippocampal activation (Evensmoen et al., 2013, 2015), and involvement of CA2/CA3/DG subfields whose volume is related to memory precision (Bakker et al., 2008; Yassa et al., 2011) of personal events (Hebscher et al., 2018) or video clips (Chadwick et al., 2014). Thus, damage restricted to CA3 leads to autobiographical memory loss for episodic details, but not semantics, across almost a lifetime (Miller et al., 2020).

Similar results are obtained in neuroimaging studies that employ more traditional laboratorybased stimuli, such as paired associates. Equating performance across all intervals from 20 minutes to 30 days, Du et al., (2019) found that hippocampal activation remained stable across all intervals for associative (relational) memory. By comparison, hippocampal activation declined for item memory, as activation in peri-rhinal cortex and vmPFC increased. Likewise, Viskontas et al. (2009a) found that as recollection of pairs of pictures declined from ten minutes to 10 days, so did hippocampal activity. Ritchey et al. (2015) found similar evidence regarding recollection of items studied in different contexts and tested immediately or after a day. Although recollection declined over the interval, insofar as items were recollected, recollectionrelated activity remained steady in the anterior hippocampus, but declined in posterior hippocampus.

\section{Multivariate analyses and memory representations in system consolidation}


Multivariate analyses, particularly multivariate pattern analysis (MVPA) and representational similarity, provide an opportunity to relate representations at the neural level to those at the psychological level over time. Bonnici et al. (2012) and Bonnici and Maguire (2017) used MVPA (Chadwick et al., 2010) to track and classify vivid (detailed, context-specific) autobiographical memories over a two year period, and compared them to ten-year old memories. They found that their neural representations remained stable over two years in the anterior hippocampus, but became more distinguishable from one another in $\mathrm{mPFC}$ and posterior hippocampus, particularly in the CA3 and DG subfields (Bonnici et al., 2013), reaching the same levels at two years as at ten. As the memories were of different events, they likely differed from one another in both peripheral and central details. Thus, what distinguished one memory from another may have differed across regions, with posterior hippocampus being sensitive to peripheral details, and mPFC to central details.

Bird and his colleagues (Bird et al., 2015; Oedekoven et al., 2017) used memory for video clips and representational similarity analyses to examine neural reinstatement effects between encoding, and retrieval a day and a week later. They found reinstatement effects that predicted memory performance at 7 days in the posterior left hippocampus and in structures in posterior midline cortex, such as the precuneus and posterior cingulate.

In an EEG study, Larzabal et al. (2020) tested participants' memory of frames from clips they viewed hours, one day and three weeks earlier. Using MVPA of the EEG signal to classify new and old items, they, too, found reinstatement effects that correlated with recollection even at the longest delay which emerged from the same neural processes as at encoding, indicating that that the engram created at acquisition was still viable weeks later. 
Applying representational similarity analysis to associative memories, Ritchey et al. (2015 see Univariate fMRI section), found that that context-related similarity in the anterior hippocampus was predictive of associative memory performance at a day's delay, a finding consistent with gist representation in the anterior hippocampus (see also Gutchess \& Schacter, 2012). The same pattern was observed for other regions, including the mPFC, that are part of the recollection network.

In picture-picture paired associate paradigm, Tompary and Davachi (2017) tested for recognition immediately and at a week's delay. They found that it was only at a week that greater representational similarity emerged between items that were paired with a common picture (overlapping) as compared to those that were paired with different pictures. Seen most prominently in $\mathrm{mPFC}$ and posterior hippocampus, this similarity was inversely related to recognition accuracy which emphasized detail specificity, suggesting that performance came to rely more on gist-like representations. Likewise, Dandolo \& Schwabe (2018), using single pictures as targets and lures from the same category (e.g. different pictures of a tractor), found that over the course of a month, targets became progressively more difficult to distinguish from lures indicative of increasing reliance on gist-like representations in memory over time. These psychological changes were accompanied by increases in neural similarity between related lures compared to unrelated items, particularly in the anterior hippocampus, consistent with TTT.

By focusing on changes in psychological and neural representations, we should not lose sight of the fact that different aspects of memory, details, gist and schema, can co-exist with one another. Though co-existing, one representation may be dominant and the other dormant or silent, but capable of reasserting dominance, when revived by a reminder (Sekeres et al, 2020) or when promoted by task requirements or retrieval orientation (Rudoy et al., 2009; Aizpurua \& Koutsaal, 
2015) (see below for similar effects in rodents in the Systems consolidation in non-human animals: Recent evidence section).

\section{Hippocampal-neocortical interactions: functional connectivity and cross-regional coupling of neural oscillations}

As the hippocampus does not act alone, according to TTT, interactions between the hippocampus and neocortex should be maintained even for remote memories as long as they retain their episodic nature, with a decline in such interactions as memories lose their episodic signature. This general pattern, with some variations, has been observed across different indices of interaction including measures of functional connectivity in fMRI studies, and cross-regional coupling of neural oscillations in electrophysiological studies. Functional connectivity between HPC and neocortex was evident during retrieval of autobiographical memory at a single, remote time point (McCormick et al., 2015; Addis et al., 2007a), cross-sectionally at recent and remote time points (Soderland et al, 2012), and longitudinally (Sheldon and Levine, 2013), and of memories acquired in the laboratory (Dolcos et al., 2004; Gais et al., 2007; but see Sterpenich et al., 2009; Cowan et al., 2020). The strucutres to which the hippocampus is functionally connected, and whether it is its anterior or posterior portion, depends on a variety of factors including whether memory is being constructed (aHPC to vmPFC) or elaborated (pHPC to posterior neocortex; McCormick et al., 2015), whether the memory is emotional (aHPC amygdala; Dolcos et al., 2004), and whether the memory is incongruent with existing schemas (pHPC-mPFC-lingual gyrus, Bonasia et al., 2018).

Recording brain activity with magnetoencephalography (MEG) as participants listened to recordings of 2-7 month old memories (episodic) or a passage from a geograpgy text (semantic), Fuentemilla et al. (2014) identified a peak of theta power within a left MTL region of interest 
that was selectively phase-synchronized with theta oscillations on precuneus (posterior neocortex) and mPFC, more so for episodic than for semantic memory. In a subsequent study, Fuentemilla et al. (2018) found that large scale gamma synchrony, which reflects integration of neural activity within and across brain regions, was greater in the episodic, than the semantic, condition.

In a more recent MEG study which sampled autobiographical memories over a ten-year interval, McCormick et al. (2020), showed that the greatest changes in broadband power spectra occurred in the mPFC and left HPC .with mPFC activity leading that of the hippocampus in all but the most recent memories. Moreover, using effective connectivity analysis, they showed that mPFC drove HPC activity throughout the entire retrieval phase, consistent with our working-withmemory model (Moscovitch, 1992, Moscovitch \& Winocur, 1992).

Other investigators, however, found that under some conditions, HPC activity precedes that of mPFC in retrieving autobiographical memories (Treder et al, submitted). Applying a novel deterministic tractography protocol to diffusion-weighted magnetic resonance imaging (dMRI) of the fornix, Williams et al. (2020) found that retrieval of episodic details of past autobiographical events (and construction of possible future events) in response to cue words (Crovitz \& Schiffman, 1974) was correlated with the size of the pre-commissural fornix whose fibres project only unidirectionally from hippocampus to $\mathrm{mPFC}$.

William et al.'s findings temper the conclusions drawn by McCormick et al. and suggest that more work needs to be done to determine the conditions under which one or the other scenario applies. With regard to systems consolidation, however, TTT's assertion remains: remote, detailed episodic memories depend on continued hippocampal-neocortical interactions. 


\section{Effects of HPC damage or disruption}

According to TTT, HPC damage or disruption by TMS should lead to corresponding declines in HPC-neocortical interactions and in recent and remote episodic memory. Thus, following unilateral MTL lesions or epilepsy, hippocampal-mPFC-posterior neocortical connectivity is disrupted and replaced by mPFC-neocortical connectivity (Addis et al., 2007a; McCormick et al., 2018b) accompanied by declines in episodic memory. Likewise, the difference in gamma synchrony between episodic and semantic memory was not found in a person with severely deficient autobiographical memory (Fuentemilla et al, 2018). Their finding is consistent with Hebscher et al.'s (2019a) observation that applying continuous theta burst stimulation to the precuneus disrupts theta and gamma synchrony between MTL and precuneus in healthy people which leads to a reduction in their episodic autobiographical memory, likely influenced by slowed frontally-distributed activity on MEG early during the construction phase of autobiographical retrieval (Hebscher et al., 2020). Damage to higher-order visual cortex (Greenberg et al., 2005; Ogden, 1993; Rubin \& Greenberg, 1998) has similar detrimental effects on episodic memory presumably because of the role visual imagery plays in episodic memory (Greenberg \& Knowlton, 2014; Shallice et al., 1994).

Argyropoulos et al. (2019) found that damage to the hippocampus in patients with autoimmune limbic encephalitis, even if confined only to CA3 (Miller et al., 2020), had remote episodic memory loss extended across the entire lifetime. Like others before them (Winocur et al., 2009; Lehmann et al., 2007; reviewed in Sutherland et al, 2019 Sekeres et al., 2018a), they found that the extent of remote memory loss was not directly related the volume of the HPC but, in Argyropoulos et al.'s (2020) study, to volume loss in the thalamus (see also Kopelman, 1999; Kopelman \& Marsh, 2018), a region that is becoming increasingly implicated in co-ordinating 
activity between mPFC and hippocampus (Varela et al., 2014; Vertes et al., 2007; and in expression of hippocampal engrams in remote memory via CA3 (Vetere et al., 2021). Using graph theoretical analyses of resting state activity, they found that remote memory loss was related to loss of global integration between the hippocampus and the necorotical regions that comprised the medial temporal component of the default mode network (Andrews-Hanna et al., 2010; Bellana et al., 2017).

When taken together with the effects of damage to CA1 (Bartsch et al., 2011) and DG (Kwan et al., 2015), the evidence suggests that damage to any of the hippocampal subfields can lead to temporally extensive retrograde amnesia, and deficient future thinking, respectively, as might be expected of an integrated system. The extent of episodic memory loss is not related to hippocampal damage in isolation, but to its ability to recruit neocortical and diencephalic representations, consistent with the idea that the engram or memory trace consists of a bound ensemble of hippocampal-neocortical-diencepahlic neurons (Diana et al., 2007; Eichenbaum et al., 2007; Cooper \& Ritchey, 2020; Ritchey \& Cooper, 2020). According to TTT, the nature of episodic memory deficits should vary depending on which subfield, or which region along the long axis, was most implicated (Poppenk et al., 2013, Dimsdale-Zucker et al., 2018), as suggested by functional neuroimaging studies on consolidation in normal people (see univariate and multivariate fMRI sections, Bonnici et al., 2013: Bonnici \& Maguire 2017 Tompary \& Davachi 2017, 2020; Dandolo \& Schwabe 2018; and Audrain \& McAndrews, 2020).

\section{Effects of damage to the mPFC: Differential effects on schemas and episodic memory}

Unlike damage to the medial temporal lobe, damage to mPFC is associated with impaired schema representations which support perception at encoding and, at retrieval, help initiate and guide search, and monitor memories to ensure they are appropriate to the goals of the task 
(Gilboa et al., 2006b; Gilboa \& Marlatte, 2017; Moscovitch, 1992). Patients with vmPFC lesions are significantly impaired during processing of schemas (Ghosh et al., 2014), schema-related memory (Stolk et al., 2015; Spalding et al., 2015) and factual semantics (Kan et al., 2009; Hebscher et al., 2016; Hebscher \& Gilboa., 2016; O'connor \& Lafleche, 2004). On tests of autobiographical memory, however, memory for details and temporal order can equal, or even surpass, that of controls if proper cuing and guidance is provided (Kurczek et al., 2015; Thaiss \& Petrides, 2008), but not if it is absent (Bertossi et al., 2016).

These different outcomes are to be expected if schemas or scripts serve as scaffolds to support retrieval of episodic details during memory construction (McCormick et al., 2018a; Robin and Moscovitch, 2017). Generation of scripts of familiar everyday activities (e.g. going to a doctor or restaurant), however, is impaired in patients with mPFC lesions (Burgess \& Shallice, 1996; Godbout \& Doyon, 1995; Godbout et al., 2004; Grafman, 1989; Grafman et al., 1993; Shallice \& Cooper, 2012; Sirigu et al., 1995, 1996), as is generation of well-known fairy tales (Gilboa et al, 2006a). Compared to controls, they made more idiosyncratic errors that were unrelated to the fairy tale's schema and were willing to endorse such schema-incongruent items on a recognition test, performance, consistent with Bonasia et al's (2018) observation in healthy people that that schema- incongruent errors in recalling video clips are negatively related to mPFC activation.

When combined with damage to adjacent orbito-frontal cortex, which control decision responses, faulty monitoring resulting from mPFC damage leads to confabulation, a disorder in which participants, without intention to deceive, produce episodic and semantic memories that are patently false and inconsistent with other knowledge (Gilboa \& Moscovitch, 2017; Moscovitch, 1989; Schnider, 2008; Moscovitch \& Melo, 1997; Gilboa et al., 2006a; Gilboa \& Marlatte, 2017; Dalla Barba \& La Corte, 2013; Schnider et al., 2017). 


\section{INTERACTIONS AMONG MEMORY SYSTEMS}

One of the guiding principles of TTT is that different distinct, yet active, representations of the same event can co-exist in the mPFC and hippocampus and interact with one another from encoding onwards (Jasnow et al., 2017; Sutherland et al., 2019; Takehara-Nishiuchi, 2020; Gilboa \& Moscovitch, 2021). We now examine how this principle plays out in the formation of schemas and episodic memory, and illustrate how they are interwoven as a result.

\section{mPFC and hippocampus in formation of schemas}

Our working definition of schemas is that they are representations of what is common across a series of events (see chapter 7.2 by Varga et al, 2022). The mPFC is implicated in mediating these representations. One approach to study schema formation, therefore, has been to present items with overlapping_content (e.g., A-B, B-C) and trace their neural and psychological representation during acquisition and retention. Using this approach, Preston and colleagues found that encoding of overlapping information is associated with increased activation in vmPFC, which is related to inference of AC pairs, and functional coupling between vmPFC and hippocampus (Zeithamova \& Preston, 2010; Zeithamova et al., 2012; Schlichting et al., 2015; Schlichting \& Preston, 2015), which is predictive of subsequent successful inference (inferring A-C). As expected, damage to vmPFC leads to impaired associative inference despite relatively preserved premise pairs learning (Spalding et al., 2015, suggesting vmPFC is needed for integrating new information with retrieved prior knowledge.

In variations of this paradigm, but with the focus on memory of the studied items, several studies have shown greater representational similarity among items with shared content than without shared content. Evident at acquisition, this similarity, as revealed also by MVPA, increased with 
time in mPFC (Ritchey et al., 2015; Tompary \& Davachi, 2017; Audrain \& McAndrews, 2020; Cowan et al., 2020), leading to reduced associative memory and recollection. Similar representational shifts were also observed in the hippocampus, though why such shifts were found in the aHPC in some studies, and pHPC in others, is unclear.

Using a learning approach, Sommer (2017) trained participants on ten different spatial arrays of object-location paired associates, in a human analogue of Tse et al's (2007) rodent study. Participants were followed over 9 months of intensive training with changes to neural representations tracked over the first two days and again at 3 and 6 months. As schemas developed for the over-trained spatially-associated pairs, there was shift in activation from the HPC to vmPFC, and later to vlPFC, the latter being part of a semantic memory network (e.g. Binder et al., 2009; Binder \& Desai, 2011). These patterns may reflect a transition of representations from schematic/gist that still hold some information about learning context to abstract semantic knowledge, devoid of context.

Wagner et al. (2015) used a learning task akin to the weather prediction task to investigate the manner in which rule-based schemas are represented over two days of training. They, too, identified increased activity over time in vmPFC, as well as involvement of angular gyrus and high-level associative visual areas in posterior cingulate. As predicted by TTT, this process was paralleled with disengagement of posterior hippocampal activity and loss of detail from memory, suggesting that angulr gyrus could serve as an important trans-modal hub of schematic representations in posterior neocortical regions (Yazar et al., 2017).

Together, these studies suggest that episodic memory and schemas are formed at acquisition, coexist and interact with one another via the hippocampus and $\mathrm{mPFC}$, respectively. In 
accordance with TTT, changes in the relative contribution of one or the other, are reflected in representational shifts at the neural and psychological level.

\section{mPFC and Hippocampus in formation of episodic memories: pre-stimulus and post- encoding effects on consolidation}

Having been formed, when do schemas begin to influence memory? As noted at the beginning of the chapter, schemas interact with environment and stored knowledge to interpret the world and help form memory representations (Ghosh \& Gilboa, 2014; Gilboa \& Marlatte, 2017; see chapter 7.2 by Varga et al, 2022). To date, however, almost all research on schemas, and memory in general, are concerned with psychological processes and neural mechanisms that occur after a stimulus is presented or an event occurs. If schemas operate as we conjecture, schemas should already be operating before the event occurs to guide perception and extract or convey meaning.

With these ideas in mind, Gilboa \& Moscovitch (2017) proposed that the relevant schema for an event is reinstated in vmPFC prior to stimulus onset to prepare individuals for the type of information that they are likely to encounter, and then the schema is instantiated to interact with the environment. To test the idea of schema reinstatement, they had participants decide whether face stimuli depicted people with whom they were personally familiar, or judge the schema membership of exemplars (viz. Does "lion" belong to the schema visiting a zoo?; Giuliano, et al., 2021). In both cases, they found that that prior to stimulus onset, there is a period of theta coherence desynchronization between medial prefrontal areas, inferotemporal and lateral temporal cortices, which is reduced in patients with vmPFC damage, especially in those with clinical histories of spontaneous confabulation. Similar post-stimulus oscillatory patterns, but in the alpha and beta frequency bands, were interpreted as evidence of schema instantiation (Giuliano et al., 2021). 
The schema-associated pre-stimulus effects may part of a class of other pre-stimulus effects that have been reported in the literature, namely, that pre-stimulus activation patterns measured by both EEG and fMRI predict subsequent memory for the upcoming stimuli (Fernández et al., 1999; Liu et al., 2021; Otten et al., 2006; Park \& Rugg, 2009; Sweeney-Reed et al., 2016). These, in turn, may be related to more general memory allocation effects reported in rodents (Silva et al., 2009; Josselyn \& Frankland, 2018) which show that neurons that are more excitable prior to encoding are more likely to be recruited to form part of the subsequent, consolidated memory trace. Using multivoxel pattern analysis in humans, Sadeh et al., (2019) reported a human analogue of the allocation effect, showing that the overlap of voxel patterns during preencoding rest and encoding in the hippocampus and related structures predicts subsequent memory for items presented at encoding.

As with pre-stimulus effects, investigators have also reported post-encoding or post-learning reactivation effects in the hippocampus and other structures, either during sleep or rest, that predict subsequent memory (consolidation) in rodents (Silva et al., 2009; Sutherland \& McNaughton, 2000; Wilson \& McNaughton, 1994) and humans (de Voogd et al., 2016; Dudai et al., 2015; Gruber et al., 2016; Hermans et al., 2016 Paller et al., 2021; Staresina et al., 2013; Tambini \& Davachi, 2019), and that are modulated by prior knowledge (Liu et al, 2017). It is noteworthy that not only changes in HPC activity alone, but also in its functional connectivity with other structures, correlated with subsequent memory, suggesting that they reflect early memory consolidation processes.

Are the pre-stimulus neurons that were activated, or subset of them, also re-activated postencoding, and does the latter set also support representations of detailed, remote memories? There is no definitive answer, but Larzabal et al.'s (2020) study tracking memory to 
reinstatement effects suggests that it is possible that similar neural populations are implicated at all time points. Using MVPA of the EEG signal to video clips, they found that although the signal faded over time, sustained patterns indicative of reinstatement effects were observed even at the most remote time tested.

\section{Episodic, semantic and schematic memory are intertwined}

The foregoing suggests that the hippocampus, in interaction with neocortex and other structures, binds into a memory trace or engram, co-activated neurons that reepresent all conscious aspects of an experience, that include schemas, semantics, and perceptual and emotional details (Gilboa \& Moscovitch, 2021; Moscovitch, 1992, Moscovitch \& Winocur, 1992),. This idea is captured in a recent review on episodic and semantic memory, in which Renoult et al (2019), following Greenberg and Verfaeillie (2010), concluded that "Current behavioural, neuropsychological and neuroimaging data are compatible with the idea that episodic and semantic memory are inextricably intertwined, yet retain a measure of distinctiveness, despite the fact that their neural correlates demonstrate considerable overlap (pp. 1041).” Here, we review briefly only those studies that are relevant for systems consolidation.

Performance on classical semantic memory tests, such a category fluency (generating animal names), is impaired in patients with medial temporal damage (Newcombe, 1969; Gleissner \& Elger, 2001; Greenberg et al., 2009; Ryan et al., 2008), presumably because their deficient episodic memory prevents them from using it (e.g.memory of a visit to the zoo) to help them identify exemplars of the category. Likewise, MTL damage or degeneration, accompanied by episodic memory loss, is associated with deficits in naming, reading and recognizing famous people, places and well-known public events, which also ostensibly part of semantic memory, but that have personal significance (Westmacott et al., 2001; Westmacott and Moscovitch, 
2003;Wesmacott et al., 2004; Petrican et al., 2010). As with memory for public events, memory for semantic narratives, such as Bible stories and fairy tales, is impoverished in people with medial temporal lobe lesions (Verfaellie et al., 2014), particularly if they have a scene construction aspect to them (Lynch et al., 2020). Waidergoren et al. (2012) also found that the hippocampus was needed during recognition of semantic facts when these facts require the retrieval of semantic information that is not intrinsic to the concept ('semantic context'). Consistent with this idea, a patient with hippocampal developmental amnesia was shown to be impaired on generation of extrinsic, but not intrinsic, semantic features of object concepts (Blumenthal et al., 2017). Conversely, performance on many such tests can be relatively preserved in people with semantic dementia and lateral and infero-temporal damage, as long as their episodic memory is not severly affected (Westmacott et al., 2001; Moss et al., 2003; Maguire et al, 2010; Hodges \& Graham, 1998; Graham et al., 1999).

The relevance of these studies for systems consolidation is that although the task is ostensibly semantic, and should be mediated by extra-hippocampal structures, such as anterior temporal or inferior frontal cortex, there is a hippocampally-mediated episodic component that contributes to performance. Although the age of the memory was not examined systematically in all these studies, in those where it was, the deficits extended for decades (Westmacott et al., 2004), indicating that it is likely that the type of information sampled drew on memories accumulated over a lifetime.

Evidence from fMRI and single untit rcordings is consistent with the lesions studies. Hippocampal activation is observed during exemplar generation in semantic fluency (Ryan et al., 2009), especially for items generated late in the sequence (Sheldon et al., 2016) and for famous faces encountered in the remote past (Trinkler et al., 2009; Liu et al., 2017). Likewise, single 
units in the hippocampus, dubbed "concept cells", respond to specific people, places and objects (or stimuli associated with them) regardless of modality or of transposition and variation within a modality as long as the entity is identifiable (e.g. different views or different pictures of the same person). Quiroga and his collaborators (Quiroga et al., 2005; Quiroga, 2012, 2019) suggested that these cells code semantic representations that "constitute the building blocks for declarative memory functions" (Quiroga, 2012, p.592). As the large majority of these cells respond to items with which the person is personally familiar (Viskontas et al., 2009b), they may more properly be called "experiential or episodic cells" that link a specific entity to an experience of which the entity was a part (Sekeres et al., 2018a; Renoult et al., 2019).

On the other side of the ledger, we already noted how on tests of autobiographical memory and of memory for narratives, such as video clips, detailed episodic components are intertwined with gist and schematic components (Levine et al., 2002). Damage to the hippocampus affects the episodic component no matter how old the memory. Damage to the vmPFC, however, produces more variable results depending on the demands of the task, in part because schemas may be needed to guide memory search and to monitor its output (Moscovitch, 1989, 1992; Moscovitch \& Winocur, 2002; Gilboa et al., 2006b; Gilboa \& Moscovitch, 2017).

There are fewer studies on the contribution of the antero-lateral, inferior temporal and inferior frontal cortex, central regions in the semantic network, on tests of episodic memory (Renoult et al., 2019). The best evidence comes from studies of individuals with semantic dementia whose antero-lateral temporal cortex has degenerated (Viard et al., 2013; Irish \& Piguet, 2013. Some cases show deficits in remote, but not recent, autobiographical memory, (Graham \& Hodges, 1997; Maguire et al., 2010), whereas others show impoverished autobiographical memory across the lifespan (Irish \& Piguet, 2013). A possible source of the difference between the two sets of 
findings are the stimuli used to cue memory. Pictorial stimuli may access recent, perceptuallypreserved memories mediated by the hippocampus more easily without the intervention of semantics, whereas verbal stimuli always depend on semantic mediation via inferior and lateral temporal cortex (Irish \& Piguet, 2013).

Other regions of the autobiographical/recollection network related to semantics are also implicated in retrieval of recent and remote autobiographical memories (Renoult et al., 2019). Examining patients with lateral, focal frontal lesions, Levine (2004) found that without cuing, their recent and remote memory for autobiographical events is impaired; with it, it is preserved. In patients with the behavioural variant of fronto-temporal dementia, however, autobiographical memory decline was related to degeneration of lateral and medial frontal regions (Liu et al., 2020; Irish \& Van Kesteren, 2018; Irish \& Vatansever, 2020; Renoult et al., 2019).

The findings reviewed in this section underscore the complexity of understanding systems consolidation. We have now gone beyond the idea that a memory is mediated by one structure or another (HPC vs neocortex) depending on memory age, as SCT predicts, or even that dividing memories into semantic and episodic is sufficient, as the early versions of MTT suggested. Instead, consistent with TTT and NPRC, what is crucial in identifying the structures that mediate memory in systems consolidation is understanding how memories are represented, leaving open the possibility that the expression of some (all?) memories consist of different, integrated, but separable components, each of which is mediated by different structures.

\section{Interim summary}

These complex patterns of activation, revealed by univariate and multivariate fMRI studies, and by studies of functional connectivity and neural oscillations underscore the complexity of 
memory transformation processes that underlie systems consolidation. In addition to being influenced by memory age, hippocampal-neocortical activation and interaction are also modulated by vividness, perceptual richness (details), congruency with prior knowledge, central or peripheral elements of the event, and recollection and familiarity (see chapter 5.5 by Yonelinas, Ramey \& Riddell, 2022). Despite the variety of findings across different methodologies, there are some notable regularities. Memory representations that are vivid and perceptually-detailed are associated with hippocampal activation, and hippocampal-neocortical connectivity whether measured by fMRI or frequency oscillations, regardless of memory age. This pattern in humans is consistent with that observed in rodents (see below section on Systems consolidation in non-human animals). These patterns are likely initiated even before the stimulus is presented (memory allocation effect) and may be related to post-encoding reinstatement effects during wakefulness and sleep. Damage to the hippocampus, or disruption of its function, leads to reduced hippocampal involvement associated with loss or reduction of rich episodic memories. Conversely, loss of rich episodic memories is associated with diminished hippocampal involvement and increased involvement of the mPFC. Activating the mPFC, however, does not restore the rich, episodic memory representation that is dependent on the hippocampus.

Results concerning activation along the long axis of the hippocampus and their functional connectivity are more variable: Some are consistent with our prediction that as memories are transformed with time, the posterior hippocampus is more implicated in perceptually detailed representations and the anterior, with gist while others show the opposite. Studies on the role of subfields in system consolidation suggest that the DG/CA2/3 subfields are implicated more in representing detailed context-specific memory and the CA1 subfields in representing gist, a 
pattern also observed in rodents (see below section on Systems consolidation in non-human animals).

A recent review by Brunec et al. (2020) on representational similarity along the long axis of the hippocampus noted that increases or decreases in similarity across the long-axis are not fixed but are modulated flexibly by task goals that emphasize extraction of generalities or reinstatement of specific experiences. No doubt, these factors will also determine the nature of memory transformations and how regions of the long axis are implicated in systems consolidation.

Memory retrieval depends on the co-activation of various structures. Whereas hippocampal involvement serves as a marker for retrieval of episodic memory, whether context-specific or gist-like, the same is not true for mPFC and anterior temporal lobes as markers, respectively, of retrieval of schematic or semantic context-general memory. Often, these structures are implicated even when context-specific, episodic memories are retrieved suggesting the following: (1) that they contribute to general functions, such as search and monitoring, that aid retrieval of episodic memory (Moscovitch, 1992; Gilboa, 2004 Gilboa \& Marlatte, 2017; Gilboa \& Moscovitch, 2017); (2) that schematic or semantic information can be part of the fabric of episodic memory (Renoult et al., 2012, 2019); and/or (3) that each type of memory representation can co-exist with the others, the extent to which one is dominant or interacts with the other being determined by a variety of factors, much like those that influence the involvement of different regions along the long axis of the hippocampus (Winocur \& Moscovitch, 2011; Robin \& Moscovitch, 2017; Sekeres et al., 2018a). Accordingly, whereas damage to the hippocampus will impair context-specific, episodic memories, and leave schematic and semantic memories relatively spared, damage to $\mathrm{mPFC}$ and anterior temporal lobe 
will not only affect schematic and semantic memory, respectively, but will also affect encoding and retrieval of episodic memory under many circumstances.

\section{Systems consolidation in non-human animals: Recent evidence}

Findings and conclusions from human studies on the role of the hippocampus and neocortex in systems consolidation are remarkably consistent with those from studies on non-human animals. Because animal studies can exert a level of control and neurobiological interventions not afforded to human studies, some vexing issues in human studies, such as the nature of engrams and the interactions of one region with another at different points in time, can be addressed more clearly in animal studies. By complementing one another, studies on humans and animals produce converging evidence that advances our knowledge of systems consolidation.

We summarize the evidence from animal studies on systems consolidation, and refer the interested reader to Moscovitch \& Gilboa (2021) for a more extensive treatment. Before proceeding, we remind the reader that we consider detailed, context-specific and context general memory in animals to be the homologues of episodic and non-episodic memory in humans. At the anatomical level, the ventral and dorsal hippocampus in rodents are the homologues of anterior and posterior hippocampus in humans.

\section{The hippocampus is necessary for retention and retrieval of recent and remote context specific memory}

Early lesion studies on systems consolidation in animals showed a temporally-graded memory loss following hippocampal damage, such that recent, but not remote memories, were affected. The most commonly used paradigm to study systems consolidation in rodents is contextual fear conditioning (Kim and Fanselow, 1992) in which the rodent (typically rat or mouse) experiences 
an aversive event (shock) in a distinctive context. The extent to which the rodent freezes in fear when reintroduced to that context is a measure of its memory. Consitent with predictions from SCT, initial tests showed that hippocampal lesions led to memory loss at short (within a day) but not at long (days or weeks) delays following acquisition. Similar results were obtained with other paradigms that were amenable to context manipulations (for review see Winocur et al., 2010). The preserved remote memories were mediated by extra-hippocampal neocortical structures, particularly the medial prefrontal cortex (mPFC), which included the anterior cingulate cortex (ACC), as lesioning or disrupting them led to remote memory loss (for review see Frankland \& Bontempi, 2005). These results were interpreted in accordance with SCT as it was assumed that performance at remote intervals was driven by what was effectively the same memory as at recent intervals.

Working within the framework of TTT, Winocur and his colleagues (2010; Sekeres et al, 2018a) and others (Wiltgen \& Silva, 2007; Wiltgen et al., 2010) challenged this interpretation. By testing animals in the same or different context from acquisition, they showed that different memories mediated performance at the two time points: context specific at recent time points (freesing only in the same context), and context-general at remote ones (freezing in both contexts) as memory for the specific context declined. Damage to the mPFC had the opposite effect (Jasnow et al., 2017. In accord with NPRC, the neural representation reflected its psychological counterpart.

Studies on hippocampal and neocortical activation using immediate early gene expression, and optogenetics, provide converging evidence to support these conclusions. Sekeres et al. (2018b) and Wiltgen et al. (2010), found greater activation of the hippocampus than of neocortex at short delays, when the memory was context-specifc, than at long delays, when the memory was 
context-general. The reverse patern held for the neorcotex. Differences between hippocampal and neocortical activation was an index of context-specificity (Wiltgen et al., 2010).

Such representational shifts, from context-specific to gist-like memories, are also observed within the hippocampus, with some reseearchers noting that activation of engram cells in DG diminishes with time as it increases in CA3 over 30 days (Tayler et al., 2013; Guo et al., 2018). Others, however, attributed a decline in specificity to diminished CA3 contribution, with CA1, and related neocortical regions, contributing to context-general memory at recent and remote time-points one month (Cullen et al., 2015; Jasnow et al., 2017) and 6-12 months later (Lux et al., 2016; Atucha et al., 2021).

\section{Systems consolidation is not a unidirectional, but a dynamic, multi-directional process, in which different forms of memory can co-exist and interact with one another.}

The co-existence of context-specific and context-general memories, the dynamic interplay between them, and the central role of functional-neural correspondence is brought into relief by studies on re-consolidation (Nader \& Hardt, 2009; Nadel \& Sederberg, in press, current volume). Reconsolidation is a phenomenon in which a memory that had become independent of the hippocampus over time becomes dependent on it once again after the organism is re-exposed to the training context prior to testing at a remote time point (28 days). In accord with TTT, Winocur et al. (2009) showed that these changes in neural representation are accompanied by corresponding changes in functional/psychological representation. Once revived, the previously context-general, hippocampally-independent memory reverted to being a context-specific and hippocampally dependent (Finnie et al, 2018). 
For the reminder to be successful, the original context-specific engram must have been dormant (Moscovitch, 2012) or "silent" (Kitamura et al., 2017), awaiting the proper cue, or elimination of competing structures, to be activated sufficiently to be expressed in behaviour. This interpretation is supported by evidence that c-Fos expression in the dorsal hippocampus remains greater in the training than novel context, even at remote time point, and by evidence that hippocampal, context specific memories can be revived by optogenetic stimulation in mouse infantile amnesia induced by neurogenesis (Guskjolen et al., 2018), in drug induced retrograde amnesia in adult mice (Einarsson et al., 2015), and in mice models of Alzheimer's Disease (Roy et al., 2016). Also, removing the influence of mPFC (schema) and CA1 (gist), eliminates the context general memory at both delays, enabling the context-specific memory to be revealed (Cullen et al., 2015; Lux et al., 2016), whreas anhancing or diminishing DG influences on CA3 increases or decreases context specificity at long delays (Guo et al., 2018).

At a remote time point, the default condition is a context-general memory mediated by the mPFC, though it may be supported in its function by connections to the hippocampus (Einarsson et al., 2015; Goshen et al., 2011; Jasnow et al., 2017). The context-specific hippocampal representation (engram) remains silent, unless activated naturally by specific cues (reminder), or artificially by optogenetic stimulation (Kitamura et al., 2017; Guskjolen et al., 2018), at which point it may come to dominate behaviour.

As these examples illustrate, context specific and context general memories can co-exist from acquisition to retrieval at recent or remote time points. Dynamic interactions among the structures mediating the memories determine which type of memory is expressed in behaviour and which is dormant/silent or masked (Moscovitch, 2012) according to principles of TTT and NPRC. 


\section{Schemas and context-specific memories (episodes): Their acquisition and utilization}

Studies of memory allocation found that neurons that are most excitable prior to the occurrence of an event are recruited to form the engram of that event suggesting that memory formation effectively begins before an event can be encoded (Josselyn \& Frakland, 2018) . Successful memory retrieval depends on reactivating these engrams (see Sadeh et al, 2019, above for humans). Although such processes have been observed for acquisition of emotional, associative and spatial memory, it is not known whether they also apply to schemas. Using trace CS-US conditioning, and recording from mPFC neurons, Takehara-Nishiuchi et al (2020) found that a subset of them showed elevated responses to the pairing within a minute, which generalized to a CS that was not used in training. Evidence that context-general memories can be formed rapidly at encoding, suggest that similar allocation processes may apply to them.

Other mPFC engrams, though formed rapidly, seem to take longer to become functionally viable. Kitamura et al. (2017) identified such mPFC engrams which initially were "silent", becoming viable only at two weeks when hippocampal engrams gradually receded and memory generalized. Removng competition from hippocampal engrams by deactivating them earlier led to accelerated mPFC engagement and contextual generalization (De Sousa et al., 2019). This finding suggests that viability of mPFC engrams may depend as much on eliminating competition with hippocampal engrams, as on a prolonged consolidation process. The rapid generalization of memories that are cortically dependent is consistent with the NPRC principle (Gilboa \& Moscovitch, 2021) and with idea that rapid cortical learning occurs at encoding but requires large-scale cortico-cortical network activity to be viable and compete for expression with hippocampal memory engrams (Hebscher et al., 2019b). 
Having been formed, how do schemas influence acquisition and retention of new memories? In a series of studies, Tse and colleagues (2007, 2011; Wang et al., 2012, cf. Hasan et al., 2019) trained rats over several weeks to form a schema consisting of eight flavour-place associations in an "event arena". The establishment of such mPFC schemas was critically dependent on the hippocampus (Hasan et al., 2019). Once established, however, this schema accelerates the consolidation of new flavour-place associations from the hippocampus to mPFC. It should be noted, however, that the above studies provide no information as to the type of memory that is assimilated to schemas and represented by the mPFC, although it is assumed by the authors that it resembles the memory that was initially dependent on the hippocampus.

An earlier study by Winocur et al. (2005) suggests otherwise. Winocur et al. gave rats extensive experience living in a complex maze, resembling a village, open to its surroundings. Once the village schema was established, they lesioned the hippocampus. Rats with hippocampal lesions learned to navigate from start boxes towards goal locations in the village as quickly as controls, and much more quickly than rats with hippocampal lesions who had no prior knowledge (experience) of the village. The way they navigated, however, indicated that rats with intact hippocampi represented the village differently from rats with lesions, as predicted by TTT. When the most direct route to the goal was blocked, intact rats took another short-cut to it, as would be expected if they based their navigation on a cognitive map (Tolman, 1948; O'Keefe \& Nadel, 1978). Rats with hippocampal lesions, on the other hand, took a circuitous route, often hugging the perimeter of the maze until they came to their goal, suggesting that they may have used distal, environmental landmark cues to identify it rather than a flexible cognitive map.

McKenzie et al. (2013, 2014) and Farovik et al. (2015) used neural similarity analytic approaches, akin to representational similarity analytic methods used in human imaging studies, 
to show that the nature of schematic representations within the rodent hippocampus and orbitofrontal cortex differ from one another. When new items are learned within previous spatial contexts, hippocampal neurons immediately display the position, valance, identity hierarchy in their representation, providing a mechanism by which hippocampal schemas support rapid integration of new knowledge based on context. By contrast, orbitofrontal neural representational similarity reflects a hierarchy driven by stimulus reward value.

Perhaps the most direct test of the dynamic nature of integration and adaptation of knowledge across multiple episodes comes from a study that used a modified version of the Morris Water Maze with mice (Richards et al., 2014). In that paradigm, the exact location of the platform varied across trials, being drawn randomly from a spatial distribution. Search patterns more accurately matched the pattern of location distribution 30 days after training, compared to 1 day after training. Moreover, there was evidence that this delay-dependent process of extraction of statistical commonalities across events (schematization) was dependent on mPFC coding that was only expressed at long delays. The slowly evolving operation of the schema was reflected by a delay-dependent increased sensitivity to new locations, mediated by the hippocampus.

What is clear from these studies is that the mPFC, and possibly other structures, do not simply replace the hippocampus as a node that activates the same neocortically represented engrams as did the hippocampus. Memories mediated by mPFC are different from those mediated by the hippocampus in the variety of ways outlined above.

\section{Theories of Memory Consolidation}

A crucial question that we did not address directly in reviewing the evidence is: What are the psychological processes that underlie memory transformation, leaving it to others to deal with 
the neurobiological processes? Time and experience can transform the initial representations in a variety of ways (Winocur \& Moscovitch, 2011): by decay (Barry \& Maguire, 2019a; Hardt et al., 2013; Sadeh et al., 2014, 2016) or interference (Frankland et al., 2019; Richards \& Frankland, 2017; Yassa \& Reagh, 2013; Yonelinas et al., 2019); by extraction of statistical regularities among events (McClelland et al., 1995; Schapiro et al., 2017b); by assimilation into pre-existing knowledge structures (Bartlett, 1932; semantics: McClelland et al., 1995; McClelland, 2013; schemas: Gilboa \& Marlatte, 2017; Tse et al., 2007, 2011; van Kesteren et al., 2012; Wang \& Morris, 2010); by updating via reconsolidation (Nadel \& Sederberg, in press, this volume); by reconstruction influenced by past knowledge as well as by current goals and motivation (Schacter et al., 2012b); by episodic simulation and imagination (Addis et al., 2007b; Addis, 2018); and by errors at retrieval (Bridge \& Paller, 2012). None of these is mutually-exclusive and, potentially, all can co-occur and influence one another.

MTT/TTT is agnostic as to which and how many of these transformations underlie the changes in psychological and neural representations observed in systems consolidation. Its crucial tenet is that whichever psychological representation is expressed as a result of the transformation process, it is accompanied by co-activation of its corresponding neural structure, and vice-versa. In comparison to MTT/TTT which considers that these transformations can occur at any point from acquisition, to retention, to retreival, and are usually bi-(multi)directional between the hippocampus, neocortex, and other structures, SCT and its derivatives posit that these transformations are unidirectional and occur only before memories have become independent of the hippocampus and been consolidated in neocortex (Squire et al., 1984).

Current theories of systems consolidation have elements in common with SCT or MTT/TTT or both, but either challenge crucial aspects of these theories or complement them in important 
ways, or both. We highlight these differences as we believe they point to the direction that future research on systems consolidation will take.

\section{Complementary Learning Systems}

Perhaps the most influential computational model of systems consolidation, Complementary Learning Systems (CLS; McClelland et al., 1995; Norman, 2010) stipulates that memories must be encoded rapidly in the hippocampus before they can be integrated slowly into neocortical representations in order to prevent catastrophic interference with old memories and loss of the newly-acquired memory (McCloskey \& Cohen, 1989). By contrast to the neocrotex, the hippocampus is suited to rapid acquisition and retention of new information. Through repeated interactions with neocortex over prolonged intervals, hippocampal replay of these memory traces, during sleep and wakefulness, induces gradual changes in neocortical semantic/schematic networks so that the new memory traces can be integrated with them and become independent of the hippocampus.

CLS computationally simulates systems consolidation according to the principles that govern SCT. CLS's weaknesses, however, are also those that bedevil SCT. The neocortical system into which episodic memories are integrated is a semantic network or knowledge structure that is not suited for supporting context-specific information that is the hallmark of episodic memory.

Episodic memories are effectively lost in that model; only semantics or schemas remain. Even if we concede that the neocortical system can support episodic memories, damage to the hippocampus should leave them unscathed. Yet the evidence we reviewed indicates that hippocampal damage impairs even remote episodic memories. 
To counter the challenge that some neocortical memories are acquired rapidly (Tse et al., 2007; Sharon et al., 2011; McClelland, 2013; Kumaran et al., 2016) showed that CLS can accommodate such rapid, neocortical learning if the new episodic memory is consistent with preexisting schemas. Such a process may be implicated in fast-mapping (Carey \& Bartlett, 1978), a procedure whereby single (or very few) presentations of novel material, is integrated into semantic networks (Coutanche \& Thompson-Schill, 2015) mediated by peri-rhinal and anterolaeral temporal cortex, without benefit of the hippocampus (Atir-Sharon et al., 2015; Merhav et al., 2014, 2015; Sharon et al., 2011; Hebscher et al, 2019b). Contrary to CLS, however,inconsistent memories, may never be fully integrated into neocortex (Bonasia et al., 2018; van Kesteren et al., 2012) yet remain viable, and dependent on the hippocampus, for an extended time. Moreover, neocortical learning mediated by $\mathrm{mPFC}$ and not related to prior knowledge can also be rapid, occurs concurrently with learning in the hippocampus, and sometimes is necessary to support the rapid acquisition of hippocampally-based memories (Takehara-Nishiuchi, 2020; Jasnow et al, 2017; Tompary \& Davachi, 2017; for review, see Hebscher et al., 2019b). Thus, while providing a good computational account of how some aspects of hippocampally mediated episodic memory are transformed with time and repetition into neocortically-mediated semantic memories, the CLS Model is not fully successful in accounting for various other aspects of systems consolidation.

\section{Complementary Memory Systems}

By assigning complementary roles to the hippocampus and neocortex, Takehara-Nishiuchi's model resemblesCLS, but unlike it, she focuses on the crucial involvement of the mPFC in the formation of episodic memory and schemas. She presents evidence from behavioural, lesion, electrophysiological and molecular studies showing that mPFC, like the hippocampus, is 
implicated in the encoding of new experiences (Lesburgueres et al., 2011; Jasnow et al., 2017), but the type of information that is encoded and their ensuing representations differ between the two structures. Whereas the hippocampus captures moment-to-moment changes in the temporal, spatial and perceptual aspects of the event, leading to context-specific representations of it, the mPFC captures similarity among inputs (and likely also with stored representations) and integrates them over time, enabling it to capture the central content of the event, its underlying schema. In short, consistent with TTT, the hippocampus and mPFC form complementary memory representations from the outset, one for context-specific representations and one for schemas, raising the possibility that the mPFC exerts top-down modulation of the hippocampus, enabling more "selective, perhaps more intelligent, encoding of new information (abstract, p1)." In all likelihood, schema-guided modulation by the mPFC operates at various levels, including early perceptual ones, to determine the type of information that is delivered to the hippocampus (Gilboa \& Marlatte, 2017; Gilboa \& Moscovitch, 2017; Moscovitch, 1992; Moscovitch \& Winocur, 1992, 2002). The model, however, has little to say about systems consolidation after encoding.

\section{Schema theories and their influence on memory formation and long-term retention}

Prior knowledge (Burnham, 1904), and schemas in particular, have also played a central role in theories of systems consolidation in humans beginning with Squire et al. (1984) and extending to the present (see Gilboa \& Marlatte, 2017 for review; chapter 7.2, by Varga et al, 2022). Schema theories work with a loose definition of schemas, often using the term interchangeably with general knowledge, context general information, and semantics. Although Gilboa and Marlatte (2017) took care to specify what distinguishes schemas from other types of prior knowledge, 
most studie on schemas rely on much looser definitions, effectively treating schemas as any type of prior knowledge that is declarative but not episodic.

van Kesteren et al. (2012) proposed a theoretical framework, dubbed schema-linked interactions between medial prefrontal and medial temporal lobes (SLIMM), to account for the influences of schemas and novelty on new learning, This framework relies heavily on neural substrates, rather than psychological representation, to define schemas. By this view, a schema is a collection of neocortical nodes that are mutually reinforcing and that when co-activated influence processing of new information. Encoding of novel information is driven by the extent to which it is congruent or incongruent with the schema represented by the activated network. When congruence is high SLIMM predicts rapid neocortical learning that is independent of the hippocampus, and may even lead to hippocampal inhibition by mPFC which, in turn, leads to suppression of memory for event details that are unrelated or incongruent with the active schema. By contrast, incongruous events produce a strong prediction error, which in turn triggers the medial temporal lobe and the HPC to support representations of event information including the main event details and the context in which they occur. Prediction-error driven memory for context serves to retain potentially important information by separating it from existing knowledge. That information could later be gradually integrated into the active schema should it prove to have future predictive value (see McClelland et al., 1995; McClelland, 2013; Kumaran et al., 2016, for comparable ideas in CLS).

Some of the interesting predictions that arise from the SLIMM model have received support while others still await empirical evidence. For example, because both extreme incongruency and extreme congruency enhance memory, SLIMM predicts a U-shaped relationship between congruency and memory performance, with mid-range levels of congruency associated with 
worse memory. This was recently demonstrated by (Greve et al., 2019) with the additional finding that incongruency influences memory at encoding whereas congruency also exert its effects post-encoding (but see Wynn et al., 2020). Findings by Bonasia et al. (2018) suggests that similar relationships may hold for remote memories.

By contrast, that vmPFC inhibits MTL during encoding of congruent events has only rarely been demonstrated (van Kesteren et al., 2012). More troubling for SLIMM is that several studies have reported increased coordination between vmPFC and HPC during encoding of schema-congruent information (e.g. Liu et al., 2017 Sommer, 2017), and Bonasia et al. (2018) found equivalent MTL activation for the two types at encoding.

These latter findings are consistent with alternative theories of schema related learning that posit that schema formation relies on the HPC (Tse et al, 2007; Wang et al, 2010), and that the vmPFC's role in the process is one of control and context-sensitive conflict resolution (Eichenbaum, 2017; McKenzie et al., 2014; Preston \& Eichenbaum, 2013). Functionally, Preston and Eichenbam's model suggests that mPFC signals events or occurrences that are inconsistent with prior knowledge and consequently mPFC-hippocampal interactions facilitate the retrieval of potentially relevant information for conflict resolution, promoting integration or assimilation of new incompatible information into existing memory networks. Thus, the SLIMM and Preston and Eichenbaum models make opposite predictions with respect to the impact of mPFChippocampal interaction on learning of new information in the context of prior knowledge. In addition, what is left unspecified by these models, but is evident in some of the other schemarelated theories we discussed, is how memories change with time and experience. Even assuming that these theories can account for memory acquisition, it is not clear how they account for changes in memory representation at the psychological and neural level with time, so as to 
provide viable models of systems consolidation. From the point of view of TTT and the evidence adduced to support it, none of the models note whether memories integrated into schemas retain or lose their episodic signature.

\section{Interference models}

In comparison to schema models, interference models are very sensitive to changes in representation. The Competitive Trace Theory (Yassa \& Reagh, 2013) and the Contextual Binding Theory (Yonelinas et al., 2019) are both based on the idea that context specific information bound by the hippocampus at encoding is lost over time due to interference from related material, resulting in reduced hippocampal, and increased neocortical, representation. Although the two theories have much in common with one another, and draw on aspects of SCT and MTT/TTT, there are some important differences between the interference theories, and between both theories and SCT and MTT.

The Competitive Trace Theory borrows from MTT/TTT the idea that many older memories are associated with more repeated retrievals than recent memories which leads to more neural representations in the hippocampus and neocortex (but see Sutherland et al's, 2020). Like MTT/TTT, Yassa and Reagh (2013) assume that each reactivation of a memory during retrieval occurs in a new context, and leads to encoding of those elements of the old memory that are retained along with the novel context. They refer to this as a process of re-contextualization. Pattern separation allows for distinct representations of each of version in the hippocampus, whereas in neocortex, the versions overlap leading to competitive interference among them. In neocortex, only those elements that overlap are retained, enabling the slow formation of semantic memories or schemas, as proposed by CLS and MTT. As a result, veridical episodic details are available only for recent memories. Older memories are either decontextualized versions of the 
original represented in neocortex, or are re-contextualized versions of the original which depend on the hippocampus but are fraught with illusory details that increase with memory age.

It is not always the case, however, that remote memories contain more illusory details than recent ones. Whereas memory quantity and episodic richness declines with retention interval, accuracy often remains high, sometimes on the order of $90 \%$, even for intervals lasting years (Diamond et al., 2020; Evans \& Fisher, 2011; Goldsmith et al., 2005), consistent with MTT/TTT. Likewise, the literature on the effects of repeated retrievals or retrieval practice on memory does not always (or even often) lead to competitive interference and memory decline. Instead, again consistent with MTT/TTT, retrieval practice typically leads to improved memory, both with respect to its episodic and semantic components when compared both to memories that have not been retrieved or to those that have been re-studied.

Contextual Binding Theory uses the effects of contextual drift, which is the change over time in environmental, cognitive, and emotional context, and their corresponding neural representations to account for systems consolidation (Folkerts et al., 2018; Howard \& Kahana, 2002; Long \& Kahana, 2019 Manning et al., 2011). Because retrieval of episodic memories depends on reinstating the encoding context at retrieval, contextual drift is a contributing factor to interference, facilitation and temporal organization in memory (see, also, Chapter 5.11 by Manning, 2021).

By their own admission, Yonelinas et al. (2019) note that Contextual Binding Theory shares most of its core assumptions with MTT/TTT, acknowledging the pivotal role that context plays in accounting for episodic memory and forgetting. Unlike MTT/TTT, however, Contextual Binding Theory says little about the role of schemas and the interactions between mPFC and hippocampus in their acquisition, maintenance and instantiation. These, it should be 
acknowledged, all play out over relatively short intervals, from minutes to days, and not over the longer intervals, extending to years or decades that are observed in human studies of systems consolidation.

Sleep has acquired a prominent role in research on memory (Dudai et al, 2015), but the primary one assigned to it by Contextual Binding Theory is one of experiential quiescence, providing an interval free of interference during which memories can be consolidated. Considering the changed neural context between wakefulness and sleep, one would assume that contextual drift would be high and lead to increased, rather than decreased, forgetting as a result of sleep. That aside, it is also not clear whether it is the period of quiescence that accounts for reduced forgetting during sleep rather than wakefulness, or whether it is the replay during sleep of hippocampal memory traces that accounts for sleep's benefits (see section on Interactions between memory systems). Studies on targeted memory activation during sleep in humans (Berkers et al., 2018; Hu et al., 2020; Lewis \& Bendor, 2019; Paller et al., 2021; Rudoy et al., 2009) and on sharp wave ripples which accompany memory replay in rodents (Buzsáki, 2015) and likely in humans (Norman et al., 2017, 2019; Vaz et al., 2019, 2020) suggest that it is more replay, than absence of interference, that is crucial. Eliminating sharp wave ripples during sleep leads to memory loss (Buzsáki, 2015) even though, on the face of it, this manipulation does not increase interference. Last, in addition to studies reporting preservation of context-specific memories with sleep, there are also many studies showing that sleep leads to decontextualization of memory and the promotion of semantic and schematic representations (Lewis \& Durrant, 2011), contrary to the predictions of Contextual Binding Theory. Specifying the conditions under which sleep helps preserve context-specific memories and those in which it promotes 
decontextualized memories would contribute greatly to our understanding of systems consolidation from which all theories would benefit (Dudai et al., 2015; Paller et al., 2021). Distributed Reinstatement Theory and Memory Manifold Theory (Sutherland \& Lehmann).

Like TTT, Distributed Reinstatement Theory holds that memories are represented concurrently in hippocampus and non-hippocampal regions, but with the added premise that the representation is stronger in the hippocampus than in non-hippocampal networks, enabling the hippocampal representation to overshadow the others. As in TTT, damage to the hippocampus leads to temporally extensive and ungraded retrograde amnesia, with the size of the lesion determining the severity of the memory loss, but not its extent as MTT predicted (Sutherland \& Lehmann, 2011; Sutherland et al., 2019). With repetition of learning episodes, the non-hippocampal representations are strengthened and, contrary to MTT/TTT, but consistent with SCT and related theories, can store context-specific memories that resemble those of the hippocampus (Sutherland et al., 2010; Sutherland \& Lehmann, 2011; Sutherland et al., 2020). Most recently, Sutherland et al. (2020) proposed an updated version of their theory which they called Memory Manifold Theory to account for the effects of repetition, pattern processing in the hippocampus, amount of damage and state matching, essentially a measure of the reinstatement of the neural activity patterns at encoding,

The evidence suggests that neocortical (non-hippocampal) memories may indeed be weaker initially than those mediated by the hippocampus (Kitamura et al., 2017) although there is not universal agreement on this point (Takehara-Nishiuchi, 2020). More contentious, from MTT/TTT's point of view, is the idea that the representation of hippocampal and nonhippocampal memories resemble one another. In most cases that have been examined closely, the two have been shown to differ from one another (see section on Multivariate analyses and 
memory representations in system consolidation). In the few studies that have used the multiple learning episodes to bolster memory representation in non-hippocampal sites as (Frankland et al., 2006; Lehmann et al., 2009) it may be the case that the extended learning afforded the rat the opportunity to become acquainted with non-configural features (Rudy \& Sutherland, 1989) that distinguish one learning environment from another, and whose association with shock does not depend on the hippocampus (Hardt \& Nadel, 2018). Unless further tests show that functionally equivalent representations are formed in the two cases, the issue remains unresolved.

More telling is Sutherland and Lehmann's (2011; Sutherland et al, 2019) critique of a major tenet of MTT, namely, that the severity and extent of retrograde amnesia for episodic memory should vary with the size of the lesion in the hippocampus. MTT/TTT concedes this point. Mindful of findings in humans (Viskontas et al, 2000) and rodents (Winocur et al, 2010) on lesion size, this claim has been dropped in more recent formulations of TTT (Winocur \& Moscovitch, 2011; Sekeres et al., 2018a). Instead, noting the burgeioning literature on specialization along the long axis, the function of hippocampal subfields, and connectivity with each other and with extrahippocampal structures reviewed above on recent and remote memory (Ferguson et al., 2019; Barry et al., 2020), we now consider it likely that damage to any part of the extended hippocampal system will lead to some episodic memory loss, with the severity and type of loss being related to the nodes in the system that are affected and their connections.

Sutherland et al. (2020) report studies in which multiple learning episodes prevent memory loss after hippocampal lesions or enable the acquisition of contextual memories without a hippocampus. The central question, however, is whether the hippocampal neurons retain their contextual specificity as MTT/TTT predicts, and that extra-hippocampal neurons are less context-specific. We know from studies in humans, however, that re-studying the same material 
has very different effects than retrieval practice behaviourally (Karpicke \& Roediger, 2008;

Roediger \& Butler, 2011; Roediger \& Karpicke, 2006, 2018).and neurally, on the hippocampus, mPFC (Wing et al., 2013; Brodt, et al., 2016, 2018) and parietal cortex (Gais et al., 2007) a region known to code for both types of information (Bellana et al., 2017; Binder et al., 2009; Binder \& Desai, 2011; Vilberg \& Rugg, 2008) and to be linked both to the hippocampus and frontal cortex. Most interestingly, retrieval practice promotes the semanticization of episodic memories (Lifanov, et al., 2020) suggesting increased reliance on extra-hippocampal structures, particularly following sleep (Brodt \& Gais, 2020; Himmer et al., 2019).

Thus, the effects of multiple retrievals on psychological and neural representations are more complex than Sutherland and Lehmann claim, and that Nadel and Moscovitch (1997) foresaw. They lead not only to stabilization of episodic memory but, contrary to Sutherland et al. (2019), to formation of non-episodic representations in neocortex. The literature on the effects of replay, or involuntary retrieval, during sleep in humans and rodents is no less complex (see Diekelman \& Born, 2010; Dudai et al., 2015 for reviews). Although there is a consensus that sleep benefits systems consolidation, there is less agreement as to which structures are affected, and whether the memory benefit pertains only to semantic or schematic aspects of studied episodes (Lewis \& Durrant, 2011) or to context-specific (episodic) aspects (Aly \& Moscovitch, 2010; Dudai et al., 2015; Yonelinas et al., 2019) or both (Schapiro et al., 2017a). Although MTT may have been incorrect in proposing that repeated retrievals lead to formation of multiple traces in the hippocampus, it was correct in recognizing that such retrievals have a profound effect on systems consolidation/memory re-organization (Nadel et al., 2000).

Scene and Event Construction and Reconstruction Theory 
All previous theories assume that some episodic representation of the originally acquired memory has been retained over extended intervals, some lasting years or decades. Barry and Maguire (2019a, 2019b), however, take Yassa and Reagh's (2013) recontextualization proposal to its extreme, arguing that all but recent memories are recontextualized around a schematic core associated with the original memory. Citing evidence of instability of hippocampal place cells and synaptic processes, such as rapid loss of dendritic spines (Attardo et al., 2015), and the interference produced by life-long neurogenesis (Richards \& Frankland, 2017), Barry and Maguire argue that the hippocampus lacks the neurobiological mechanisms needed to sustain detailed, context-specific memories over long intervals. All that remains are gist of episodes or schemas mediated by extra-hippocampal structures, particularly the mPFC. To account for ostensible evidence of detailed, context specific (episodic) remote memories, some of it emanating from their own laboratory, Barry and Maguire propose that cues at retrieval activate appropriate schemas of events mediated by the mPFC which in turn guides the hippocampus to construct scenes that serve as scaffolds for binding event content on the fly. The process, essentially, is no different from the one engaged in episodic simulation of fictitious or imagined events. Damage to the hippocampus disrupts this on-line process and leads to impoverished memories, whether recent or remote, an argument resembling one that proponents of SCT used to account for impaired, remote memory of rodents on various spatial tasks (Clark et al., 2005). Moscovitch and Nadel (2019), while acknowledging the instability of hippocampal processes, suggest that such instability is not sufficient to discount the hippocampus as a viable substrate for long-term memory retention. They note that instability is also evident in neocortex, suggesting that may be a general characteristic of the brain, and possibly the entire organism. Moreover, in cortex, stabilizing spines is not always necessary for learning to persist (Clark et al., 2018). 
More importantly, Moscovitch and Nadel note that instability at the neuronal level does not translate into instability at the behavioural/psychological level. Considering that the engram consists of at least tens of thousands of cells (Josselyn \& Tonegawa, 2020; Quiroga, 2012, 2019), retention of a proportion of them, properly configured, may be sufficient to support contextspecific memories and, in the case of neurogenesis, to recruit novel neurons into their orbit (Ziv et al, 2013; Pavlowsky et al., 2017; Hsieh et al., 2017; Attardo et al, 2018).

As noted earlier, studies on reconsolidation, (see section on System Consolidation is not unidirectional) and retrieval through optegenetic stimulation or strong environmental cues (Guskjolen et al., 2018; personal communication) of memories forgotten as a result of neurogenesis, suggests that these hippocampal mediated memories were not lost but merely inaccessible. Likewise, degraded remote engram cells in CA1 (Goode et al., 2020; Tanaka et al., 2018; Tanaka \& McHugh, 2018) can be activated through the direct projections from EC. Moreover, recent evidence suggests that neurogenesis also simultaneously acts to stabilize and protect the remaining memories from degradation (Guo et al., 2018). Conversely, optogenetic suppression of engram cells leads to memory loss even at long delays, attesting to the longevity and viability of hippocampal traces (Cullen et al., 2015; Einarsson et al., 2015; Goshen et al., 2011). Cellular mechanisms that could support such long-term retention have been demonstrated in the hippocampus (Migues et al., 2016). In sum, there is little evidence from animal research to support the view that the flux observed in hippocampus renders it incapable of forming and sustaining long-lasting representations within networks of its neurons.

The evidence from humans is no more supportive of Barry and Maguire's (2019a; 2019b) model than that from rodents. As Alba and Hasher (1983 noted in their review, evidence is lacking for a radical reconstructive view of memory that relies on schemas. As we noted earlier, although 
many memories are forgotten, accuracy, and even precision, can be maintained if participants are free to report only those memories about which they are certain, rather than being forced to report or recognize memories about which they are uncertain (Diamond et al., 2020; Evans \& Fisher, 2011; Goldsmith et al., 2005). Note that even the distorted, schema-driven memories of Bartlett's famous War of the Ghosts story retained details specific to its origins.

We agree with Barry and Maguire that retrieval is an iterative process in which the mPFC may be necessary for implementing the appropriate search strategy by directing hippocampal processes (McCormick et al., 2018a, 2020), monitoring its output, and initiating the process anew if the output is found wanting (Moscovitch, 1989, 1992; Moscovitch \& Winocur, 1992). The retention of accurate event-specific information, particularly if it schema-inconsistent, depends on the hippocampus (Bonasia et al., 2018; Gilboa \& Marlatte, 2017; van Kesteren et al., 2012).

Let us relate an anecdote that indicates how resilient context-specific memories are, and how unlikely they are merely to be reconstructed. A few years ago, one of us (M.M.) took his ten-year old grandson to a Raptors' basketball game. During a security check, M.M. was told he could not bring his yellow Swiss-army pen-knife into the arena. Instead of having them confiscate it, M.M. hid it inside the bumper of a car that was displayed in the lobby. At the end of the game, after we left the arena, M.M. went to retrieve his knife, but it was gone.

This event had nothing to do with the schema of going to a basketball game, the penknife did not have the prototypical red colour of Swiss army knives, and the bumper of a car is not a typical hiding place for a knife. With these thoughts in mind, M.M. asked his now 14-year old grandson, if he remembered what happened when he took him to the Raptors' game. $\mathrm{He}$ remembered, without prompting, that M.M. was stopped at security because he had a pen-knife. 
When M.M. asked him the colour, he said, "Yellow?" M.M. asked if he remembered what M.M. did with it, and he immediately replied that M.M. hid it under a car's bumper in the lobby. M.M. asked him if he had thought of this event since then, and he replied he had not.

\section{Conclusion}

We have reviewed a number of theories of systems consolidation, and found each able to account for some, but not all, of the evidence on systems consolidation. Given the magnitude and complexity of the evidence we reviewed, that is to be expected. Having an all-encompassing theory of systems consolidation is almost tantamount to having a unified theory of memory. We are not there yet. What remains to be done is to test the predictions of each theory that survived scrutiny and determine which open up avenues of discovery and which lead to dead ends. In the meantime, the principles enunciated at the beginning of the paper ( $\mathrm{pp} 18-20)$ can serve as a foundation for a new theory of systems consolidation

\section{References}

Addis, D. R. (2018). Are episodic memories special? On the sameness of remembered and imagined event simulation. Journal of the Royal Society of New Zealand, 48(2-3), 64-88. https://doi.org/10.1080/03036758.2018.1439071

Addis, D. R. (2020). Mental Time Travel? A Neurocognitive Model of Event Simulation. Review of Philosophy and Psychology, 11(2), 233-259. https://doi.org/10.1007/s13164-02000470-0 
Addis, D. R., Moscovitch, M., Crawley, A. P., \& McAndrews, M. P. (2004). Recollective qualities modulate hippocampal activation during autobiographical memory retrieval. Hippocampus, 14(6), 752-762. https://doi.org/10.1002/hipo.10215

Addis, D. R., Moscovitch, M., \& McAndrews, M. P. (2007a). Consequences of hippocampal damage across the autobiographical memory network in left temporal lobe epilepsy. Brain, 130(Pt 9), 2327-2342. https://doi.org/10.1093/brain/awm166

Addis, D. R., Wong, A. T., \& Schacter, D. L. (2007b). Remembering the past and imagining the future: Common and distinct neural substrates during event construction and elaboration. Neuropsychologia, 45(7), 1363-1377. https://doi.org/10.1016/j.neuropsychologia.2006.10.016

Addis, D. R., \& Schacter, D. L. (2012). The Hippocampus and Imagining the Future: Where Do We Stand? Frontiers in Human Neuroscience, 5. https://doi.org/10.3389/fnhum.2011.00173

Aizpurua, A., \& Koutstaal, W. (2015). A matter of focus: Detailed memory in the intentional autobiographical recall of older and younger adults. Consciousness and Cognition, 33, 145-155. https://doi.org/10.1016/j.concog.2014.12.006

Alba, J., \& Hasher, L. (1983). Is memory schematic? Psychological Bulletin, 93, 203-231. Aly, M., \& Moscovitch, M. (2010). The effects of sleep on episodic memory in older and younger adults. Memory, 18(3), 327-334. https://doi.org/10.1080/09658211003601548

Andrews-Hanna, J. R., Reidler, J. S., Sepulcre, J., Poulin, R., \& Buckner, R. L. (2010). Functional-anatomic fractionation of the brain's default network. Neuron, 65(4), 550562. https://doi.org/10.1016/j.neuron.2010.02.005 
Argyropoulos, G. P., \& Butler, C. R. (2020). Does hippocampal atrophy explain anterograde and retrograde amnesia following autoimmune limbic encephalitis? Hippocampus, 30(9), 1013-1017. https://doi.org/10.1002/hipo.23208

Argyropoulos, G. P., Loane, C., Roca-Fernandez, A., Lage-Martinez, C., Gurau, O., Irani, S. R., \& Butler, C. R. (2019). Network-wide abnormalities explain memory variability in hippocampal amnesia. ELife, 8, e46156. https://doi.org/10.7554/eLife.46156

Atir-Sharon, T., Gilboa, A., Hazan, H., Koilis, E., \& Manevitz, L. M. (2015). Decoding the Formation of New Semantics: MVPA Investigation of Rapid Neocortical Plasticity during Associative Encoding through Fast Mapping. Neural Plasticity, 2015, 804385. https://doi.org/10.1155/2015/804385

Attardo, A., Fitzgerald, J. E., \& Schnitzer, M. J. (2015). Impermanence of dendritic spines in live adult CA1 hippocampus. Nature, 523(7562), 592-596. https://doi.org/10.1038/nature14467

Attardo, A., Lu, J., Kawashima, T., Okuno, H., Fitzgerald, J. E., Bito, H., \& Schnitzer, M. J. (2018). Long-Term Consolidation of Ensemble Neural Plasticity Patterns in Hippocampal Area CA1. Cell Reports, 25(3), 640-650.e2. https://doi.org/10.1016/j.celrep.2018.09.064

Atucha, E., Ku, S. P., Lippert, M., \& Sauvage, M. (2021). Remembering the gist of an event over a lifetime depends on the hippocampus. bioRxiv.

Audrain, S., \& McAndrews, M. P. (2020). Schemas provide a scaffold for neocortical integration at the cost of memory specificity over time. bioRxiv.

Bakker, A., Kirwan, C. B., Miller, M., \& Stark, C. E. (2008). Pattern separation in the human hippocampal CA3 and dentate gyrus. Science, 319(5870), 1640-1642. https://doi.org/10.1126/science.1152882 
Barry, D. N., Clark, I. A., \& Maguire, E. A. (2020). The relationship between hippocampal subfield volumes and autobiographical memory persistence. Hippocampus, hipo.23293. https://doi.org/10.1002/hipo.23293

Barry, D. N., \& Maguire, E. A. (2019a). Remote Memory and the Hippocampus: A Constructive Critique. Trends in Cognitive Sciences, 23(2), 128-142. https://doi.org/10.1016/j.tics.2018.11.005

Barry, D. N., \& Maguire, E. A. (2019b). Consolidating the Case for Transient Hippocampal Memory Traces. Trends in Cognitive Sciences, 23(8), 635-636. https://doi.org/10.1016/j.tics.2019.05.008

Bartlett, F. C. (1932). Remembering: A Study in Experimental and Social Psychology. Cambridge University Press.

Bartsch, T., Dohring, J., Rohr, A., Jansen, O., \& Deuschl, G. (2011). CA1 neurons in the human hippocampus are critical for autobiographical memory, mental time travel, and autonoetic consciousness. Proceedings of the National Academy of Sciences, 108(42), 17562-17567. https://doi.org/10.1073/pnas.1110266108

Bartsch, T., \& Butler, C. (2013). Transient amnesic syndromes. Nature Reviews Neurology, 9(2), 86-97. https://doi.org/10.1038/nrneurol.2012.264

Bellana, B., Liu, Z. X., Diamond, N. B., Grady, C. L., \& Moscovitch, M. (2017). Similarities and differences in the default mode network across rest, retrieval, and future imagining. Hum Brain Mapp, 38(3), 1155-1171. https://doi.org/10.1002/hbm.23445

Berkers, R. M. W. J., Ekman, M., van Dongen, E. V., Takashima, A., Barth, M., Paller, K. A., \& Fernández, G. (2018). Cued reactivation during slow-wave sleep induces brain 
connectivity changes related to memory stabilization. Scientific Reports, 8(1), 16958. https://doi.org/10.1038/s41598-018-35287-6

Berkers, R. M. W. J., van der Linden, M., de Almeida, R. F., Müller, N. C. J., Bovy, L., Dresler, M., Morris, R. G. M., \& Fernández, G. (2017). Transient medial prefrontal perturbation reduces false memory formation. Cortex, $88,42-52$. https://doi.org/10.1016/j.cortex.2016.12.015

Bertossi, E., Tesini, C., Cappelli, A., \& Ciaramelli, E. (2016). Ventromedial prefrontal damage causes a pervasive impairment of episodic memory and future thinking. Neuropsychologia, 90, 12-24. https://doi.org/10.1016/j.neuropsychologia.2016.01.034

Binder, J. R., \& Desai, R. H. (2011). The neurobiology of semantic memory. Trends in Cognitive Sciences, 15(11), 527-536. https://doi.org/10.1016/j.tics.2011.10.001

Binder, J. R., Desai, R. H., Graves, W. W., \& Conant, L. L. (2009). Where Is the Semantic System? A Critical Review and Meta-Analysis of 120 Functional Neuroimaging Studies. Cerebral Cortex, 19(12), 2767-2796. https://doi.org/10.1093/cercor/bhp055

Bird, C. M., Keidel, J. L., Ing, L. P., Horner, A. J., \& Burgess, N. (2015). Consolidation of Complex Events via Reinstatement in Posterior Cingulate Cortex. Journal of Neuroscience, 35(43), 14426-14434. https://doi.org/10.1523/JNEUROSCI.1774-15.2015

Blumenthal, A., Duke, D., Bowles, B., Gilboa, A., Rosenbaum, R. S., Köhler, S., \& McRae, K. (2017). Abnormal semantic knowledge in a case of developmental amnesia. Neuropsychologia, 102, 237-247. https://doi.org/10.1016/j.neuropsychologia.2017.06.018

Boccia, M., Teghil, A., \& Guariglia, C. (2019). Looking into recent and remote past: Metaanalytic evidence for cortical re-organization of episodic autobiographical memories. 
Neuroscience \& Biobehavioral Reviews, 107, 84-95.

https://doi.org/10.1016/j.neubiorev.2019.09.003

Bonasia, K., Sekeres, M. J., Gilboa, A., Grady, C. L., Winocur, G., \& Moscovitch, M. (2018).

Prior knowledge modulates the neural substrates of encoding and retrieving naturalistic events at short and long delays. Neurobiology of Learning and Memory, 153, 26-39. https://doi.org/10.1016/j.nlm.2018.02.017

Bonnici, H. M., Chadwick, M. J., Lutti, A., Hassabis, D., Weiskopf, N., \& Maguire, E. A. (2012). Detecting Representations of Recent and Remote Autobiographical Memories in vmPFC and Hippocampus. Journal of Neuroscience, 32(47), 16982-16991. https://doi.org/10.1523/JNEUROSCI.2475-12.2012

Bonnici, H. M., Chadwick, M. J., \& Maguire, E. A. (2013). Representations of recent and remote autobiographical memories in hippocampal subfields. Hippocampus, 23(10), 849-854. https://doi.org/10.1002/hipo.22155

Bonnici, H. M., \& Maguire, E. A. (2017). Two years later - Revisiting autobiographical memory representations in vmPFC and hippocampus. Neuropsychologia. https://doi.org/10.1016/j.neuropsychologia.2017.05.014

Bonnici, H. M., Richter, F. R., Yazar, Y., \& Simons, J. S. (2016). Multimodal Feature Integration in the Angular Gyrus during Episodic and Semantic Retrieval. Journal of Neuroscience, 36(20), 5462-5471. https://doi.org/10.1523/JNEUROSCI.4310-15.2016

Bridge, D. J., \& Paller, K. A. (2012). Neural correlates of reactivationand retrieval-induced distortion. The Journal of Neuroscience, 32, 12144 -12151. https://doi.org/10.1523/JNEUROSCI.1378-12.20

Brodt, S., \& Gais, S. (2020). Memory Engrams in the Neocortex. The Neuroscientist, 107385842094152. https://doi.org/10.1177/1073858420941528 
Brodt, S., Gais, S., Beck, J., Erb, M., Scheffler, K., \& Schönauer, M. (2018). Fast track to the neocortex: A memory engram in the posterior parietal cortex. Science, 362(6418), 10451048. https://doi.org/10.1126/science.aau2528

Brodt, S., Pöhlchen, D., Flanagin, V. L., Glasauer, S., Gais, S., \& Schönauer, M. (2016). Rapid and independent memory formation in the parietal cortex. Proceedings of the National Academy of Sciences, 113(46), 13251-13256. https://doi.org/10.1073/pnas.1605719113

Brunec, I. K., Bellana, B., Ozubko, J. D., Man, V., Robin, J., Liu, Z.-X., ... \& Moscovitch, M. (2018). Multiple Scales of Representation along the Hippocampal Anteroposterior Axis in Humans. Current Biology, 28(13), 2129-2135.e6.

https://doi.org/10.1016/j.cub.2018.05.016

Brunec, I. K., Robin, J., Olsen, R. K., Moscovitch, M., \& Barense, M. D. (2020). Integration and differentiation of hippocampal memory traces. Neuroscience \& Biobehavioral Reviews, 118, 196-208. https://doi.org/10.1016/j.neubiorev.2020.07.024

Burnham, W. H. (1904). Retroactive amnesia: Illustrative cases and a tentative explanation. American Journal of Psychology, 14, 382-396.

Burgess, P. W., \& Shallice, T. (1996). Confabulation and the control of recollection. Memory (Hove, England), 4(4), 359-411.

Butler, C. R., \& Zeman, A. Z. (2008). Recent insights into the impairment of memory in epilepsy: Transient epileptic amnesia, accelerated long-term forgetting and remote memory impairment. Brain, 131(Pt 9), 2243-2263. https://doi.org/10.1093/brain/awn127

Buzsáki, G. (2015). Hippocampal sharp wave-ripple: A cognitive biomarker for episodic memory and planning. Hippocampus, 25(10), 1073-1188. https://doi.org/10.1002/hipo.22488 
György Buzsáki, M. D. (2019). The brain from inside out. Oxford University Press.

Cabeza, R., Ciaramelli, E., \& Moscovitch, M. (2012). Cognitive contributions of the ventral parietal cortex: An integrative theoretical account. Trends in Cognitive Sciences, 16(6), 338-352. https://doi.org/10.1016/j.tics.2012.04.008

Cabeza, R., Ciaramelli, E., Olson, I. R., \& Moscovitch, M. (2008). The parietal cortex and episodic memory: An attentional account. Nature Reviews Neuroscience, 9(8), 613-625. https://doi.org/10.1038/nrn2459

Cabeza, R., \& Moscovitch, M. (2013). Memory Systems, Processing Modes, and Components: Functional Neuroimaging Evidence. Perspectives on Psychological Science, 8(1), 49-55. https://doi.org/10.1177/1745691612469033

Cabeza, R., \& St Jacques, P. (2007). Functional neuroimaging of autobiographical memory. Trends in Cognitive Sciences, 11(5), 219-227. https://doi.org/10.1016/j.tics.2007.02.005

Carey, S., \& Bartlett, E. (1978). Acquiring a single new word. Papers and Reports in Child Language Development, 15, 17-29.

Chadwick, M. J., Bonnici, H. M., \& Maguire, E. A. (2014). CA3 size predicts the precision of memory recall. Proceedings of the National Academy of Sciences, 111(29), 10720_ 10725. https://doi.org/10.1073/pnas.1319641111

Chadwick, M. J., Hassabis, D., Weiskopf, N., \& Maguire, E. A. (2010). Decoding individual episodic memory traces in the human hippocampus. Current Biology, 20(6), 544-547. https://doi.org/10.1016/j.cub.2010.01.053

Chadwick, M. J., Anjum, R. S., Kumaran, D., Schacter, D. L., Spiers, H. J., \& Hassabis, D. (2016). Semantic representations in the temporal pole predict false memories. Proceedings of the National Academy of Sciences, 113(36), 10180-10185. https://doi.org/10.1073/pnas.1610686113 
Ciaramelli, E., Grady, C. L., \& Moscovitch, M. (2008). Top-down and bottom-up attention to memory: A hypothesis (AtoM) on the role of the posterior parietal cortex in memory retrieval. Neuropsychologia, 46(7), 1828-1851. https://doi.org/10.1016/j.neuropsychologia.2008.03.022

Clark, R. E., Broadbent, N. J., \& Squire, L. R. (2005). Hippocampus and remote spatial memory in rats. Hippocampus, 15(2), 260-272. https://doi.org/10.1002/hipo.20056

Clark, T. A., Fu, M., Dunn, A. K., Zuo, Y., \& Jones, T. A. (2018). Preferential stabilization of newly formed dendritic spines in motor cortex during manual skill learning predicts performance gains, but not memory endurance. Neurobiology of Learning and Memory, 152, 50-60. https://doi.org/10.1016/j.nlm.2018.05.005

Coutanche, M. N., \& Thompson-Schill, S. L. (2015). Rapid consolidation of new knowledge in adulthood via fast mapping. Trends in Cognitive Sciences, 19(9), 486-488. https://doi.org/10.1016/j.tics.2015.06.001

Cowan, E., Liu, A., Henin, S., Kothare, S., Devinsky, O., \& Davachi, L. (2020). Sleep Spindles Promote the Restructuring of Memory Representations in Ventromedial Prefrontal Cortex through Enhanced Hippocampal-Cortical Functional Connectivity. The Journal of Neuroscience, 40(9), 1909-1919. https://doi.org/10.1523/JNEUROSCI.1946-19.2020

Craik, F. I. M. (2020). Remembering: An Activity of Mind and Brain. Annual Review of Psychology, 71, 1-24. https://doi.org/10.1146/annurev-psych-010419-051027

Crovitz, H. F., \& Schiffman, H. (1974). Frequency of episodic memories as a function of their age. Bulletin of the Psychonomic Society, 4(5), 517-518. https://doi.org/10.3758/BF03334277 
Cullen, P. K., Gilman, T. L., Winiecki, P., Riccio, D. C., \& Jasnow, A. M. (2015). Activity of the anterior cingulate cortex and ventral hippocampus underlie increases in contextual fear generalization. Neurobiology of Learning and Memory, 124, 19-27. https://doi.org/10.1016/j.nlm.2015.07.001

Dalla Barba, G., \& La Corte, V. (2013). The hippocampus, a time machine that makes errors. Trends in Cognitive Sciences, 17(3), 102-104.

Dandolo, L. C., \& Schwabe, L. (2018). Time-dependent memory transformation along the hippocampal anterior-posterior axis. Nature Communications, 9(1), 1205. https://doi.org/10.1038/s41467-018-03661-7

De Sousa, A. F., Cowansage, K. K., Zutshi, I., Cardozo, L. M., Yoo, E. J., Leutgeb, S., \& Mayford, M. (2019). Optogenetic reactivation of memory ensembles in the retrosplenial cortex induces systems consolidation. Proceedings of the National Academy of Sciences, 116(17), 8576-8581. https://doi.org/10.1073/pnas.1818432116

de Voogd, L. D., Fernández, G., \& Hermans, E. J. (2016). Awake reactivation of emotional memory traces through hippocampal-neocortical interactions. NeuroImage, 134, 563572. https://doi.org/10.1016/j.neuroimage.2016.04.026

Dede, A. J. O., Wixted, J. T., Hopkins, R. O., \& Squire, L. R. (2016). Autobiographical memory, future imagining, and the medial temporal lobe. Proceedings of the National Academy of Sciences, 113(47), 13474-13479. https://doi.org/10.1073/pnas.1615864113

Deese, J. (1959). On the prediction of occurrence of particular verbal intrusions in immediate recall. Journal of Experimental Psychology, 58(1), 17-22. https://doi.org/10.1037/h0046671 
Diamond, N. B., Armson, M. J., \& Levine, B. (2020). The Truth Is Out There: Accuracy in Recall of Verifiable Real-World Events. Psychological Science, 31(12), 1544-1556. https://doi.org/10.1177/0956797620954812

Diana, R.A., Yonelinas, A.P., \& Ranganath, C. (2007) Imaging recollection and familiarity in the medial temporal lobe: a three-component model. Trends in Cognitivce Science, 11, 379-386. doi:10.1016/j.tics.2007.08.001 pmid:17707683

Diekelmann, S., \& Born, J. (2010). The memory function of sleep. Nat Rev Neurosci, 11(2), 114-126. https://doi.org/10.1038/nrn2762

Dimsdale-Zucker, H. R., Ritchey, M., Ekstrom, A. D., Yonelinas, A. P., \& Ranganath, C. (2018). CA1 and CA3 differentially support spontaneous retrieval of episodic contexts within human hippocampal subfields. Nature Communications, 9(1), 294. https://doi.org/10.1038/s41467-017-02752-1

Dolcos, F., LaBar, K. S., \& Cabeza, R. (2004). Dissociable effects of arousal and valence on prefrontal activity indexing emotional evaluation and subsequent memory: An eventrelated fMRI study. NeuroImage, 23(1), 64-74. https://doi.org/10.1016/j.neuroimage.2004.05.015

Dudai, Y. (2012). The restless engram: Consolidations never end. Annual Review of Neuroscience, 35, 227-247. https://doi.org/10.1146/annurev-neuro-062111-150500

Dudai, Y., Karni, A., \& Born, J. (2015). The Consolidation and Transformation of Memory. Neuron, 88(1), 20-32. https://doi.org/10.1016/j.neuron.2015.09.004

Eichenbaum, H. (2017). Prefrontal-hippocampal interactions in episodic memory. Nature Reviews Neuroscience. https://doi.org/10.1038/nrn.2017.74 
Eichenbaum, H., Yonelinas, A. P., \& Ranganath, C. (2007). The medial temporal lobe and recognition memory. Annual Review of Neuroscience, 30, 123-152. https://doi.org/10.1146/annurev.neuro.30.051606.094328

Einarsson, E. O., Pors, J., \& Nader, K. (2015). Systems reconsolidation reveals a selective role for the anterior cingulate cortex in generalized contextual fear memory expression. Neuropsychopharmacology, 40(2), 480-487. https://doi.org/10.1038/npp.2014.197

Epstein, R. A. (2008). Parahippocampal and retrosplenial contributions to human spatial navigation. Trends in Cognitive Sciences, 12(10), 388-396. https://doi.org/10.1016/j.tics.2008.07.004

Epstein, R. A., \& Baker, C. I. (2019). Scene Perception in the Human Brain. Annual Review of Vision Science, 5(1), 373-397. https://doi.org/10.1146/annurev-vision-091718-014809

Evans, J. R., \& Fisher, R. P. (2011). Eyewitness memory: Balancing the accuracy, precision and quantity of information through metacognitive monitoring and control. Applied Cognitive Psychology, 25(3), 501-508. https://doi.org/10.1002/acp.1722

Evensmoen, H. R., Ladstein, J., Hansen, T. I., Moller, J. A., Witter, M. P., Nadel, L., \& Haberg, A. K. (2015). From details to large scale: The representation of environmental positions follows a granularity gradient along the human hippocampal and entorhinal anteriorposterior axis. Hippocampus, 25(1), 119-135. https://doi.org/10.1002/hipo.22357

Evensmoen, H. R., Lehn, H., Xu, J., Witter, M. P., Nadel, L., \& Haberg, A. K. (2013). The anterior hippocampus supports a coarse, global environmental representation and the posterior hippocampus supports fine-grained, local environmental representations. Journal of Cognitive Neuroscience, 25(11), 1908-1925. https://doi.org/10.1162/jocn_a_00436 
Farovik, A., Place, R. J., McKenzie, S., Porter, B., Munro, C. E., \& Eichenbaum, H. (2015). Orbitofrontal cortex encodes memories within value-based schemas and represents contexts that guide memory retrieval. Journal of Neuroscience, 35(21), 8333-8344. https://doi.org/10.1523/JNEUROSCI.0134-15.2015

Ferguson, M. A., Lim, C., Cooke, D., Darby, R. R., Wu, O., Rost, N. S., .. \& Fox, M. D. (2019). A human memory circuit derived from brain lesions causing amnesia. Nature Communications, 10(1), 3497. https://doi.org/10.1038/s41467-019-11353-z

Fernández, G., Brewer, J. B., Zhao, Z., Glover, G. H., \& Gabrieli, J. D. (1999). Level of sustained entorhinal activity at study correlates with subsequent cued-recall performance: A functional magnetic resonance imaging study with high acquisition rate. Hippocampus, 9(1), 35-44. https://doi.org/10.1002/(SICI)1098-1063(1999)9:1<35::AIDHIPO4>3.0.CO;2-Z

Finnie, P. S. B., Gamache, K., Protopoulos, M., Sinclair, E., Baker, A. G., Wang, S. H., \& Nader, K. (2018). Cortico-hippocampal Schemas Enable NMDAR-Independent Fear Conditioning in Rats. Current Biology, 28(18), 2900-2909.e5. https://doi.org/10.1016/j.cub.2018.07.037

Fletcher, P. (1998a). The functional roles of prefrontal cortex in episodic memory. I. Encoding. Brain, 121(7), 1239-1248. https://doi.org/10.1093/brain/121.7.1239

Fletcher, P. (1998b). The functional roles of prefrontal cortex in episodic memory. II. Retrieval. Brain, 121(7), 1249-1256. https://doi.org/10.1093/brain/121.7.1249

Fletcher, P. C., Shallice, T., Frith, C. D., Frackowiak, R. S. J., \& Dolan, R. J. (1996). Brain activity during memory retrieval: The influence of imagery and semantic cueing. Brain, 119(5), 1587-1596. https://doi.org/10.1093/brain/119.5.1587 
Folkerts, S., Rutishauser, U., \& Howard, M. W. (2018). Human Episodic Memory Retrieval Is Accompanied by a Neural Contiguity Effect. The Journal of Neuroscience, 38(17), 42004211. https://doi.org/10.1523/JNEUROSCI.2312-17.2018

Foster, B. L., Kaveh, A., Dastjerdi, M., Miller, K. J., \& Parvizi, J. (2013). Human Retrosplenial Cortex Displays Transient Theta Phase Locking with Medial Temporal Cortex Prior to Activation during Autobiographical Memory Retrieval. Journal of Neuroscience, 33(25), 10439-10446. https://doi.org/10.1523/JNEUROSCI.0513-13.2013

Frankland, P. W., \& Bontempi, B. (2005). The organization of recent and remote memories. Nature Reviews in Neuroscience, 6(2), 119-130. https://doi.org/10.1038/nrn1607

Frankland, P. W., Ding, H.-K., Takahashi, E., Suzuki, A., Kida, S., \& Silva, A. (2006). Stability of recent and remote contextual fear memory. Learning \& Memory, 13(4), 451-457. https://doi.org/10.1101/lm.183406

Frankland, P. W., Josselyn, S. A., \& Köhler, S. (2019). The neurobiological foundation of memory retrieval. Nature Neuroscience, 22(10), 1576-1585. https://doi.org/10.1038/s41593-019-0493-1

Fuentemilla, L., Barnes, G. R., Duzel, E., \& Levine, B. (2014). Theta oscillations orchestrate medial temporal lobe and neocortex in remembering autobiographical memories. Neuroimage, 85 Pt 2, 730-737. https://doi.org/10.1016/j.neuroimage.2013.08.029

Fuentemilla, L., Palombo, D. J., \& Levine, B. (2018). Gamma phase-synchrony in autobiographical memory: Evidence from magnetoencephalography and severely deficient autobiographical memory. Neuropsychologia, 110, 7-13. https://doi.org/10.1016/j.neuropsychologia.2017.08.020 
Fujii, T., Moscovitch, M., \& Nadel, L. (2000). Consolidation, retrograde amnesia, and the temporal lobe. In F. Boller \& J. Grafman (Eds.). The Handbook of Neuropsychology, (2nd ed., Vol. 2) (2nd ed., Vol. 2). Elsevier.

Furman, O., Mendelsohn, A., \& Dudai, Y. (2012). The episodic engram transformed: Time reduces retrieval-related brain activity but correlates it with memory accuracy. Learning and Memory, 19(12), 575-587. https://doi.org/10.1101/lm.025965.112

Gais, S., Albouy, G., Boly, M., Dang-Vu, T. T., Darsaud, A., Desseilles, M., ... \& Peigneux, P. (2007). Sleep transforms the cerebral trace of declarative memories. Proceedings of the National Academy of Sciences, 104(47), 18778-18783. https://doi.org/10.1073/pnas.0705454104

Gallistel, C. R. (2020). The physical basis of memory. Cognition, 104533. https://doi.org/10.1016/j.cognition.2020.104533

Gallistel, C. R., \& Matzel, L. D. (2013). The neuroscience of learning: Beyond the Hebbian synapse. Annual Review of Psychology, 64, 169-200. https://doi.org/10.1146/annurevpsych-113011-143807

Ghosh, V. E., \& Gilboa, A. (2014). What is a memory schema? A historical perspective on current neuroscience literature. Neuropsychologia, 53, 104-114. https://doi.org/10.1016/j.neuropsychologia.2013.11.010

Ghosh, V. E., Moscovitch, M., Melo C. B., \& Gilboa, A. (2014). Schema representation in patients with ventromedial PFC lesions. Journal of Neuroscience, 34(36), 12057-12070. https://doi.org/10.1523/JNEUROSCI.0740-14.2014 
Gilboa, A. (2004). Autobiographical and episodic memory-One and the same? Evidence from prefrontal activation in neuroimaging studies. Neuropsychologia, 42(10), 1336-1349. https://doi.org/10.1016/j.neuropsychologia.2004.02.014

Gilboa, A., Alain, C., Stuss, D. T., Melo, B., Miller, S., \& Moscovitch, M. (2006a). Mechanisms of spontaneous confabulations: A strategic retrieval account. Brain, 129(Pt 6), 1399_ 1414. https://doi.org/10.1093/brain/aw1093

Gilboa, A., Ramirez, J., Köhler, S., Westmacott, R., Black, S. E., \& Moscovitch, M. (2005). Retrieval of autobiographical memory in Alzheimer's disease: relation to volumes of medial temporal lobe and other structures. Hippocampus, 15(4), 535-550.

Gilboa, A., \& Marlatte, H. (2017). Neurobiology of Schemas and Schema-Mediated Memory. Trends in Cognitive Sciences, 21(8), 618-631. https://doi.org/10.1016/j.tics.2017.04.013

Gilboa, A., \& Moscovitch, M. (2017). Ventromedial prefrontal cortex generates pre-stimulus theta coherence desynchronization: A schema instantiation hypothesis. Cortex, 87, 1630. https://doi.org/10.1016/j.cortex.2016.10.008

Gilboa, A., \& Moscovitch, M. (2021). No consolidation without representation: Correspondence between neural and psychological representations in recent and remote memory. Neuron.

Gilboa, A., Winocur, G., Grady, C. L., Hevenor, S. J., \& Moscovitch, M. (2004). Remembering our past: Functional neuroanatomy of recollection of recent and very remote personal events. Cerebal Cortex, 14(11), 1214-1225. https://doi.org/10.1093/cercor/bhh082

Gilboa, A., Winocur, G., Rosenbaum, R. S., Poreh, A., Gao, F., Black, S. E., ... \& Moscovitch, M. (2006b). Hippocampal contributions to recollection in retrograde and anterograde amnesia. Hippocampus, 16(11), 966-980. https://doi.org/10.1002/hipo.20226

Gilmore, A. W., Quach, A., Kalinowski, S.E., González-Araya, E.I., Gotts, S.J., Schacter, D.L., \& Martin, A. (2021). Evidence supporting a time-limited hippocampal role in retrieving 
autobiographical memories. Proceedings of the Natioanl Academy of Sciences, USA, 118, (1-12) https://www.pnas.org/content/118/12/e2023069118

Giuliano, A.E., Bonasia, K., Ghosh, V.E., Moscovitch, M., \& Gilboa, A. (2021).Differential Influence of Ventromedial Prefrontal Cortex Lesions on Neural Representations of Schema and Semantic Category Knowledge. Journal of Cognitive Neuroscience.

Gleissner, U., \& Elger, C. E. (2001). The hippocampal contribution to verbal fluency in patients with temporal lobe epilepsy. Cortex, 37(1), 55-63.

Godbout, L., Cloutier, P., Bouchard, C., Braun, C. M. J., \& Gagnon, S. (2004). Script Generation Following Frontal and Parietal Lesions. Journal of Clinical and Experimental Neuropsychology, 26(7), 857-873. https://doi.org/10.1080/13803390490510671

Godbout, L., \& Doyon, J. (1995). Mental representation of knowledge following frontal-lobe or postrolandic lesions. Neuropsychologia, 33(12), 1671-1696. https://doi.org/10.1016/0028-3932(95)00047-X

Goldsmith, M., Koriat, A., \& Pansky, A. (2005). Strategic regulation of grain size in memory reporting over time. Journal of Memory and Language, 52(4), 505-525. https://doi.org/10.1016/j.jml.2005.01.010

Goode, T. D., Tanaka, K. Z., Sahay, A., \& McHugh, T. J. (2020). An Integrated Index: Engrams, Place Cells, and Hippocampal Memory. Neuron, 107(5), 805-820. https://doi.org/10.1016/j.neuron.2020.07.011

Goshen, I., Brodsky, M., Prakash, R., Wallace, J., Gradinaru, V., Ramakrishnan, C., \& Deisseroth, K. (2011). Dynamics of retrieval strategies for remote memories. Cell, 147(3), 678-689. https://doi.org/10.1016/j.cell.2011.09.033 
Grafman, J. (1989). Plans, actions, and mental sets: Managerial knowledge units in the frontal lobes. In E. Perecman (Ed.), Integrating theory and practice in clinical neuropsychology (pp. 93-138). Lawrence Erlbaum Associates, Inc.

Grafman, J., Sirigu, A., Spector, L., \& Hendler, J. (1993). Damage to the prefrontal cortex leads to decomposition of structured event complexes: Journal of Head Trauma Rehabilitation, 8(1), 73-87. https://doi.org/10.1097/00001199-199303000-00008

Graham, K. S., \& Hodges, J. R. (1997). Differentiating the roles of the hippocampus complex and the neocortex in long-term memory storage: Evidence from the study of semantic dementia and Alzheimer's disease. Neuropsychology, 11(1), 77-89. https://doi.org/10.1037/0894-4105.11.1.77

Graham, K. S., Patterson, K., \& Hodges, J. R. (1999). Episodic memory: new insights from the study of semantic dementia. Current Opinion in Neurobiology, 9(2), 245-250.

Greenberg, D., Eacott, M., Brechin, D., \& Rubin, D. (2005). Visual memory loss and autobiographical amnesia: A case study. Neuropsychologia, 43(10), 1493-1502. https://doi.org/10.1016/j.neuropsychologia.2004.12.009

Greenberg, D. L., Keane, M. M., Ryan, L., \& Verfaellie, M. (2009). Impaired category fluency in medial temporal lobe amnesia: The role of episodic memory. Journal of Neuroscience, 29(35), 10900-10908. https://doi.org/10.1523/JNEUROSCI.1202-09.2009

Greenberg, D. L., \& Knowlton, B. J. (2014). The role of visual imagery in autobiographical memory. Memory \& Cognition, 42(6), 922-934. https://doi.org/10.3758/s13421-014$0402-5$ 
Greenberg, D. L., \& Verfaellie, M. (2010). Interdependence of episodic and semantic memory: Evidence from neuropsychology. Journal of the International Neuropsychological Society, 16(5), 748-753. https://doi.org/10.1017/S1355617710000676

Greve, A., Cooper, E., Tibon, R., \& Henson, R. N. (2019). Knowledge is power: Prior knowledge aids memory for both congruent and incongruent events, but in different ways. Journal of Experimental Psychology: General, 148(2), 325-341. https://doi.org/10.1037/xge0000498

Gruber, M. J., Ritchey, M., Wang, S.-F., Doss, M. K., \& Ranganath, C. (2016). Post-learning Hippocampal Dynamics Promote Preferential Retention of Rewarding Events. Neuron, 89(5), 1110-1120. https://doi.org/10.1016/j.neuron.2016.01.017

Guo, N., Soden, M. E., Herber, C., Kim, M. T., Besnard, A., Lin, P., .. \& Sahay, A. (2018). Dentate granule cell recruitment of feedforward inhibition governs engram maintenance and remote memory generalization. Nature Medicine, 24(4), 438-449. https://doi.org/10.1038/nm.4491

Guskjolen, A., Kenney, J. W., de la Parra, J., Yeung, B. A., Josselyn, S. A., \& Frankland, P. W. (2018). Recovery of "Lost” Infant Memories in Mice. Current Biology, 28(14), 22832290.e3. https://doi.org/10.1016/j.cub.2018.05.059

Gutchess, A. H., \& Schacter, D. L. (2012). The neural correlates of gist-based true and false recognition. NeuroImage, 59(4), 3418-3426. https://doi.org/10.1016/j.neuroimage.2011.11.078

Hardt, O., Wang, S. H., \& Nader, K. (2009). Storage or retrieval deficit: The yin and yang of amnesia. Learning and Memory, 16(4), 224-230. https://doi.org/10.1101/lm.1267409 
Hardt, O., \& Nadel, L. (2018). Systems consolidation revisited, but not revised: The promise and limits of optogenetics in the study of memory. Neuroscience Letters, 680, 54-59. https://doi.org/10.1016/j.neulet.2017.11.062

Hardt, O., Nader, K., \& Nadel, L. (2013). Decay happens: The role of active forgetting in memory. Trends in Cognitive Sciences, 17(3), 111-120. https://doi.org/10.1016/j.tics.2013.01.001

Hasan, M., Kanna, M. S., Jun, W., Ramkrishnan, A. S., Iqbal, Z., Lee, Y., \& Li, Y. (2019). Schema-like learning and memory consolidation acting through myelination. The Federation of American Societies for Experimental Biology Journal, 33(11), 1175811775. https://doi.org/10.1096/fj.201900910R

Hassabis, D., Kumaran, D., Vann, S. D., \& Maguire, E. A. (2007). Patients with hippocampal amnesia cannot imagine new experiences. Proceedings of the National Academy of Sciences of the United States of America, 104(5), 1726-1731. https://doi.org/10.1073/pnas.0610561104

Hebb, D. O. (1949). The Organization of Behavior: A Neuropsychological Theory. John Wiley \& Sons.

Hebscher, M., Barkan-Abramski, M., Goldsmith, M., Aharon-Peretz, J., \& Gilboa, A. (2016). Memory, Decision-Making, and the Ventromedial Prefrontal Cortex (vmPFC): The Roles of Subcallosal and Posterior Orbitofrontal Cortices in Monitoring and Control Processes. Cerebral Cortex, 26(12), 4590-4601. https://doi.org/10.1093/cercor/bhv220

Hebscher, M., \& Gilboa, A. (2016). A boost of confidence: The role of the ventromedial prefrontal cortex in memory, decision-making, and schemas. Neuropsychologia, 90, 4658. https://doi.org/10.1016/j.neuropsychologia.2016.05.003 
Hebscher, M., Ibrahim, C., \& Gilboa, A. (2020). Precuneus stimulation alters the neural dynamics of autobiographical memory retrieval. NeuroImage, 210, 116575. https://doi.org/10.1016/j.neuroimage.2020.116575

Hebscher, M., Levine, B., \& Gilboa, A. (2018). The precuneus and hippocampus contribute to individual differences in the unfolding of spatial representations during episodic autobiographical memory. Neuropsychologia, 110, 123-133. https://doi.org/10.1016/j.neuropsychologia.2017.03.029

Hebscher, M., Meltzer, J. A., \& Gilboa, A. (2019a). A causal role for the precuneus in networkwide theta and gamma oscillatory activity during complex memory retrieval. ELife, 8 , e43114. https://doi.org/10.7554/eLife.43114

Hebscher, M., Wing, E., Ryan, J., \& Gilboa, A. (2019b). Rapid Cortical Plasticity Supports Long-Term Memory Formation. Trends in Cognitive Sciences, 23(12), 989-1002. https://doi.org/10.1016/j.tics.2019.09.009

Herdman, K. A., Calarco, N., Moscovitch, M., Hirshhorn, M., \& Rosenbaum, R. S. (2015). Impoverished descriptions of familiar routes in three cases of hippocampal/medial temporal lobe amnesia. Cortex, 71, 248-263. https://doi.org/10.1016/j.cortex.2015.06.008

Hermans, E. J., Kanen, J. W., Tambini, A., Fernández, G., Davachi, L., \& Phelps, E. A. (2016). Persistence of Amygdala-Hippocampal Connectivity and Multi-Voxel Correlation Structures During Awake Rest After Fear Learning Predicts Long-Term Expression of Fear. Cerebral Cortex, bhw145. https://doi.org/10.1093/cercor/bhw145

Herold, C. J., Lässer, M. M., Schmid, L. A., Seidl, U., Kong, L., Fellhauer, I., ... \& Schröder, J. (2015). Neuropsychology, autobiographical memory, and hippocampal volume in 
"younger" and "older" patients with chronic schizophrenia. Frontiers in Psychiatry, 6. https://doi.org/10.3389/fpsyt.2015.00053

Himmer, L., Schönauer, M., Heib, D. P. J., Schabus, M., \& Gais, S. (2019). Rehearsal initiates systems memory consolidation, sleep makes it last. Science Advances, 5(4), eaav1695. https://doi.org/10.1126/sciadv.aav1695

Hirshhorn, M., Grady, C., Rosenbaum, R. S., Winocur, G., \& Moscovitch, M. (2012a). The hippocampus is involved in mental navigation for a recently learned, but not a highly familiar environment: A longitudinal fMRI study. Hippocampus, 22(4), 842-852. https://doi.org/10.1002/hipo.20944

Hirshhorn, M., Grady, C., Rosenbaum, R. S., Winocur, G., \& Moscovitch, M. (2012b). Brain regions involved in the retrieval of spatial and episodic details associated with a familiar environment: An fMRI study. Neuropsychologia, 50(13), 3094-3106.

https://doi.org/10.1016/j.neuropsychologia.2012.08.008

Hodges J. R., Graham K. S. (1998). A reversal of the temporal gradient for famous person knowledge in semantic dementia: implications for the neural organisation of long-term memory. Neuropsychologia. 36: 803-25. PMID 9751444 DOI: 10.1016/S0028$\underline{3932(97) 00126-7}$

Howard, M. W., \& Kahana, M. J. (2002). A Distributed Representation of Temporal Context. Journal of Mathematical Psychology, 46(3), 269-299. https://doi.org/10.1006/jmps.2001.1388

Hsieh, C., Tsokas, P., Serrano, P., Hernández, A. I., Tian, D., Cottrell, J. E., ... \& Sacktor, T. C. (2017). Persistent increased PKM $\zeta$ in long-term and remote spatial memory. 
Neurobiology of Learning and Memory, 138, 135-144.

https://doi.org/10.1016/j.nlm.2016.07.008

Hu, X., Cheng, L., Chiu, M.H., \& Paller, K.A. (2020). Promoting memory consolidation during sleep: A meta-analysis of targeted memory reactivation. Psychological Bulletin, 146, 218-244.

Irish, M., \& Piguet, O. (2013). The Pivotal Role of Semantic Memory in Remembering the Past and Imagining the Future. Frontiers in Behavioral Neuroscience, 7. https://doi.org/10.3389/fnbeh.2013.00027

Irish, M., \& van Kesteren, M. T. R. (2018). New Perspectives on the Brain Lesion Approach Implications for Theoretical Models of Human Memory. Neuroscience, 374, 319-322. https://doi.org/10.1016/j.neuroscience.2017.10.049

Irish, M., \& Vatansever, D. (2020). Rethinking the episodic-semantic distinction from a gradient perspective. Current Opinion in Behavioral Sciences, 32, 43-49. https://doi.org/10.1016/j.cobeha.2020.01.016

Jasnow, A. M., Lynch, J. F., Gilman, T. L., \& Riccio, D. C. (2017). Perspectives on fear generalization and its implications for emotional disorders: Fear Generalization and Emotional Disorders. Journal of Neuroscience Research, 95(3), 821-835. https://doi.org/10.1002/jnr.23837

Josselyn, S. A., \& Frankland, P. W. (2018). Memory Allocation: Mechanisms and Function. Annual Review of Neuroscience, 41(1), 389-413. https://doi.org/10.1146/annurev-neuro080317-061956 
Josselyn, S. A., Kohler, S., \& Frankland, P. W. (2017). Heroes of the Engram. The Journal of Neuroscience: The Official Journal of the Society for Neuroscience, 37(18), 4647-4657. https://doi.org/10.1523/JNEUROSCI.0056-17.2017

Josselyn, S. A., \& Tonegawa, S. (2020). Memory engrams: Recalling the past and imagining the future. Science, 367(6473). https://doi.org/10.1126/science.aaw4325

Kan, I. P., Alexander, M. P., \& Verfaellie, M. (2009). Contribution of Prior Semantic Knowledge to New Episodic Learning in Amnesia. Journal of Cognitive Neuroscience, 21(5), 938-944. https://doi.org/10.1162/jocn.2009.21066

Kandel, E. R., Dudai, Y., \& Mayford, M. R. (2014). The molecular and systems biology of memory. Cell, 157(1), 163-186. https://doi.org/10.1016/j.cell.2014.03.001

Karpicke, J. D., \& Roediger, H. L. (2008). The Critical Importance of Retrieval for Learning. Science, 319(5865), 966-968. https://doi.org/10.1126/science.1152408

Kim, J., \& Fanselow, M. (1992). Modality-specific retrograde amnesia of fear. Science, 256(5057), 675-677. https://doi.org/10.1126/science.1585183

Kim, J., Gulati, T., \& Ganguly, K. (2019). Competing Roles of Slow Oscillations and Delta Waves in Memory Consolidation versus Forgetting. Cell, 179(2), 514-526.e13. https://doi.org/10.1016/j.cell.2019.08.040

Kinsbourne, M., \& Wood, F. (1975). Short-term memory processes and the amnesic syndrome. In D. Deutsch Deutsch, A. (Ed.), Short-term Memory (pp. 258-291). Academic Press.

Kitamura, T., Ogawa, S. K., Roy, D. S., Okuyama, T., Morrissey, M. D., Smith, L. M., ... \& Tonegawa, S. (2017). Engrams and circuits crucial for systems consolidation of a memory. Science, 356(6333), 73-78. https://doi.org/10.1126/science.aam6808 
Kopelman, M. D. (1999). Retrograde amnesia in patients with diencephalic,temporal lobe or frontal lesions. Neuropsychologia, 37(8), 939-958. https://doi.org/10.1016/S00283932(98)00143-2

Kopelman, M. D. (1989). Remote and autobiographical memory, temporal context memory and frontal atrophy in Korsakoff and Alzheimer patients. Neuropsychologia, 27(4), 437-460. https://doi.org/10.1016/0028-3932(89)90050-X

Kopelman, M. D., Wilson, B. A., \& Baddeley, A. D. (1989). The autobiographical memory interview: A new assessment of autobiographical and personal semantic memory in amnesic patients. Journal of Clinical and Experimental Neuropsychology, 11(5), 724744. https://doi.org/10.1080/01688638908400928

Kopelman, M.D., \& Marsh, L.C. (2018). Autobiographical memory in amnesia. Revue de Neuropsychologie, Neurosciences Cognitives et Cliniques, 9, 219-227. https://doi.org/10.1684/nrp.2017.0437

Korsakoff, S. S. (1889). Psychic disorder in conjunction with multiple neuritis. Translated in: Neurology (1955), 5, 394-406.

Kumaran, D., Hassabis, D., \& McClelland, J. L. (2016). What Learning Systems do Intelligent Agents Need? Complementary Learning Systems Theory Updated. Trends in Cognitive Sciences, 20(7), 512-534. https://doi.org/10.1016/j.tics.2016.05.004

Kurczek, J., Wechsler, E., Ahuja, S., Jensen, U., Cohen, N. J., Tranel, D., \& Duff, M. (2015). Differential contributions of hippocampus and medial prefrontal cortex to self-projection and self-referential processing. Neuropsychologia, 73, 116-126. https://doi.org/10.1016/j.neuropsychologia.2015.05.002 
Kwan, D., Craver, C. F., Green, L., Myerson, J., Gao, F., Black, S. E., \& Rosenbaum, R. S. (2015). Cueing the personal future to reduce discounting in intertemporal choice: Is episodic prospection necessary?: INTERTEMPORAL CHOICE IN EPISODIC AMNESIA. Hippocampus, 25(4), 432-443. https://doi.org/10.1002/hipo.22431

Lad, M., Mullally, S. L., Houston, A. L., Kelly, T., \& Griffiths, T. D. (2019). Characterizing memory loss in patients with autoimmune limbic encephalitis hippocampal lesions. Hippocampus, 29(11), 1114-1120. https://doi.org/10.1002/hipo.23150

Lah, S., \& Miller, L. (2008). Effects of temporal lobe lesions on retrograde memory: A critical review. Neuropsychology Review, 18(1), 24-52. https://doi.org/10.1007/s11065-0089053-2

Lambon Ralph, M. A. (2014). Neurocognitive insights on conceptual knowledge and its breakdown. Philosophical Transactions of the Royal Society B: Biological Sciences, 369(1634), 20120392. https://doi.org/10.1098/rstb.2012.0392

Lambon Ralph, M. A., Jefferies, E., Patterson, K., \& Rogers, T. T. (2017). The neural and computational bases of semantic cognition. Nature Reviews Neuroscience, 18(1), 42-55. https://doi.org/10.1038/nrn.2016.150

Lambon Ralph, M. A., \& Patterson, K. (2008). Generalization and differentiation in semantic memory: Insights from semantic dementia. Annals of the New York Acadamy of Sciences, 1124, 61-76. https://doi.org/10.1196/annals.1440.006

Larzabal, C., Bacon-Macé, N., Muratot, S., \& Thorpe, S. J. (2020). Tracking Your Mind's Eye during Recollection: Decoding the Long-Term Recall of Short Audiovisual Clips. Journal of Cognitive Neuroscience, 32(1), 50-64. https://doi.org/10.1162/jocn_a_01468 
Lashley, K. S. (1950). In search of the engram. In Society of Experimental Biology Symposium No. 4: Physiological mechanisms in animal behaviour (pp. 454-482). Cambridge University Press.

Lechner, H. A., Squire, L. R., \& Byrne, J. H. (1999). 100 Years of ConsolidationRemembering Müller and Pilzecker. Learning \& Memory, 6(2), 77-87. https://doi.org/10.1101/1m.6.2.77

Lehmann, H., Lacanilao, S., \& Sutherland, R. J. (2007). Complete or partial hippocampal damage produces equivalent retrograde amnesia for remote contextual fear memories: Retrograde amnesia for contextual fear memories. European Journal of Neuroscience, 25(5), 1278-1286. https://doi.org/10.1111/j.1460-9568.2007.05374.x

Lehmann, H., Sparks, F. T., Spanswick, S. C., Hadikin, C., McDonald, R. J., \& Sutherland, R. J. (2009). Making context memories independent of the hippocampus. Learning and Memory, 16(7), 417-420. https://doi.org/10.1101/1m.1385409

Lesburgueres, E., Gobbo, O. L., Alaux-Cantin, S., Hambucken, A., Trifilieff, P., \& Bontempi, B. (2011). Early tagging of cortical networks is required for the formation of enduring associative memory. Science, 331(6019), 924-928. https://doi.org/10.1126/science. 1196164

Levine, B. (2004). Autobiographical memory and the self in time: Brain lesion effects, functional neuroanatomy, and lifespan development. Brain and Cognition, 55(1), 54-68. https://doi.org/10.1016/S0278-2626(03)00280-X

Levine, B., Fan, C.L., Simpson, S. \& Sokolowski, H.M. (2022). Autobiographical Memory. In Kahana, M. \& Wagner, A.D. (Eds.), Handbook of Human Memory: Foundations and Applications. Oxford University Press. 
Levine, B., Svoboda, E., Hay, J. F., Winocur, G., \& Moscovitch, M. (2002). Aging and autobiographical memory: Dissociating episodic from semantic retrieval. Psychology and Aging, 17(4), 677-689. https://doi.org/10.1037/0882-7974.17.4.677

Lewis, P. A., \& Bendor, D. (2019). How Targeted Memory Reactivation Promotes the Selective Strengthening of Memories in Sleep. Current Biology, 29(18), R906-R912. https://doi.org/10.1016/j.cub.2019.08.019

Lewis, P. A., \& Durrant, S. J. (2011). Overlapping memory replay during sleep builds cognitive schemata. Trends in Cognitive Science, 15(8), 343-351. https://doi.org/10.1016/j.tics.2011.06.004

Lifanov, J., Linde-Domingo, J., \& Wimber, M. (2020). Feature-specific reaction times reveal a semanticisation of memories over time and with repeated remembering [Preprint]. Neuroscience. https://doi.org/10.1101/2020.09.11.292813

Liu, E. S., Koen, J. D., \& Rugg, M. D. (2021). Effects of Age on Prestimulus Neural Activity Predictive of Successful Memory Encoding: An fMRI Study. Cerebral Cortex, 31(2), 917-932. https://doi.org/10.1093/cercor/bhaa265

Liu, L., Roquet, D., Ahmed, R., Hodges, J., Piguet, O., \& Irish, M. (2020). Examining prefrontal contributions to past- and future-oriented memory disturbances in daily life in dementia. Cortex, 134, 307-319

Liu, Z. X., Grady, C., \& Moscovitch, M. (2017). Effects of Prior-Knowledge on Brain Activation and Connectivity During Associative Memory Encoding. Cerebal Cortex, 27(3), 19912009. https://doi.org/10.1093/cercor/bhw047

Lomas, M., Rickard, V., Milton, F., Savage, S., Weir, A., \& Zeman, A. (2021). Electroconvulsive therapy related autobiographical amnesia: A review and case report. Cognitive Neuropsychiatry, 26(2), 107-121. https://doi.org/10.1080/13546805.2021.1871889 
Long, N. M., \& Kahana, M. J. (2019). Hippocampal contributions to serial-order memory. Hippocampus, 29(3), 252-259. https://doi.org/10.1002/hipo.23025

Lux V., Atucha E., Kitsukawa T., Sauvage M. M. (2016). Imaging a memory trace over half a life-time in the medial temporal lobe reveals a time-limited role of CA3 neurons in retrieval. Elife. 5: e11862. PMID 26880561 DOI: 10.7554/Elife.11862

Lynch, K., Keane, M. M., \& Verfaellie, M. (2020). The status of semantic memory in medial temporal lobe amnesia varies with demands on scene construction. Cortex, 131, 114-122. https://doi.org/10.1016/j.cortex.2020.07.005

Maguire, E. A., Frith, C. D., \& Morris, R. G. M. (1999). The functional neuroanatomy of comprehension and memory: The importance of prior knowledge. Brain, 122(10), 18391850. https://doi.org/10.1093/brain/122.10.1839

Maguire, E. A., \& Hassabis, D. (2011). Role of the hippocampus in imagination and future thinking. Proceedings of the National Academy of Sciences of the United States of America, 108(11), E39. https://doi.org/10.1073/pnas.1018876108

Maguire, E. A., Kumaran, D., Hassabis, D., \& Kopelman, M. D. (2010). Autobiographical memory in semantic dementia: A longitudinal fMRI study. Neuropsychologia, 48(1), 123-136. https://doi.org/10.1016/j.neuropsychologia.2009.08.020

Maguire, E. A., \& Mullally, S. L. (2013). The hippocampus: A manifesto for change. Journal of Experimental Psychology: General, 142(4), 1180-1189. https://doi.org/10.1037/a0033650

Maguire, E.A., Henson, R. N. A., Mummery, C. J., \& Frith, C. D. (2001). Modulation of activity in prefrontal cortex, but not hippocampus, by the age of memories. NeuroImage, 13(6), 706. https://doi.org/10.1016/S1053-8119(01)92049-X 
Maguire, E. A. (2001). Neuroimaging studies of autobiographical event memory. Philosophical Transactions of the Royal Society of London. Series B: Biological Sciences, 356(1413), 1441-1451. https://doi.org/10.1098/rstb.2001.0944

Manning, J. R., Polyn, S. M., Baltuch, G. H., Litt, B., \& Kahana, M. J. (2011). Oscillatory patterns in temporal lobe reveal context reinstatement during memory search. Proceedings of the National Academy of Sciences, 108(31), 12893-12897. https://doi.org/10.1073/pnas.1015174108

Manning, J. (2022). Context Reinstatement. In Kahana, M. \& Wagner, A.D. (Eds.), Handbook of Human Memory: Foundations and Applications. Oxford University Press.

Martin, A. (2016). GRAPES-Grounding representations in action, perception, and emotion systems: How object properties and categories are represented in the human brain. Psychonomic Bulletin and Review, 23(4), 979-990. https://doi.org/10.3758/s13423-0150842-3

Martin, A., Simmons, W. K., Beauchamp, M. S., \& Gotts, S. J. (2014). Is a single 'hub', with lots of spokes, an accurate description of the neural architecture of action semantics? Physics of Life Reviews, 11(2), 261-262. https://doi.org/10.1016/j.plrev.2014.01.002

McClelland, J. L. (2013). Incorporating rapid neocortical learning of new schema-consistent information into complementary learning systems theory. Journal of Experimental Psychology: General, 142(4), 1190-1210. https://doi.org/10.1037/a0033812

McClelland, J. L., McNaughton, B. L., \& O’Reilly, R. C. (1995). Why there are complementary learning systems in the hippocampus and neocortex: Insights from the successes and failures of connectionist models of learning and memory. Psychological Review, 102(3), 419-457. https://doi.org/10.1037/0033-295X.102.3.419 
McCloskey, M., \& Cohen, N. J. (1989). Catastrophic Interference in Connectionist Networks: The Sequential Learning Problem. In Psychology of Learning and Motivation (Vol. 24, pp. 109-165). Elsevier. https://doi.org/10.1016/S0079-7421(08)60536-8

McCormick, C., Ciaramelli, E., De Luca, F., \& Maguire, E. A. (2018a). Comparing and Contrasting the Cognitive Effects of Hippocampal and Ventromedial Prefrontal Cortex Damage: A Review of Human Lesion Studies. Neuroscience, 374, 295-318. https://doi.org/10.1016/j.neuroscience.2017.07.066

McCormick, C., Moscovitch, M., Valiante, T. A., Cohn, M., \& McAndrews, M. P. (2018b). Different neural routes to autobiographical memory recall in healthy people and individuals with left medial temporal lobe epilepsy. Neuropsychologia, 110, 26-36. https://doi.org/10.1016/j.neuropsychologia.2017.08.014

McCormick, C., Barry, D. N., Jafarian, A., Barnes, G. R., \& Maguire, E. A. (2020). VmPFC Drives Hippocampal Processing during Autobiographical Memory Recall Regardless of Remoteness. Cerebral Cortex, 30(11), 5972-5987. https://doi.org/10.1093/cercor/bhaa172

McCormick, C., St-Laurent, M., Ty, A., Valiante, T. A., \& McAndrews, M. P. (2015). Functional and Effective Hippocampal-Neocortical Connectivity During Construction and Elaboration of Autobiographical Memory Retrieval. Cerebral Cortex, 25(5), 12971305. https://doi.org/10.1093/cercor/bht324

McGaugh, J. L. (2000). Memory-A century of consolidation. Science, 287(5451), 248-251. https://doi.org/10.1126/science.287.5451.248

McKenzie, S., Frank, A. J., Kinsky, N. R., Porter, B., Riviere, P. D., \& Eichenbaum, H. (2014). Hippocampal representation of related and opposing memories develop within distinct, 
hierarchically organized neural schemas. Neuron, 83(1), 202-215.

https://doi.org/10.1016/j.neuron.2014.05.019

McKenzie, S., Robinson, N. T., Herrera, L., Churchill, J. C., \& Eichenbaum, H. (2013). Learning causes reorganization of neuronal firing patterns to represent related experiences within a hippocampal schema. Journal of Neuroscience, 33(25), 10243-10256.

https://doi.org/10.1523/JNEUROSCI.0879-13.2013

McLeod, H. J., Wood, N., \& Brewin, C. R. (2006). Autobiographical memory deficits in schizophrenia. Cognition and Emotion, 20(3-4), 536-547. https://doi.org/10.1080/02699930500342472

Merhav, M., Karni, A., \& Gilboa, A. (2014). Neocortical catastrophic interference in healthy and amnesic adults: A paradoxical matter of time. Hippocampus, 24(12), 1653-1662. https://doi.org/10.1002/hipo.22353

Merhav, M., Karni, A., \& Gilboa, A. (2015). Not all declarative memories are created equal: Fast Mapping as a direct route to cortical declarative representations. Neuroimage, 117, 8092. https://doi.org/10.1016/j.neuroimage.2015.05.027

Migues, P. V., Liu, L., Archbold, G. E. B., Einarsson, E. O., Wong, J., Bonasia, K., ... \& Hardt, O. (2016). Blocking Synaptic Removal of GluA2-Containing AMPA Receptors Prevents the Natural Forgetting of Long-Term Memories. Journal of Neuroscience, 36(12), 34813494. https://doi.org/10.1523/JNEUROSCI.3333-15.2016

Miller, R. R., \& Matzel, L. D. (2006). Retrieval failure versus memory loss in experimental amnesia: Definitions and processes. Learning and Memory, 13(5), 491-497. https://doi.org/10.1101//m.241006 
Miller, T. D., Chong, T. T.-J., Aimola Davies, A. M., Johnson, M. R., Irani, S. R., Husain, M., ... \& Rosenthal, C. R. (2020). Human hippocampal CA3 damage disrupts both recent and remote episodic memories. ELife, 9, e41836. https://doi.org/10.7554/eLife.41836

Milner, B., \& Penfield, W. (1955). The effect of hippocampal lesions on recent memory. Transactions of the American Neurological Association, 80, 42-48.

Misanin, J. R., Miller, R. R., \& Lewis, D. J. (1968). Retrograde Amnesia Produced by Electroconvulsive Shock after Reactivation of a Consolidated Memory Trace. Science, 160(3827), 554-555. https://doi.org/10.1126/science.160.3827.554

Moscovitch, M. (1982). Multiple dissociations of function in amnesia. In L. S. Cermak (Ed.), Human Memory and Amnesia. Hillsdale, NJ.: Lawrence Erlbaum.

Moscovitch, M. (1989). Confabulation and the frontal systems: Strategic versus associative retrieval in neuropsychological theories of memory. In H. L. Roediger III Craik, F. I. M. (Ed.), Varieties of memory and consciousness: Essays in honour of Endel Tulving (pp. 133-160). Erlbaum.

Moscovitch, M. (1992). Memory and Working-with-Memory: A Component Process Model Based on Modules and Central Systems. Journal of Cognitive Neuroscience, 4(3), 257267. https://doi.org/10.1162/jocn.1992.4.3.257

Moscovitch, M. (1995). Recovered consciousness: A hypothesis concerning modularity and episodic memory. Journal of Clinical and Experimental Neuropsychology, 17(2), 276290. https://doi.org/10.1080/01688639508405123

Moscovitch, M. \& Melo, B. (1997). Strategic retrieval and the frontal lobes: Evidence from confabulation and amnesia. Neuropsychologia, 35(7), 1017-1034. https://doi.org/10.1016/S0028-3932(97)00028-6 
Moscovitch, M. (2008). The hippocampus as a "stupid," domain-specific module: Implications for theories of recent and remote memory, and of imagination. Can J Exp Psychol, 62(1), 62-79. https://doi.org/10.1037/1196-1961.62.1.62

Moscovitch, M. (2012). Memory before and after HM: An Impressionistic Historical Perspective. In A. Zeman Jones-Gotman, M., Kapur, N. (Ed.), Epilepsy and Memory. Oxford University Press.

Moscovitch, M., Cabeza, R., Winocur, G., \& Nadel, L. (2016). Episodic Memory and Beyond: The Hippocampus and Neocortex in Transformation. Annual Review of Psychology, 67(1), 105-134. https://doi.org/10.1146/annurev-psych-113011-143733

Moscovitch, M. \& Gilboa, A. (2021). Systems consolidation, transformation and reorganization: Multiple Trace Theory, Trace Transformation Theory and their competitors. PsyRxiv. Moscovitch, M., \& Nadel, L. (2019). Sculpting Remote Memory: Enduring Hippocampal Traces and vmPFC Reconstructive Processes. Trends in Cognitive Sciences, 23(8), 634-635. https://doi.org/10.1016/j.tics.2019.05.001

Moscovitch, M., Rosenbaum, R. S., Gilboa, A., Addis, D. R., Westmacott, R., Grady, C., ... \& Nadel, L. (2005). Functional neuroanatomy of remote episodic, semantic and spatial memory: A unified account based on multiple trace theory: A unified account based on multiple trace theory. Journal of Anatomy, 207(1), 35-66. https://doi.org/10.1111/j.14697580.2005.00421.x

Moscovitch, M., \& Winocur, G. (1992). Frontal lobes and memory. In L. R. Squire (Ed.), The encyclopedia of learning and memory: A volume in neuropsychology. Macmillan Publishing Co. 
Moscovitch, M., \& Winocur, G. (2002). The frontal cortex and working with memory. In D. T. (Ed); K. Stuss Robert T. (Ed.), Principles of frontal lobe function. (pp. 188-209). London: Oxford University Press.

Moser, E. I., Kropff, E., \& Moser, M. B. (2008). Place cells, grid cells, and the brain's spatial representation system. Annual Review in Neuroscience, 31, 69-89. https://doi.org/10.1146/annurev.neuro.31.061307.090723

Moss, H. E., Kopelman, M. D., Cappelletti, M., de Mornay Davies, P., \& Jaldow, E. (2003). Lost for Words or Loss of Memories? Autobiographical Memory in Semantic Dementia. Cognitive Neuropsychology, 20(8), 703-732. https://doi.org/10.1080/02643290242000916

Müller, G. E., \& Pilzecker, A. (1900). Experimentelle beitrage zur lehre vom gedachtnis. Zeitschrift Fur Psychologie Und Physiologie Der Sinnesorganne, S1, 1-288.

Murphy, K. J., Troyer, A. K., Levine, B., \& Moscovitch, M. (2008). Episodic, but not semantic, autobiographical memory is reduced in amnestic mild cognitive impairment. Neuropsychologia, 46(13), 3116-3123. https://doi.org/10.1016/j.neuropsychologia.2008.07.004

Nadel, L., Samsonovich, A., Ryan, L., \& Moscovitch, M. (2000). Multiple trace theory of human memory: Computational, neuroimaging, and neuropsychological results. Hippocampus, 10(4), 352-368. https://doi.org/10.1002/1098-1063(2000)10:4<352::AIDHIPO2>3.0.CO;2-D

Nadel, L., \& Sederberg, P. B (in press). Memory Reconsolidation: Making Predictions Better. In M. Kahana \& A. Wagner (Eds.), Handbook of Human Memory. 
Nadel, L., \& Moscovitch, M. (1997). Memory consolidation, retrograde amnesia and the hippocampal complex. Current Opinion in Neurobiology, 7(2), 217-227. https://doi.org/10.1016/S0959-4388(97)80010-4

Nader, K., \& Hardt, O. (2009). A single standard for memory: The case for reconsolidation. Nature Review Neuroscience, 10(3), 224-234. https://doi.org/10.1038/nrn2590

Newcombe, F. (1969.). Missile Wounds of the Brain: A Study of Psychological Deficits. Oxford University Press.

Norman, K. A. (2010). How hippocampus and cortex contribute to recognition memory: Revisiting the complementary learning systems model. Hippocampus, 20(11), 12171227. https://doi.org/10.1002/hipo.20855

Norman, Y., Yeagle, E. M., Harel, M., Mehta, A. D., \& Malach, R. (2017). Neuronal baseline shifts underlying boundary setting during free recall. Nature Communications, 8(1), 1301. https://doi.org/10.1038/s41467-017-01184-1

Norman, Y., Yeagle, E. M., Khuvis, S., Harel, M., Mehta, A. D., \& Malach, R. (2019). Hippocampal sharp-wave ripples linked to visual episodic recollection in humans. Science, 365(6454), eaax1030. https://doi.org/10.1126/science.aax1030

O’Connor, M. G., \& Lafleche, G. M. C. (2004). Retrograde amnesia in patients with rupture and surgical repair of anterior communicating artery aneurysms. Journal of the International Neuropsychological Society, 10(2), 221-229. https://doi.org/10.1017/S1355617704102087

Oedekoven, C. S. H., Keidel, J. L., Berens, S. C., \& Bird, C. M. (2017). Reinstatement of memory representations for lifelike events over the course of a week. Scientific Reports, 7(1), 14305. https://doi.org/10.1038/s41598-017-13938-4 
Ogden, J. A. (1993). Visual object agnosia, prosopagnosia, achromatopsia, loss of visual imagery, and autobiographical amnesia following recovery from cortical blindness: Case M.H. Neuropsychologia, 31(6), 571-589. https://doi.org/10.1016/0028-3932(93)90053-3

O’Keefe, J., \& Nadel, L. (1978). The Hippocampus as a Cognitive Map. Oxford University Press.

Otten, L. J., Quayle, A. H., Akram, S., Ditewig, T. A., \& Rugg, M. D. (2006). Brain activity before an event predicts later recollection. Nature Neuroscience, 9(4), 489-491. https://doi.org/10.1038/nn1663

Paller, K. A., Creery, J. D., \& Schechtman, E. (2021). Memory and Sleep: How Sleep Cognition Can Change the Waking Mind for the Better. Annual Review of Psychology, 72(1), 123150. https://doi.org/10.1146/annurev-psych-010419-050815

Park, H., \& Rugg, M. D. (2009). Prestimulus hippocampal activity predicts later recollection. Hippocampus, NA-NA. https://doi.org/10.1002/hipo.20663

Pavlowsky, A., Wallace, E., Fenton, A. A., \& Alarcon, J. M. (2017). Persistent modifications of hippocampal synaptic function during remote spatial memory. Neurobiology of Learning and Memory, 138, 182-197. https://doi.org/10.1016/j.nlm.2016.08.015

Penfield, W., \& Milner, B. (1958). Memory deficit produced by bilateral lesions in the hippocampal zone. AMA Archives of Neurology and Psychiatry, 79(5), 475-497.

Petrican, R., Gopie, N., Leach, L., Chow, T. W., Richards, B., \& Moscovitch, M. (2010). Recollection and familiarity for public events in neurologically intact older adults and two brain-damaged patients. Neuropsychologia, 48(4), 945-960. https://doi.org/10.1016/j.neuropsychologia.2009.11.015 
Piolino, P., Desgranges, B., Belliard, S., Matuszewski, V., Lalevee, C., La Sayette, V., \& Eustache, F. (2003). Autobiographical memory and autonoetic consciousness: Triple dissociation in neurodegenerative diseases. Brain, 126(10), 2203-2219. https://doi.org/10.1093/brain/awg222

Piolino, P., Desgranges, B., \& Eustache, F. (2009). Episodic autobiographical memories over the course of time: Cognitive, neuropsychological and neuroimaging findings. Neuropsychologia, 47(11), 2314-2329. https://doi.org/10.1016/j.neuropsychologia.2009.01.020

Poppenk, J., Evensmoen, H. R., Moscovitch, M., \& Nadel, L. (2013). Long-axis specialization of the human hippocampus. Trends in Cognitive Sciences, 17(5), 230-240. https://doi.org/10.1016/j.tics.2013.03.005

Poppenk, J., \& Moscovitch, M. (2011). A hippocampal marker of recollection memory ability among healthy young adults: Contributions of posterior and anterior segments. Neuron, 72(6), 931-937. https://doi.org/10.1016/j.neuron.2011.10.014

Poreh, A., Winocur, G., Moscovitch, M., Backon, M., Goshen, E., Ram, Z., \& Feldman, Z. (2006). Anterograde and retrograde amnesia in a person with bilateral fornix lesions following removal of a colloid cyst. Neuropsychologia, 44, 2241-2248.

Preston, A. R., \& Eichenbaum, H. (2013). Interplay of hippocampus and prefrontal cortex in memory. Current Biology, 23(17), R764-73. https://doi.org/10.1016/j.cub.2013.05.041

Quiroga, R. (2019). Plugging in to Human Memory: Advantages, Challenges, and Insights from Human Single-Neuron Recordings. Cell, 179(5), 1015-1032. https://doi.org/10.1016/j.cell.2019.10.016 
Quiroga, R. Q. (2012). Concept cells: The building blocks of declarative memory functions. Nature Reviews Neuroscience, 13(8), 587-597. https://doi.org/10.1038/nrn3251

Quiroga, R. Q., Reddy, L., Kreiman, G., Koch, C., \& Fried, I. (2005). Invariant visual representation by single neurons in the human brain. Nature, 435(7045), 1102-1107. https://doi.org/10.1038/nature03687

Ranganath, C. (2022). Episodic Memory. In Kahana, M. \& Wagner, A.D. (Eds.), Handbook of Human Memory: Foundations and Applications. Oxford University Press.

Ranganath, C. \& Ritchey, M. (2012). Two cortical systems for memory-guided behaviour. Nature Reviews. Neuroscience, 13, 713-26. PMID 22992647 DOI: http://doi.org/10.1038/nrn3338

Renoult, L., Armson, M. J., Diamond, N. B., Fan, C. L., Jeyakumar, N., Levesque, L., ... \& Levine, B. (2020). Classification of general and personal semantic details in the Autobiographical Interview. Neuropsychologia, 144, 107501. https://doi.org/10.1016/j.neuropsychologia.2020.107501

Renoult, L., Davidson, P. S. R., Palombo, D. J., Moscovitch, M., \& Levine, B. (2012). Personal semantics: At the crossroads of semantic and episodic memory. Trends in Cognitive Sciences, 16(11), 550-558. https://doi.org/10.1016/j.tics.2012.09.003

Renoult, L., Irish, M., Moscovitch, M., \& Rugg, M. D. (2019). From Knowing to Remembering: The Semantic-Episodic Distinction. Trends in Cognitive Sciences, 23(12), 1041-1057. https://doi.org/10.1016/j.tics.2019.09.008

Reyna, V. F., \& Brainerd, C. J. (1995). Fuzzy-trace theory: An interim synthesis. Learning and Individual Differences, 7(1), 1-75. https://doi.org/10.1016/1041-6080(95)90031-4

Ribot, T. (1882). Diseases of Memory. New York: Appleton-Century-Crofts. 
Richards, B. A., Xia, F., Santoro, A., Husse, J., Woodin, M. A., Josselyn, S. A., \& Frankland, P. W. (2014). Patterns across multiple memories are identified over time. Nature Neuroscience, 17(7), 981-986. https://doi.org/10.1038/nn.3736

Richards, B. A., \& Frankland, P. W. (2017). The Persistence and Transience of Memory. Neuron, 94(6), 1071-1084. https://doi.org/10.1016/j.neuron.2017.04.037

Richter, F. R., Cooper, R. A., Bays, P. M., \& Simons, J. S. (2016). Distinct neural mechanisms underlie the success, precision, and vividness of episodic memory. ELife, 5, e18260. https://doi.org/10.7554/eLife.18260

Ritchey, M., \& Cooper, R. A. (2020). Deconstructing the Posterior Medial Episodic Network. Trends in Cognitive Sciences, 24(6), 451-465. https://doi.org/10.1016/j.tics.2020.03.006

Ritchey, M., Montchal, M. E., Yonelinas, A. P., \& Ranganath, C. (2015). Delay-dependent contributions of medial temporal lobe regions to episodic memory retrieval. Elife, 4. https://doi.org/10.7554/eLife.05025

Robin, J. (2018). Spatial scaffold effects in event memory and imagination. Wiley Interdisciplinary Reviews: Cognitive Science, 9(4), e1462. https://doi.org/10.1002/wcs.1462

Robin, J., \& Moscovitch, M. (2017). Details, gist and schema: Hippocampal-neocortical interactions underlying recent and remote episodic and spatial memory. Current Opinion in Behavioral Sciences, 17, 114-123. https://doi.org/10.1016/j.cobeha.2017.07.016

Roediger, H. L., \& Butler, A. C. (2011). The critical role of retrieval practice in long-term retention. Trends in Cognitive Sciences, 15(1), 20-27.

https://doi.org/10.1016/j.tics.2010.09.003 
Roediger, H. L., \& Karpicke, J. D. (2006). Test-Enhanced Learning: Taking Memory Tests Improves Long-Term Retention. Psychological Science, 17(3), 249-255. https://doi.org/10.1111/j.1467-9280.2006.01693.x

Roediger, H. L., \& Karpicke, J. D. (2018). Reflections on the Resurgence of Interest in the Testing Effect. Perspectives on Psychological Science, 13(2), 236-241. https://doi.org/10.1177/1745691617718873

Roediger, H. L., \& McDermott, K. B. (1995). Creating false memories: Remembering words not presented in lists. Journal of Experimental Psychology: Learning, Memory, and Cognition, 21(4), 803-814. https://doi.org/10.1037/0278-7393.21.4.803

Rosenbaum, R. S., Gilboa, A., Levine, B., Winocur, G., \& Moscovitch, M. (2009). Amnesia as an impairment of detail generation and binding: Evidence from personal, fictional, and semantic narratives in K.C. Neuropsychologia, 47(11), 2181-2187. https://doi.org/10.1016/j.neuropsychologia.2008.11.028

Rosenbaum, R. S., Kohler, S., Schacter, D. L., Moscovitch, M., Westmacott, R., Black, S. E., ... \& Tulving, E. (2005a). The case of K.C.: Contributions of a memory-impaired person to memory theory. Neuropsychologia, 43(7), 989-1021. https://doi.org/10.1016/j.neuropsychologia.2004.10.007

Rosenbaum, R. S., Priselac, S., Kohler, S., Black, S. E., Gao, F., Nadel, L., \& Moscovitch, M. (2000). Remote spatial memory in an amnesic person with extensive bilateral hippocampal lesions. Nature Neuroscience, 3(10), 1044-1048. https://doi.org/10.1038/79867 
Rosenbaum, R. S., Winocur, G., Ziegler, M., Hevenor, S. J., Grady, C. L., \& Moscovitch, M. (2004a). FMRI studies of remote spatial memory in an amnesic person. Brain and Cognition, 54(2), 170-172.

Rosenbaum, R. S., Ziegler, M., Winocur, G., Grady, C. L., \& Moscovitch, M. (2004b). "I have often walked down this street before": FMRI studies on the hippocampus and other structures during mental navigation of an old environment. Hippocampus, 14(7), 826835. https://doi.org/10.1002/hipo.10218

Rosenbaum, R. S., Gao, F., Richards, B., Black, S. E., \& Moscovitch, M. (2005). "Where to?” Remote Memory for Spatial Relations and Landmark Identity in Former Taxi Drivers with Alzheimer's Disease and Encephalitis. Journal of Cognitive Neuroscience, 17(3), 446-462. https://doi.org/10.1162/0898929053279496

Rosenbaum, R. S., Moscovitch, M., Foster, J. K., Schnyer, D. M., Gao, F., Kovacevic, N., ... \& Levine, B. (2008). Patterns of Autobiographical Memory Loss in Medial-Temporal Lobe Amnesic Patients. Journal of Cognitive Neuroscience, 20(8), 1490-1506. https://doi.org/10.1162/jocn.2008.20105

Rosenbaum, R.S., Winocur, G., \& Moscovitch, M. (2001). New views on old memories: Reevaluating the role of the hippocampal complex. Behavioural Brain Research, 127(1-2), 183-197. https://doi.org/10.1016/S0166-4328(01)00363-1

Roy, D. S., Arons, A., Mitchell, T. I., Pignatelli, M., Ryan, T. J., \& Tonegawa, S. (2016). Memory retrieval by activating engram cells in mouse models of early Alzheimer's disease. Nature, 531(7595), 508-512. https://doi.org/10.1038/nature17172 
Rubin, D. C., \& Greenberg, D. L. (1998). Visual memory-deficit amnesia: A distinct amnesic presentation and etiology. Proceedings of the National Academy of Sciences, 95(9), 5413-5416. https://doi.org/10.1073/pnas.95.9.5413

Rudy, J. W., \& Sutherland, R. J. (1989). The hippocampal formation is necessary for rats to learn and remember configural discriminations. Behavioural Brain Research, 34(1-2), 97-109. https://doi.org/10.1016/S0166-4328(89)80093-2

Rudy J. W., \& Sutherland R. J. (2008). Is it systems or cellular consolidation? Time will tell. An alternative interpretation of the Morris group's recent science paper. Neurobiology of Learning and Memory. 89: 366-9. PMID 17977757 DOI: $\underline{10.1016 / \mathrm{j} . n 1 m .2007 .07 .017}$

Rudoy, J. D., Voss, J. L., Westerberg, C. E., \& Paller, K. A. (2009). Strengthening Individual Memories by Reactivating Them During Sleep. Science, 326(5956), 1079-1079. https://doi.org/10.1126/science.1179013

Rugg, M. D., \& Vilberg, K. L. (2013). Brain networks underlying episodic memory retrieval. Current Opinion in Neurobiology, 23(2), 255-260. https://doi.org/10.1016/j.conb.2012.11.005

Russell, W. R. (1948). Traumatic Amnesia. Quarterly Journal of Experimental Psychology, 1(1), 2-6. https://doi.org/10.1080/17470214808416737

Ryan, L., Cox, C., Hayes, S. M., \& Nadel, L. (2008). Hippocampal activation during episodic and semantic memory retrieval: Comparing category production and category cued recall. Neuropsychologia, 46(8), 2109-2121. https://doi.org/10.1016/j.neuropsychologia.2008.02.030 
Ryan, L., Lin, C.-Y., Ketcham, K., \& Nadel, L. (2009). The role of medial temporal lobe in retrieving spatial and nonspatial relations from episodic and semantic memory. Hippocampus, NA-NA. https://doi.org/10.1002/hipo.20607

Ryan, L., Nadel, L., Keil, K., Putnam, K., Schnyer, D., Trouard, T., \& Moscovitch, M. (2001). Hippocampal complex and retrieval of recent and very remote autobiographical memories: Evidence from functional magnetic resonance imaging in neurologically intact people. Hippocampus, 11(6), 707-714. https://doi.org/10.1002/hipo.1086

Sadeh, T., Chen, J., Goshen-Gottstein, Y., \& Moscovitch, M. (2019). Overlap between hippocampal pre-encoding and encoding patterns supports episodic memory. Hippocampus, 29(9), 836-847. https://doi.org/10.1002/hipo.23079

Sadeh, T., Ozubko, J. D., Winocur, G., \& Moscovitch, M. (2014). How we forget may depend on how we remember. Trends in Cognitive Sciences, 18(1), 26-36. https://doi.org/10.1016/j.tics.2013.10.008

Sadeh, T., Ozubko, J. D., Winocur, G., \& Moscovitch, M. (2016). Forgetting Patterns Differentiate Between Two Forms of Memory Representation. Psychological Science, 27(6), 810-820. https://doi.org/10.1177/0956797616638307

Sanders, H. I., \& Warrington, E. K. (1971). Memory for remote events in amnesic patients. Brain, 94(4), 661-668. https://doi.org/10.1093/brain/94.4.661

Sara, S. J. (2000a). Retrieval and reconsolidation: Toward a neurobiology of remembering. Learning and Memory, 7(2), 73-84. https://doi.org/10.1101/1m.7.2.73

Sara, S. J. (2000b). Strengthening the shaky trace through retrieval. Nature Reviews Neuroscience, 1(3), 212-213. https://doi.org/10.1038/35044575 
Schacter, D. L. (2012a). Adaptive constructive processes and the future of memory. American Psychologist, 67(8), 603-613. https://doi.org/10.1037/a0029869

Schacter, D. L. (2012b). Constructive memory: Past and future. Dialogues in Clinical Neuroscience, 14(1), 7-18. https://doi.org/10.31887/DCNS.2012.14.1/dschacter

Schacter, D. L., Addis, D. R., Hassabis, D., Martin, V. C., Spreng, R. N., \& Szpunar, K. K. (2012). The future of memory: Remembering, imagining, and the brain. Neuron, 76(4), 677-694. https://doi.org/10.1016/j.neuron.2012.11.001

Schacter, D. L., Eich, J. E., \& Tulving, E. (1978). Richard Semon's theory of memory. Journal of Verbal Learning and Verbal Behavior, 17(6), 721-743. https://doi.org/10.1016/S00225371(78)90443-7

Schapiro, A. C., McDevitt, E. A., Chen, L., Norman, K. A., Mednick, S. C., \& Rogers, T. T. (2017a). Sleep Benefits Memory for Semantic Category Structure While Preserving Exemplar-Specific Information. Scientific Reports, 7(1), 14869. https://doi.org/10.1038/s41598-017-12884-5

Schapiro, A. C., Turk-Browne, N. B., Botvinick, M. M., \& Norman, K. A. (2017b). Complementary learning systems within the hippocampus: A neural network modelling approach to reconciling episodic memory with statistical learning. Philosophical Transactions of the Royal Society B: Biological Sciences, 372(1711), 20160049. https://doi.org/10.1098/rstb.2016.0049

Schlichting, M. L., Mumford, J. A., \& Preston, A. R. (2015). Learning-related representational changes reveal dissociable integration and separation signatures in the hippocampus and prefrontal cortex. Nature Communications, 6, 8151. https://doi.org/10.1038/ncomms9151 
Schlichting, M. L., \& Preston, A. R. (2015). Memory integration: Neural mechanisms and implications for behavior. Current Opinion in Behavioral Sciences, 1, 1-8. https://doi.org/10.1016/j.cobeha.2014.07.005

Schnider, A. (2008). The confabulating mind: How the brain creates reality. Oxford University Press.

Schnider, A., Nahum, L., \& Ptak, R. (2017). What does extinction have to do with confabulation? Cortex, 87, 5-15. https://doi.org/10.1016/j.cortex.2016.10.015

Scoville, W. B., \& Milner, B. (1957). Loss of recent memory after bilateral hippocampal lesions. Journal of Neurology, Neurosurgery \& Psychiatry, 20(1), 11-21. https://doi.org/10.1136/jnnp.20.1.11

Sekeres, M. J., Bonasia, K., St-Laurent, M., Pishdadian, S., Winocur, G., Grady, C., \& Moscovitch, M. (2016). Recovering and preventing loss of detailed memory: Differential rates of forgetting for detail types in episodic memory. Learning and Memory, 23(2), 7282. https://doi.org/10.1101/1m.039057.115

Sekeres, M. J., Moscovitch, M., Grady, C. L., Sullens, D. G., \& Winocur, G. (2020). Reminders reinstate context-specificity to generalized remote memories in rats: Relation to activity in the hippocampus and aCC. Learning \& Memory, 27(1), 1-5. https://doi.org/10.1101/lm.050161.119

Sekeres, M., Moscovitch, M., Winocur, G. (2017). Mechanisms of Memory Consolidation and Transformation. In N. Axmacher Rasch, B. (Ed.), Cognitive Neuroscience of Memory Consolidation (pp. 17-44). Springer International Publishing. 
Sekeres, M. J., Moscovitch, M., Winocur, G., Pishdadian, S., Nichol, D., \& Grady, C. L. (2021). Reminders activate the prefrontal-medial temporal cortex and attenuate forgetting of event memory. Hippocampus, 31(1), 28-45. https://doi.org/10.1002/hipo.23260

Sekeres, M. J., Winocur, G., \& Moscovitch, M. (2018a). The hippocampus and related neocortical structures in memory transformation. Neuroscience Letters, 680, 39-53. https://doi.org/10.1016/j.neulet.2018.05.006

Sekeres, M. J., Winocur, G., Moscovitch, M., Anderson, J. A. E., Pishdadian, S., Martin Wojtowicz, J., ... \& Grady, C. L. (2018b). Changes in patterns of neural activity underlie a time-dependent transformation of memory in rats and humans. Hippocampus, 28(10), 745-764. https://doi.org/10.1002/hipo.23009

Semon, R. (1904). Die Mneme als erhaltendes Prinzip im Wechsel des organischen Geschehens. W. Engelmann.

Semon, R. (1921). The Mneme. Allen \& Unwin.

Shallice, T., \& Cooper, R. P. (2012). The Organisation of Mind. Cortex, 48(10), 1366-1370. https://doi.org/10.1016/j.cortex.2011.07.004

Shallice, T., Fletcher, P., Frith, C. D., Grasby, P., Frackowiak, R. S. J., \& Dolan, R. J. (1994). Brain regions associated with acquisition and retrieval of verbal episodic memory. Nature, 368(6472), 633-635. https://doi.org/10.1038/368633a0

Sharon, T., Moscovitch, M., \& Gilboa, A. (2011). Rapid neocortical acquisition of long-term arbitrary associations independent of the hippocampus. Proc Natl Acad Sci U S A, 108(3), 1146-1151. https://doi.org/10.1073/pnas.1005238108

Sheldon, S., McAndrews, M. P., Pruessner, J., \& Moscovitch, M. (2016). Dissociating patterns of anterior and posterior hippocampal activity and connectivity during distinct forms of 
category fluency. Neuropsychologia, 90, 148-158.

https://doi.org/10.1016/j.neuropsychologia.2016.06.028

Sheldon, S., Fenerci, C., \& Gurguryan, L. (2019). A Neurocognitive Perspective on the Forms and Functions of Autobiographical Memory Retrieval. Frontiers in Systems Neuroscience, 13, 4. https://doi.org/10.3389/fnsys.2019.00004

Sheldon, S., \& Levine, B. (2016). The role of the hippocampus in memory and mental construction: Memory and mental construction. Annals of the New York Academy of Sciences, 1369(1), 76-92. https://doi.org/10.1111/nyas.13006

Sheldon, S., \& Levine, B. (2018). The medial temporal lobe functional connectivity patterns associated with forming different mental representations. Hippocampus, 28(4), 269-280. https://doi.org/10.1002/hipo.22829

Silva, A. J., Zhou, Y., Rogerson, T., Shobe, J., \& Balaji, J. (2009). Molecular and Cellular Approaches to Memory Allocation in Neural Circuits. Science, 326(5951), 391-395. https://doi.org/10.1126/science.1174519

Simons J.S., \& Mayes A. R. (2008). What is the parietal lobe contribution to human memory? Neuropsychologia. 46: 1739-42. PMID 18501933 DOI: 10.1016/j.neuropsychologia.2008.05.001

Sirigu, A., Zalla, T., Pillon, B., Grafman, J., Agid, Y., \& Dubois, B. (1996). Encoding of Sequence and Boundaries of Scripts Following Prefrontal Lesions. Cortex, 32(2), $297-$ 310. https://doi.org/10.1016/S0010-9452(96)80052-9

Sirigu, A., Zalla, T., Pillon, B., Grafman, J., Dubois, B., \& Agid, Y. (1995). Planning and Script Analysis following Prefrontal Lobe Lesions. Annals of the New York Academy of 
Sciences, 769(1 Structure and), 277-288. https://doi.org/10.1111/j.1749-

6632.1995.tb38145.x

Söderlund H., Moscovitch M., Kumar N., Daskalakis Z. J., Flint A., Herrmann N., \& Levine B. (2014) Autobiographical episodic memory in major depressive disorder. Journal of Abnormal Psychology. 123: 51-60. PMID $\underline{24661159}$ DOI: $\underline{\text { 10.1037/A0035610 }}$

Söderlund, H., Moscovitch, M., Kumar, N., Mandic, M., \& Levine, B. (2012). As time goes by: Hippocampal connectivity changes with remoteness of autobiographical memory retrieval. Hippocampus, 22(4), 670-679. https://doi.org/10.1002/hipo.20927

Sommer, T. (2017). The Emergence of Knowledge and How it Supports the Memory for Novel Related Information. Cerebal Cortex, 27(3), 1906-1921. https://doi.org/10.1093/cercor/bhw031

Spalding, K. N., Jones, S. H., Duff, M. C., Tranel, D., \& Warren, D. E. (2015). Investigating the Neural Correlates of Schemas: Ventromedial Prefrontal Cortex Is Necessary for Normal Schematic Influence on Memory. Journal of Neuroscience, 35(47), 15746-15751. https://doi.org/10.1523/JNEUROSCI.2767-15.2015

Squire, L. R. (1992). Memory and the hippocampal region: A synthesis of findings with rats, monkeys, and humans. Psychol Rev, 99, 195-231.

Squire, L. R. (2006). Lost forever or temporarily misplaced? The long debate about the nature of memory impairment. Learning \& Memory, 13(5), 522-529. https://doi.org/10.1101//m.310306

Squire, L. R. (2009). The legacy of patient H.M. for neuroscience. Neuron, 61(1), 6-9. https://doi.org/10.1016/j.neuron.2008.12.023 
Squire, L. R., \& Alvarez, P. (1995). Retrograde amnesia and memory consolidation: A neurobiological perspective. Current Opinion in Neurobiology, 5(2), 169-177. https://doi.org/10.1016/0959-4388(95)80023-9

Squire, L. R., \& Bayley, P. J. (2007). The neuroscience of remote memory. Current Opinion in Neurobiology, 17(2), 185-196. https://doi.org/10.1016/j.conb.2007.02.006

Squire, L. R., Cohen, N. J., \& Nadel, L. (1984). The medial temporal region and memory consolidation: A new hypothesis. In H. Weingartner \& E. Parker (Eds.), Memory Consolidation (pp. 185-210). Lawrence Erlbaum Associates.

Squire, L. R., Genzel, L., Wixted, J. T., \& Morris, R. G. (2015). Memory consolidation. Cold Spring Harbor Perspectives in Biology, 7(8), a021766. https://doi.org/10.1101/cshperspect.a021766

Staresina, B. P., Alink, A., Kriegeskorte, N., \& Henson, R. N. (2013). Awake reactivation predicts memory in humans. Proceedings of the National Academy of Sciences USA, 110(52), 21159-21164. https://doi.org/10.1073/pnas.1311989110

Sterpenich, V., Albouy, G., Darsaud, A., Schmidt, C., Vandewalle, G., Dang Vu, T. T., ... \& Maquet, P. (2009). Sleep Promotes the Neural Reorganization of Remote Emotional Memory. Journal of Neuroscience, 29(16), 5143-5152. https://doi.org/10.1523/JNEUROSCI.0561-09.2009

St-Laurent, M., Moscovitch, M., Levine, B., \& McAndrews, M. P. (2009). Determinants of autobiographical memory in patients with unilateral temporal lobe epilepsy or excisions. Neuropsychologia, 47(11), 2211-2221. https://doi.org/10.1016/j.neuropsychologia.2009.01.032 
Stolk, A., D’Imperio, D., di Pellegrino, G., \& Toni, I. (2015). Altered Communicative Decisions following Ventromedial Prefrontal Lesions. Current Biology, 25(11), 1469-1474. https://doi.org/10.1016/j.cub.2015.03.057

Strange, B. A., Witter, M. P., Lein, E. S., \& Moser, E. I. (2014). Functional organization of the hippocampal longitudinal axis. Nature Reviews Neuroscience, 15(10), 655-669. https://doi.org/10.1038/nrn3785

Suddendorf, T., \& Corballis, M. C. (1997). Mental time travel and the evolution of the human mind. Genetic, Social, and General Psychology Monographs, 123(2), 133-167.

Suddendorf, T., \& Corballis, M. C. (2007). The evolution of foresight: What is mental time travel, and is it unique to humans? Behav Brain Sci, 30(3), 299-313. https://doi.org/10.1017/S0140525X07001975

Summerfield, J. J., Hassabis, D., \& Maguire, E. A. (2009). Cortical midline involvement in autobiographical memory. Neuroimage, 44(3), 1188-1200. https://doi.org/10.1016/j.neuroimage.2008.09.033

Sutherland R. J., Lee J. Q., McDonald R. J., \& Lehmann H. (2019). Has multiple trace theory been refuted? Hippocampus. PMID 31584226 DOI: 10.1002/hipo.23162

Sutherland, R. J., \& Lehmann, H. (2011). Alternative conceptions of memory consolidation and the role of the hippocampus at the systems level in rodents. Current Opinions in Neurobiology, 21(3), 446-451. https://doi.org/10.1016/j.conb.2011.04.007

Sutherland, R. J., Sparks, F. T., \& Lehmann, H. (2010). Hippocampus and retrograde amnesia in the rat model: A modest proposal for the situation of systems consolidation. Neuropsychologia, 48(8), 2357-2369. https://doi.org/10.1016/j.neuropsychologia.2010.04.015 
Sutherland, R. J., Lee, J. Q., McDonald, R. J., \& Lehmann, H. (2019). Has multiple trace theory been refuted? Hippocampus, 30(8), 842-850. https://doi.org/10.1002/hipo.23162

Svoboda, E., McKinnon, M. C., \& Levine, B. (2006). The functional neuroanatomy of autobiographical memory: A meta-analysis. Neuropsychologia, 44(12), 2189-2208. https://doi.org/10.1016/j.neuropsychologia.2006.05.023

Sweeney-Reed, C. M., Zaehle, T., Voges, J., Schmitt, F. C., Buentjen, L., Kopitzki, K., ... \& Rugg, M. D. (2016). Clinical, neuropsychological, and pre-stimulus dorsomedial thalamic nucleus electrophysiological data in deep brain stimulation patients. Data in Brief, 8, 557-561. https://doi.org/10.1016/j.dib.2016.06.008

Takehara-Nishiuchi, K. (2020). Prefrontal-hippocampal interaction during the encoding of new memories. Brain and Neuroscience Advances, 4, 239821282092558. https://doi.org/10.1177/2398212820925580

Tambini, A., \& Davachi, L. (2019). Awake Reactivation of Prior Experiences Consolidates Memories and Biases Cognition. Trends in Cognitive Sciences, 23(10), 876-890. https://doi.org/10.1016/j.tics.2019.07.008

Tanaka, K. Z., He, H., Tomar, A., Niisato, K., Huang, A. J. Y., \& McHugh, T. J. (2018). The hippocampal engram maps experience but not place. Science, 361(6400), 392-397. https://doi.org/10.1126/science.aat5397

Tanaka, K. Z., \& McHugh, T. J. (2018). The Hippocampal Engram as a Memory Index. Journal of Experimental Neuroscience, 12, 117906951881594. https://doi.org/10.1177/1179069518815942 
Tayler, K. K., Tanaka, K. Z., Reijmers, L. G., \& Wiltgen, B. J. (2013). Reactivation of neural ensembles during the retrieval of recent and remote memory. Current Biology, 23(2), 99106. https://doi.org/10.1016/j.cub.2012.11.019

Teng, E., \& Squire, L. R. (1999). Memory for places learned long ago is intact after hippocampal damage. Nature, 400(6745), 675-677. https://doi.org/10.1038/23276

Teyler, T. J., \& Rudy, J. W. (2007). The hippocampal indexing theory and episodic memory: Updating the index. Hippocampus, 17(12), 1158-1169. https://doi.org/10.1002/hipo.20350

Teyler, T. J., \& DiScenna, P. (1986). The hippocampal memory indexing theory. Behavioral Neuroscience, 100(2), 147-154. https://doi.org/10.1037/0735-7044.100.2.147

Thaiss, L., \& Petrides, M. (2008). Autobiographical memory of the recent past following frontal cortex or temporal lobe excisions. European Journal of Neuroscience, 28(4), 829-840. https://doi.org/10.1111/j.1460-9568.2008.06381.x

Tolman, E. C. (1948). Cognitive maps in rats and men. Psychological Review, 55(4), 189-208. https://doi.org/10.1037/h0061626

Tompary, A., \& Davachi, L. (2017). Consolidation Promotes the Emergence of Representational Overlap in the Hippocampus and Medial Prefrontal Cortex. Neuron, 96(1), 228-241 e5. https://doi.org/10.1016/j.neuron.2017.09.005

Tompary, A., \& Davachi, L. (2020). Consolidation Promotes the Emergence of Representational Overlap in the Hippocampus and Medial Prefrontal Cortex. Neuron, 105(1), 199-200. https://doi.org/10.1016/j.neuron.2019.12.020

Tonegawa, S., Liu, X., Ramirez, S., \& Redondo, R. (2015). Memory Engram Cells Have Come of Age. Neuron, 87(5), 918-931. https://doi.org/10.1016/j.neuron.2015.08.002 
Treder, M.S., Charest, I., et al., \& Staresina, B.P. (submitted). The hippocampus as the switchboard between perception and memory.

Trinkler, I., King, J.A., Doeller, C.F., Rugg, M.D., Burgess, N. (2009). Neural bases of autobiographical support for episodic recollection of faces. Hippocampus, 19 (8), 718 730

Tse, D., Langston, R. F., Kakeyama, M., Bethus, I., Spooner, P. A., Wood, E. R., ... \& Morris, R. G. (2007). Schemas and memory consolidation. Science, 316(5821), 76-82. https://doi.org/10.1126/science.1135935

Tse, D., Takeuchi, T., Kakeyama, M., Kajii, Y., Okuno, H., Tohyama, C., .. \& Morris, R. G. (2011). Schema-dependent gene activation and memory encoding in neocortex. Science, 333(6044), 891-895. https://doi.org/10.1126/science.1205274

Tulving, E. (1972). Episodic and semantic memory. In E. Tulving \& W. Donaldson (Eds.), Organization of memory (pp. 381-403). Academic Press.

Tulving, E. (1985). Memory and consciousness. Canadian Psychology/Psychologie Canadienne, 26(1), 1-12. https://doi.org/10.1037/h0080017

Tulving, E. (2001). Episodic memory and common sense: How far apart? Philos Trans R Soc Lond B Biol Sci, 356(1413), 1505-1515. https://doi.org/10.1098/rstb.2001.0937

Tulving, E. (2002). Episodic memory: From mind to brain. Annual Review in Psychology, 53, 125. https://doi.org/10.1146/annurev.psych.53.100901.135114

van Kesteren, M. T. R., Ruiter, D. J., Fernández, G., \& Henson, R. N. (2012). How schema and novelty augment memory formation. Trends in Neurosciences, 35(4), 211-219. https://doi.org/10.1016/j.tins.2012.02.001 
Vann, S. D., Aggleton, J. P., \& Maguire, E. A. (2009). What does the retrosplenial cortex do? Nature Reviews Neuroscience, 10(11), 792-802. https://doi.org/10.1038/nrn2733

Varela, C., Kumar, S., Yang, J.Y., \& Wilson, M.A. (2014) Anatomical substrates for direct interactions between hippocampus medial prefrontal cortex, and the thalamic nucleus reuniens, Brain Structure and Function, 219, 911-929.

Varga, N., Morton, N., \& Preston, A. (2022). Schema, Inference, and Memory. In Kahana, M. \& Wagner, A.D. (Eds.), Handbook of Human Memory: Foundations and Applications. Oxford University Press.

Vaz, A. P., Inati, S. K., Brunel, N., \& Zaghloul, K. A. (2019). Coupled ripple oscillations between the medial temporal lobe and neocortex retrieve human memory. Science, 363(6430), 975-978. https://doi.org/10.1126/science.aau8956

Vaz, A. P., Wittig, J. H., Inati, S. K., \& Zaghloul, K. A. (2020). Replay of cortical spiking sequences during human memory retrieval. Science, 367(6482), 1131-1134.

\section{https://doi.org/10.1126/science.aba0672}

Vertes, R.P., Hoover, W.P., Szigeti-Buck, K., \& Leranth, C. (2007). Nucleus reuniens of the midline thalamus: link between the medial prefrontal cortex and the hippocampus, Brain Research Bulletin, 71, 601-609.

Verfaellie, M., Bousquet, K., \& Keane, M. M. (2014). Medial temporal and neocortical contributions to remote memory for semantic narratives: Evidence from amnesia. Neuropsychologia, 61, 105-112. https://doi.org/10.1016/j.neuropsychologia.2014.06.018

Vetere, G., Xia, F., Ramsaran, A.I., Tran, L. M., Josselyn, S.A. \& Frankland, P.W. (2021) An inhibitory hippocampal-thalamic pathway modulates remote memory retrieval. Nature Neuroscience, 24(5):685-693.

Viard, A., Desgranges, B., Eustache, F., \& Piolino, P. (2012). Factors affecting medial temporal lobe engagement for past and future episodic events: An ALE meta-analysis of 
neuroimaging studies. Brain and Cognition, 80(1), 111-125.

https://doi.org/10.1016/j.bandc.2012.05.004

Viard, A., Piolino, P., Desgranges, B., Chetelat, G., Lebreton, K., Landeau, B., ... \& Eustache, F. (2007). Hippocampal Activation for Autobiographical Memories over the Entire Lifetime in Healthy Aged Subjects: An fMRI Study. Cerebral Cortex, 17(10), 2453-2467. https://doi.org/10.1093/cercor/bhl153

Viard, A., Desgranges, B., Matuszewski, V., Lebreton, K., Belliard, S., de La Sayette, V... \& Piolino, P. (2013). Autobiographical memory in semantic dementia: New insights from two patients using fMRI. Neuropsychologia, 51(13), 2620-2632. https://doi.org/10.1016/j.neuropsychologia.2013.08.007

Vilberg, K. L., \& Rugg, M. D. (2008). Memory retrieval and the parietal cortex: A review of evidence from a dual-process perspective. Neuropsychologia, 46(7), 1787-1799. https://doi.org/10.1016/j.neuropsychologia.2008.01.004

Vilberg, K. L., \& Rugg, M. D. (2009). Left parietal cortex is modulated by amount of recollected verbal information. NeuroReport, 20(14), 1295-1299. https://doi.org/10.1097/WNR.0b013e3283306798

Vilberg, K. L., \& Rugg, M. D. (2012). The Neural Correlates of Recollection: Transient Versus Sustained fMRI Effects. Journal of Neuroscience, 32(45), 15679-15687. https://doi.org/10.1523/JNEUROSCI.3065-12.2012

Viskontas, I. V., Carr, V. A., Engel, S. A., \& Knowlton, B. J. (2009a). The neural correlates of recollection: Hippocampal activation declines as episodic memory fades. Hippocampus, 19(3), 265-272. https://doi.org/10.1002/hipo.20503 
Viskontas, I. V., McAndrews, M. P., \& Moscovitch, M. (2000). Remote episodic memory deficits in patients with unilateral temporal lobe epilepsy and excisions. Journal of Neuroscience, 20, 5853-5857.

Viskontas, I. V., Quiroga, R. Q., \& Fried, I. (2009b). Human medial temporal lobe neurons respond preferentially to personally relevant images. Proceedings of the National Academy of Sciences, 106(50), 21329-21334. https://doi.org/10.1073/pnas.0902319106

Wagner, I. C., van Buuren, M., Kroes, M. C., Gutteling, T. P., van der Linden, M., Morris, R. G., \& Fernández, G. (2015). Schematic memory components converge within angular gyrus during retrieval. ELife, 4, e09668. https://doi.org/10.7554/eLife.09668

Waidergoren, S., Segalowicz, J., \& Gilboa, A. (2012). Semantic memory recognition is supported by intrinsic recollection-like processes: "The butcher on the bus" revisited. Neuropsychologia, 50(14), 3573-3587. https://doi.org/10.1016/j.neuropsychologia.2012.09.040

Wang, S. H., \& Morris, R. G. (2010). Hippocampal-neocortical interactions in memory formation, consolidation, and reconsolidation. Annual Review in Psychology, 61, 49-79, C1-4. https://doi.org/10.1146/annurev.psych.093008.100523

Wang, J. X., Rogers, L. M., Gross, E. Z., Ryals, A. J., Dokucu, M. E., Brandstatt, K. L., ... \& Voss, J. L. (2014). Targeted enhancement of cortical-hippocampal brain networks and associative memory. Science, 345(6200), 1054-1057. https://doi.org/10.1126/science. 1252900

Wang, S.H., Tse, D., \& Morris, R. G. M. (2012). Anterior cingulate cortex in schema assimilation and expression. Learning and Memory, 19(8), 315-318. https://doi.org/10.1101/lm.026336.112 
Westmacott, R., Black, S. E., Freedman, M., \& Moscovitch, M. (2004). The contribution of autobiographical significance to semantic memory: Evidence from Alzheimer's disease, semantic dementia, and amnesia. Neuropsychologia, 42(1), 25-48. https://doi.org/10.1016/S0028-3932(03)00147-7

Westmacott, R., Leach, L., Freedman, M., \& Moscovitch, M. (2001). Different patterns of autobiographical memory loss in semantic dementia and medial temporal lobe amnesia: A challenge to consolidation theory. Neurocase, 7(1), 37-55. https://doi.org/10.1093/neucas/7.1.37

Westmacott, R., \& Moscovitch, M. (2003). The contribution of autobiographical significance to semantic memory. Memory \& Cognition, 31(5), 761-774. https://doi.org/10.3758/BF03196114

Williams, J. M., Barnhofer, T., Crane, C., Herman, D., Raes, F., Watkins, E., \& Dalgleish, T. (2007). Autobiographical memory specificity and emotional disorder. Psychological Bulletin, 133(1), 122-148. https://doi.org/10.1037/0033-2909.133.1.122

Williams, A. N., Ridgeway, S., Postans, M., Graham, K. S., Lawrence, A. D., \& Hodgetts, C. J. (2020). The role of the pre-commissural fornix in episodic autobiographical memory and simulation. Neuropsychologia, 142, 107457. https://doi.org/10.1016/j.neuropsychologia.2020.107457

Wilson, M., \& McNaughton, B. (1994). Reactivation of hippocampal ensemble memories during sleep. Science, 265(5172), 676-679. https://doi.org/10.1126/science.8036517

Wiltgen, B. J., \& Silva, A. J. (2007). Memory for context becomes less specific with time. Learning and Memory, 14(4), 313-317. https://doi.org/10.1101/1m.430907 
Wiltgen, B. J., \& Tanaka, K. Z. (2013). Systems consolidation and the content of memory. Neurobiology of Learning and Memory, 106, 365-371. https://doi.org/10.1016/j.nlm.2013.06.001

Wiltgen, B. J., Zhou, M., Cai, Y., Balaji, J., Karlsson, M. G., Parivash, S. N., .. \& Silva, A. J. (2010). The hippocampus plays a selective role in the retrieval of detailed contextual memories. Current Biology, 20(15), 1336-1344. https://doi.org/10.1016/j.cub.2010.06.068

Wing, E. A., Marsh, E. J., \& Cabeza, R. (2013). Neural correlates of retrieval-based memory enhancement: An fMRI study of the testing effect. Neuropsychologia, 51(12), 23602370. https://doi.org/10.1016/j.neuropsychologia.2013.04.004

Winocur, G. (1990). Anterograde and Retrograde-Amnesia in Rats with Dorsal Hippocampal or Dorsomedial Thalamic Lesions. Behavioural Brain Research, 38(2), 145-154. https://doi.org/10.1016/0166-4328(90)90012-4

Winocur, G., Frankland, P. W., Sekeres, M., Fogel, S., \& Moscovitch, M. (2009). Changes in context-specificity during memory reconsolidation: Selective effects of hippocampal lesions. Learning and Memory, 16(11), 722-729. c10.1101/1m.1447209

Winocur, G., \& Moscovitch, M. (2011). Memory transformation and systems consolidation. Journal of the International Neuropsychological Society, 17(5), 766-780. https://doi.org/10.1017/S1355617711000683

Winocur, G., Moscovitch, M., \& Bontempi, B. (2010). Memory formation and long-term retention in humans and animals: Convergence towards a transformation account of hippocampal-neocortical interactions. Neuropsychologia, 48(8), 2339-2356. https://doi.org/10.1016/j.neuropsychologia.2010.04.016 
Winocur, G., Moscovitch, M., Fogel, S., Rosenbaum, R. S., \& Sekeres, M. (2005). Preserved spatial memory after hippocampal lesions: Effects of extensive experience in a complex environment. Nature Neuroscience, 8(3), 273-275. https://doi.org/10.1038/nn1401

Winocur, G., Moscovitch, M., \& Sekeres, M. (2007). Memory consolidation or transformation: Context manipulation and hippocampal representations of memory. Nature Neuroscience, 10(5), 555-557. https://doi.org/10.1038/nn1880

Winocur, G., Moscovitch, M., \& Sekeres, M. J. (2013). Factors affecting graded and ungraded memory loss following hippocampal lesions. Neurobiology of Learning and Memory, 106, 351-364. https://doi.org/10.1016/j.nlm.2013.10.001

Wynn J. S., Ryan J. D., \& Moscovitch M. (2020). Effects of prior knowledge on active vision and memory in younger and older adults. Journal of Experimental Psychology. General. PMID 31343184 DOI: $10.1037 / \mathrm{Xge} 0000657$

Yassa, M. A., Lacy, J. W., Stark, S. M., Albert, M. S., Gallagher, M., \& Stark, C. E. (2011). Pattern separation deficits associated with increased hippocampal CA3 and dentate gyrus activity in nondemented older adults. Hippocampus, 21(9), 968-979. https://doi.org/10.1002/hipo.20808

Yassa, M. A., \& Reagh, Z. M. (2013). Competitive Trace Theory: A Role for the Hippocampus in Contextual Interference during Retrieval. Frontiers in Behavioral Neuroscience, 7 , 107. https://doi.org/10.3389/fnbeh.2013.00107

Yazar, Y., Bergström, Z. M., \& Simons, J. S. (2017). Reduced multimodal integration of memory features following continuous theta burst stimulation of angular gyrus. Brain Stimulation, 10(3), 624-629. https://doi.org/10.1016/j.brs.2017.02.011 
Yazar, Y., Bergstrom, Z. M., \& Simons, J. S. (2014). Continuous theta burst stimulation of angular gyrus reduces subjective recollection. PLoS One, 9(10), e110414. https://doi.org/10.1371/journal.pone.0110414

Yonelinas, A. P., Ranganath, C., Ekstrom, A. D., \& Wiltgen, B. J. (2019). A contextual binding theory of episodic memory: Systems consolidation reconsidered. Nature Reviews Neuroscience, 20(6), 364-375. https://doi.org/10.1038/s41583-019-0150-4

Yonelinas, A.P., Ramey, M.M., \& Riddell, C. (2022). Recognition Memory: The Role of Recollection and Familiarity. In Kahana, M. \& Wagner, A.D. (Eds.), Handbook of Human Memory: Foundations and Applications. Oxford University Press.

Zeidman, P., \& Maguire, E. A. (2016). Anterior hippocampus: The anatomy of perception, imagination and episodic memory. Nature Reviews Neuroscience, 17(3), 173-182. https://doi.org/10.1038/nrn.2015.24

Zeithamova, D., \& Preston, A. R. (2010). Flexible memories: Differential roles for medial temporal lobe and prefrontal cortex in cross-episode binding. Journal of Neuroscience, 30(44), 14676-14684. https://doi.org/10.1523/JNEUROSCI.3250-10.2010

Zeithamova, D., Schlichting, M. L., \& Preston, A. R. (2012). The hippocampus and inferential reasoning: Building memories to navigate future decisions. Frontiers in Human Neuroscience, 6, 70. https://doi.org/10.3389/fnhum.2012.00070

Ziv, Y., Burns, L. D., Cocker, E. D., Hamel, E. O., Ghosh, K. K., Kitch, L. J., ... \& Schnitzer, M. J. (2013). Long-term dynamics of CA1 hippocampal place codes. Nature Neuroscience, 16(3), 264-266. https://doi.org/10.1038/nn.3329 
